University of Louisville

ThinkIR: The University of Louisville's Institutional Repository

Electronic Theses and Dissertations

$12-2007$

\title{
Using Schlossberg's transition theory to identify coping strategies of welfare recipients attending postsecondary institutions.
}

Kathy J. Pendleton 1949-

University of Louisville

Follow this and additional works at: https://ir.library.louisville.edu/etd

\section{Recommended Citation}

Pendleton, Kathy J. 1949-, "Using Schlossberg's transition theory to identify coping strategies of welfare recipients attending postsecondary institutions." (2007). Electronic Theses and Dissertations. Paper 1110.

https://doi.org/10.18297/etd/1110

This Doctoral Dissertation is brought to you for free and open access by ThinkIR: The University of Louisville's Institutional Repository. It has been accepted for inclusion in Electronic Theses and Dissertations by an authorized administrator of ThinkIR: The University of Louisville's Institutional Repository. This title appears here courtesy of the author, who has retained all other copyrights. For more information, please contact thinkir@louisville.edu. 


\begin{abstract}
USING SCHLOSSBERG'S TRANSITION THEORY TO IDENTIFY COPING STRATEGIES OF WELFARE RECIPIENTS ATTENDING POSTSECONDARY INSTITUTIONS
\end{abstract}

\author{
By \\ Kathy J. Pendleton \\ B.S., Eastern Illinois University, 1979 \\ M.S., Eastern Illinois University, 1980 \\ M.Ed, University of Louisville, 2000 \\ A Dissertation \\ Submitted to the Faculty of the \\ Graduate School of the University of Louisville \\ in Partial Fulfillment of the Requirements \\ for the Degree of \\ Doctor of Philosophy \\ Department of Education and Counseling Psychology \\ University of Louisville \\ Louisville, Kentucky
}

December 2007 

DEDICATION

This dissertation is dedicated to my daughters Tamar D. Perry, Karla D. McDonald, Kenya N. Howery, and Mellodey Darden-Hoskins for your love, and support.

To Krystal Jamelle McDonald, who calls herself my favorite granddaughter, and tells everyone "my granny is in college and getting her Ph.D.". Remember that no less is expected of you, and your future is in your hands.

In memory of my grandmothers, Hazel Katherine ElkinsCampbell and Hattie Tucker thank you for loving me.

To my mother, Olivia Blanche Elkins, you succeeded against the odds. I love you.

To Marquis John McDonald, for being an awesome grandson, a sweet spirit, and understanding that Granny had a job to do. 


\section{ACKNOWLEDGEMENTS}

I would like to acknowledge the chair of my dissertation committee Micheal J. Cuyjet who has encouraged and supported my academic pursuit from the beginning. I appreciate your guidance, feedback, and encouragement. Thank you my good friend.

It has been a pleasure to work with my committee members Bridgette Pregliasco, Thomas Reio, Karen Christopher, and Amy Hirschy. I appreciate your guidance and encouragement.

I would like to thank my husband, MacArthur Wilson Pendleton for his love, support and prodding over the years. Thank you for being the wind beneath my wings when I almost lost hope. You have truly been my "Sweet Companion".

I would like to thank my daughter, Karla for serving as my typist. I could not have done it without you.

My deepest thanks and appreciation to the women who agreed to participate in this study, welcomed me into their homes and lives, and shared their experiences with me. Thank you Mindy Steinberg for your encouragement. 


\begin{abstract}
USING SCHLOSSBERG'S TRANSITION THEORY TO IDENTIFY COPING STRATEGIES OF WELFARE RECIPIENTS ATTENDING POSTSECONDARY INSTITUTIONS
\end{abstract}

Kathy J. Pendleton

\begin{abstract}
Using Schlossberg's transition theory as the conceptual framework, this case study explored and identified the coping strategies used by seven welfare recipients attending postsecondary institutions. Three participants were enrolled in the local community college, three in a local 4-year research intuition and one attended four-year private institution. The case study used semi-structured interviews and each participant were interviewed three times over a three-month period. The findings identified multiple personal and psychological barriers to persistence. The participants had histories of childhood sexual abuse, rape, and domestic violence. Friends and community agencies, rather than family, provided the primary sources of emotional and financial support. To extend TANF benefits participants
\end{abstract}




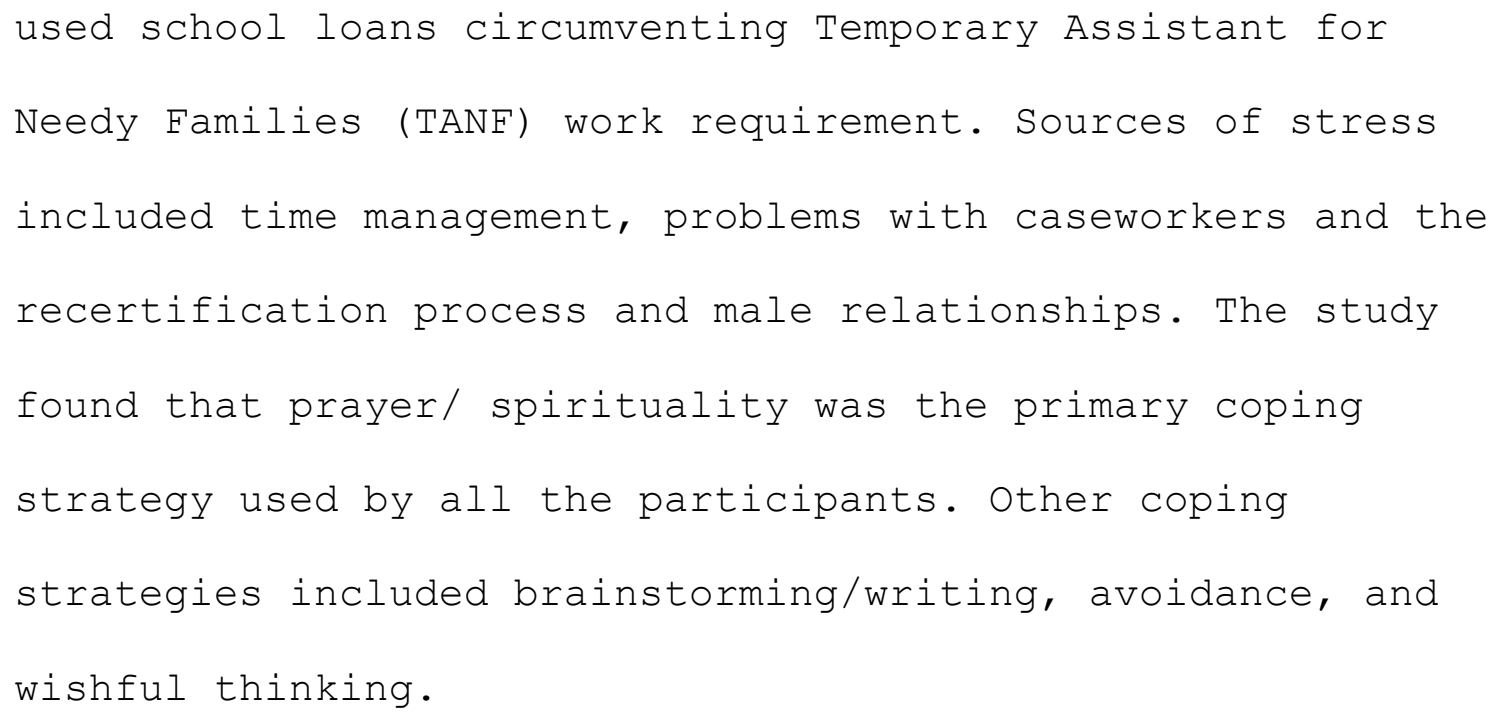


TABLE OF CONTENTS

PAGE

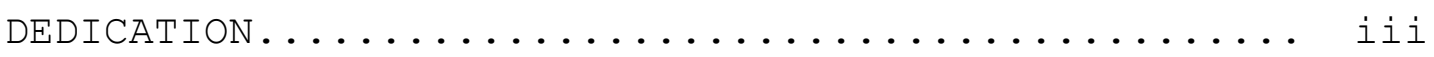

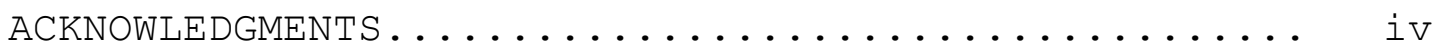

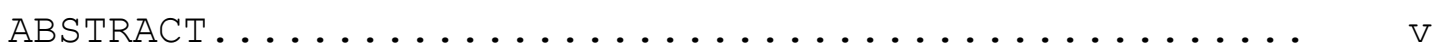

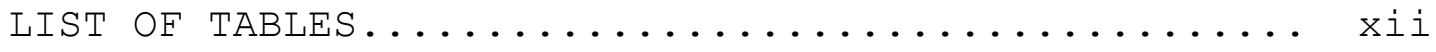

CHAPTER I

Introduction..................... 1

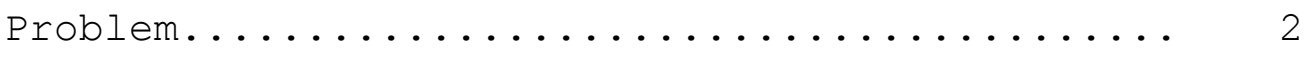

Barriers to Postsecondary Education.......... 4

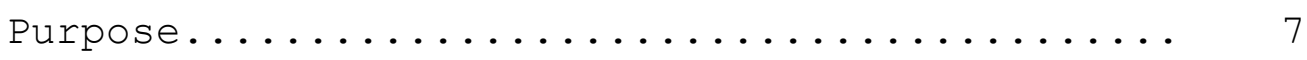

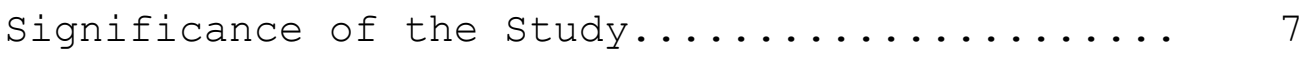

Conceptual Framework.................. 9

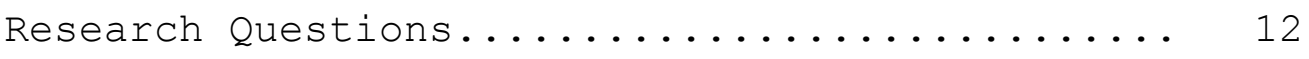

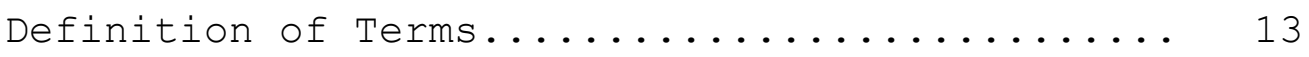

CHAPTER II

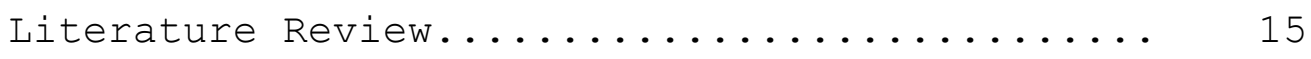

History of Welfare and Welfare Reform........ 15

Impact of TANF Regulations on Postsecondary

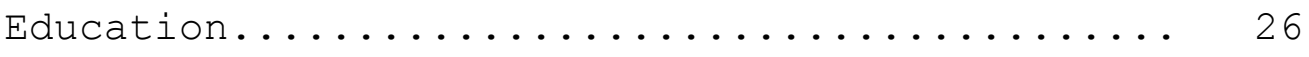

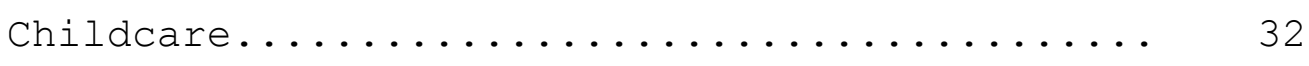

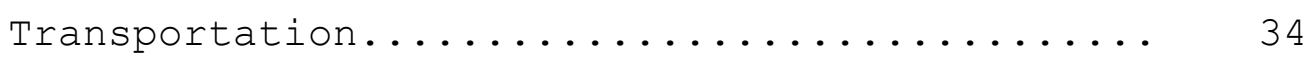

Financial Aid and Federal Work Study........ 36 
Nontraditional College Students............ 39

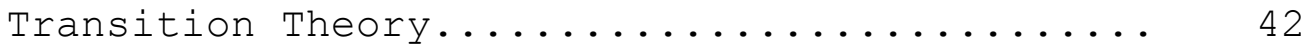

Schlossberg's Transition Theory.......... 45

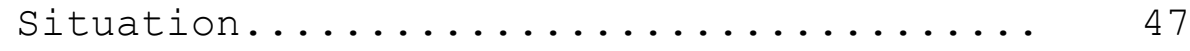

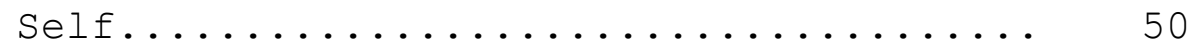

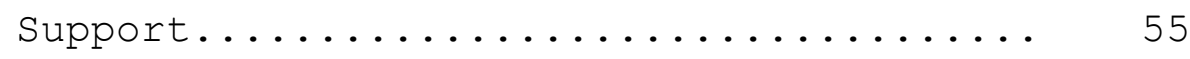

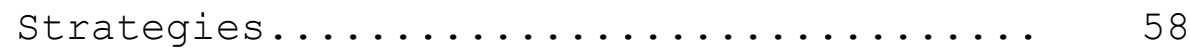

Research using Schlossberg's Theory......... 63

Research Related to Higher Education Using

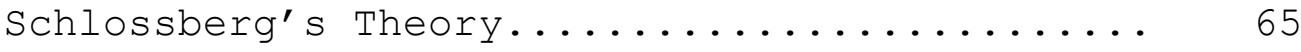

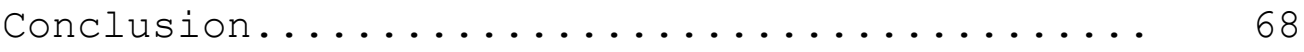

CHAPTER III

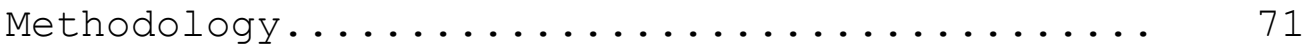

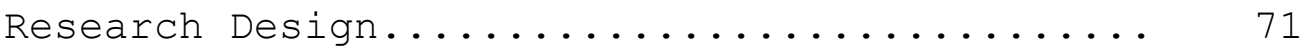

Rationale for a Qualitative Design.......... 73

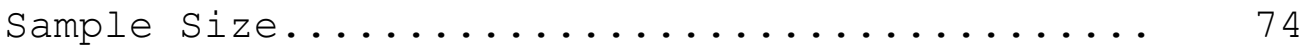

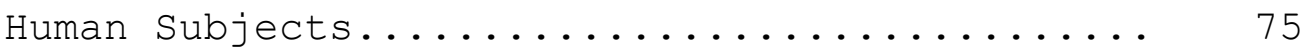

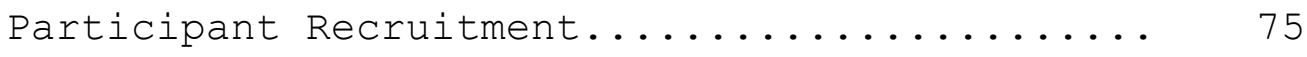

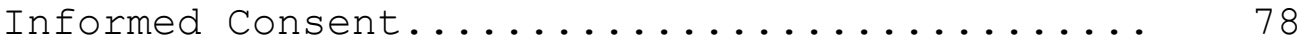

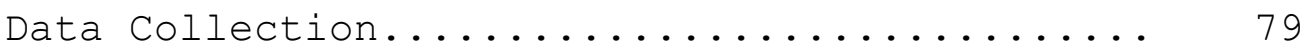

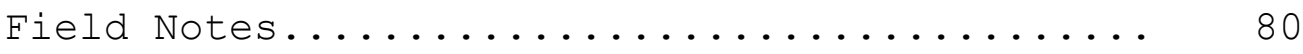

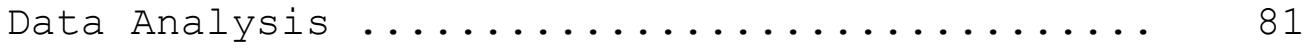

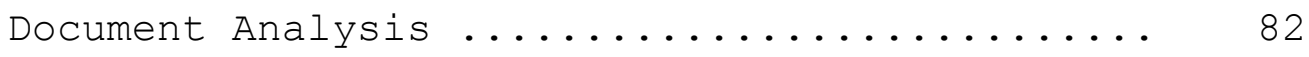

Validity $\ldots \ldots \ldots \ldots \ldots \ldots \ldots \ldots \ldots \ldots \ldots \ldots$

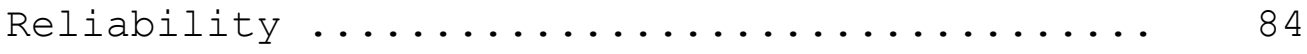




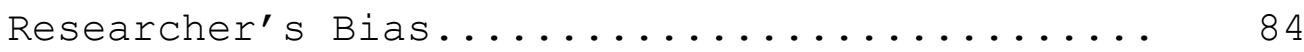

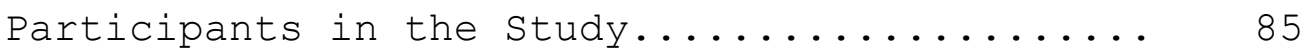

The Study in Context/Limitations.......... 87 CHAPTER IV

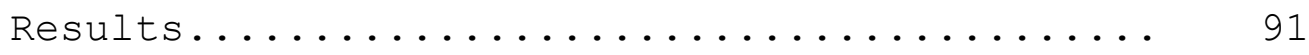

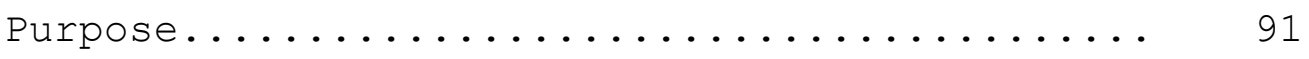

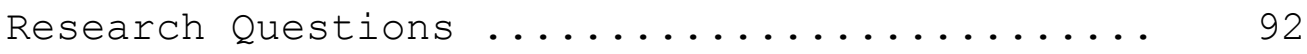

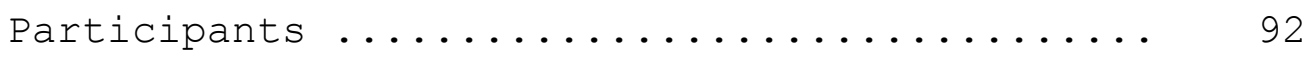

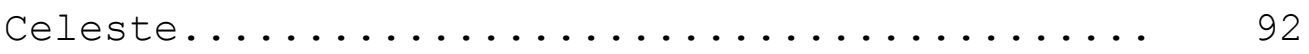

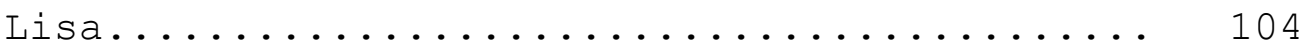

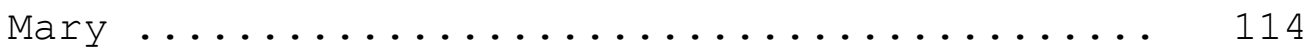

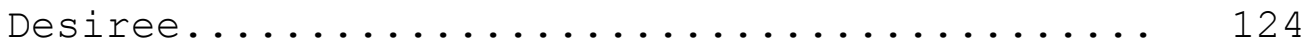

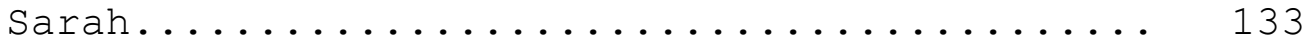

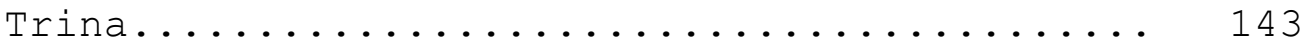

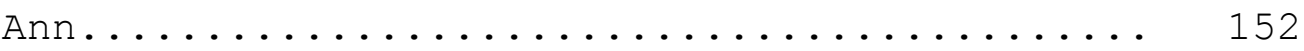

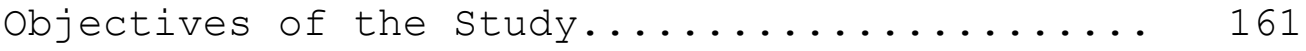

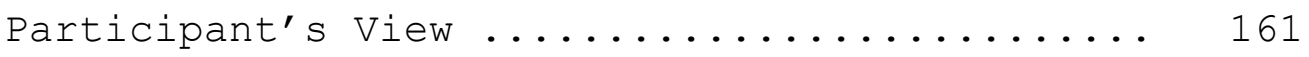

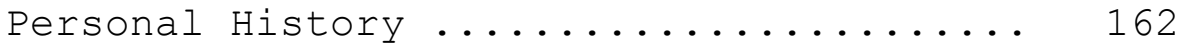

Domestic Violence, Rape, Physical or

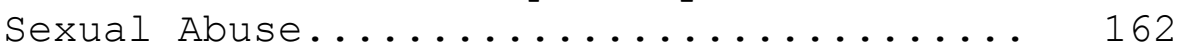

Drug/Alcohol/Criminal History.......... 168

Work Prior to Welfare .................. 170

Impact of $\mathrm{TANF} \ldots \ldots \ldots \ldots \ldots \ldots \ldots \ldots \ldots \ldots \ldots$ 
Work Requirements and Loans.............. 172

Child Care \& Transportation .......... 173

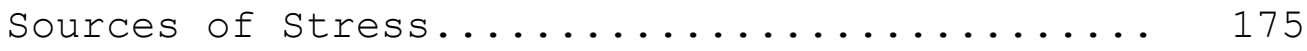

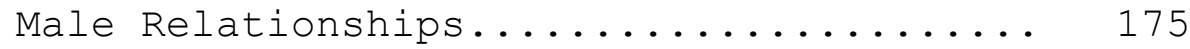

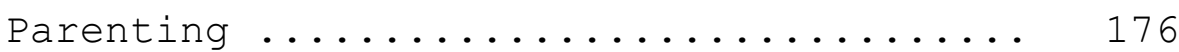

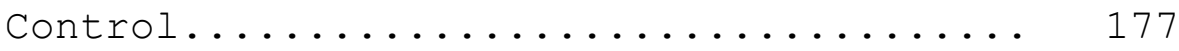

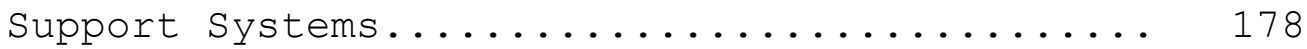

Family Support ................... 178

Friends.......................... 179

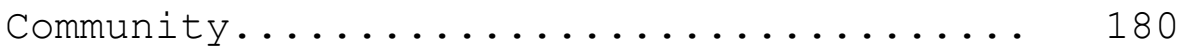

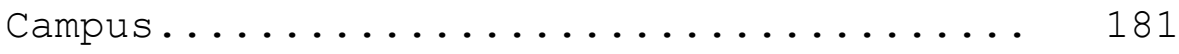

No Perceived Support............... 183

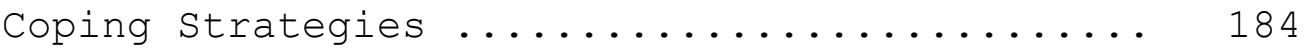

Prayer/Spirituality .................. 184

Brainstorming/Writing ............... 185

Wishful Thinking ............... 187

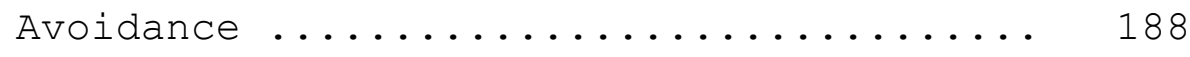

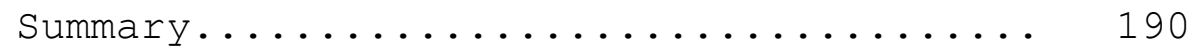

CHAPTER V

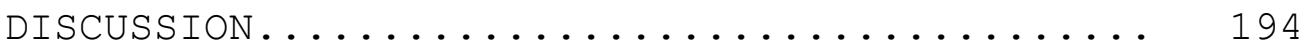

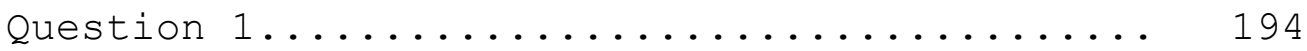

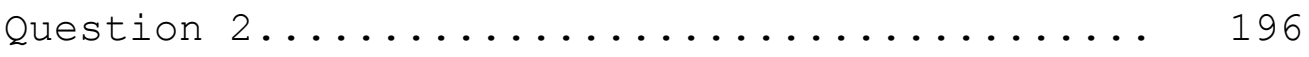

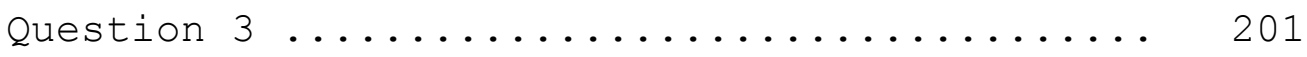




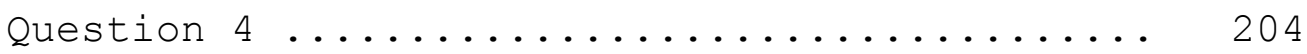

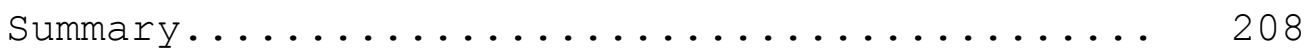

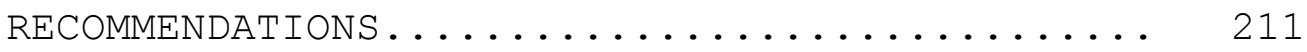

RECOMMENDATIONS FOR HIGHER EDUCATION........ 212

RECOMMENDATIONS FOR WELFARE POLICY......... 215

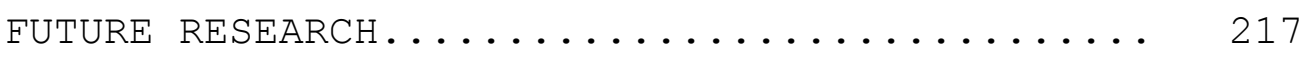

CONCLUSION $\ldots \ldots \ldots \ldots \ldots \ldots \ldots \ldots \ldots \ldots \ldots \ldots \ldots \ldots \ldots$

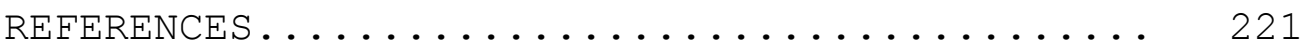

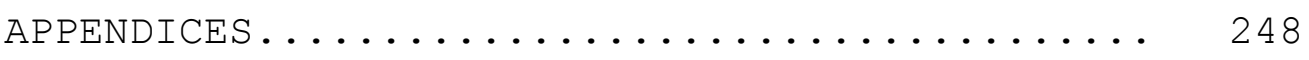

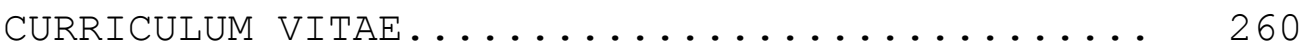




\section{LIST OF TABLES}

TABLE

PAGE

1. Education Counted as a Work Activity....... 23

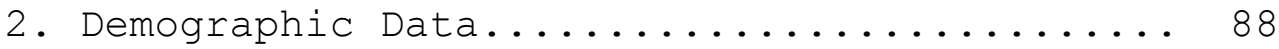

3. Credit Hours Completed, Institution Type,

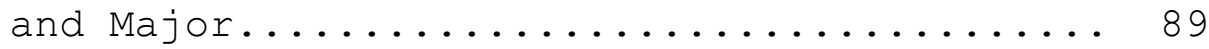

4. Interview Schedule .................... 90

5. Domestic Violence, Physical Abuse, Sexual

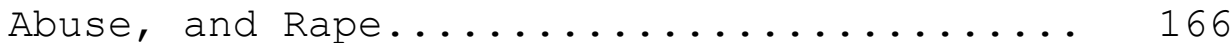

6. Participant Work History............. 171

7. Participant Coping Strategies........... 190 


\section{CHAPTER I}

\section{INTRODUCTION}

"I loved being at the university, and my girls were thriving and happy. University professors pushed me harder and harder, and sometimes I thought my head would explode with all the new information and ways of thinking. We were poor, and I was always tired, but we were moving forward. Yet I was in school only a few months when president Clinton signed the Personal Responsibility and Work Opportunity Reconciliation Act of 1996 into law, and my life and my ability to be a responsible parent and medical practitioner was forever altered" (Mitchell, 2003, p.117).

Aslanian (2001) and Aslanian and Brickell (1980)

indicated that the majority of adults pursue higher

education because of a life event that results in change.

Whatever the motive, entering college is a stress-producing

event. The stress may be the result of a life event, the

fear of failure or of the unknown, or negotiating an

unfamiliar environment. Bridges (1980) and Schlossberg, Lynch and Chickering (1989) identified three phases in an educational transition: moving into the college environment, moving through it, and moving out (preparation for graduation). Each phase of the transition demands change, and each student experiences the change in response both old and new responsibilities. Welfare recipients 
attending college face the threat of the loss of economic resources, work requirements, and time limits, as well as the demands of attending college. Each individual must learn to manage multiple roles simultaneously in addition to the ever-changing rules of welfare reform. How one responds to transition and stress is determined by the individual's coping skills. Each transition is a process, requiring a repertoire of coping skills that ultimately determine whether a student persists or does not finish his/her educational goals, or develops new coping skills.

\section{Problem}

Prior to 1996, postsecondary education was a viable option for welfare recipients who wished to become economically self-sufficient. In many states, welfare recipients attended two-year and four-year institutions while receiving welfare funds (Cohen, 1998). The passage of the Personal Responsibility and Work Opportunity Reconciliation Act of 1996 (PRWORA) was the result of thirty years of societal and political pressure to replace welfare in the form of cash grants with employment. PRWORA replaced Aid for Dependent Children (AFDC) with Temporary Assistance to Needy Families (TANF). No longer an entitlement program, TANF required that welfare recipients 
find employment within twenty-four months of receiving welfare benefits, and instituted a mandatory five-year lifetime limit on financial assistance (Hayes, 1999; Ntiri, 2000). Beginning in fiscal year 1997 each state was required to meet a minimum work participation rate. The minimum participation rate for single parents was 25 percent of each state's welfare caseload. The work participation rate increased five percent each year until fiscal year 2002 when the minimum reached 50 percent of the welfare caseload of each state. For two-parent families, in fiscal years 1997 and 1998, the requirement was 75 percent of the state welfare caseload. In fiscal year 1999, the work participation rate increased to 90 percent (Hagan, 1998). Beginning in 2000, welfare recipients were required to work at least 30 hours per week to be counted as being engaged in work activity (Cohen, 1999; Friedman, 1999; Kahn, 1998). TANF also capped high school, General Education Diploma (GED), and college enrollment, and at 30 percent of the state welfare caseload.

The final rules of TANF allowed states to use funds to support the participation of welfare recipients in postsecondary education, but recipients were still required to meet the work requirements as well as the time limit requirements which created barriers for many welfare 
recipients (Golonka and Matus-Grossman, 2001; Jacobs and Winslow, 2003; Mazzeo, Rab and Eachus, 2003). Education leading to a college degree was not prohibited by federal law, but not encouraged in most states (Bok, 2004; Butler and Deprez, 2002; Cox and Spriggs, 2002; Greenburg, Strawn, and Plimpton, 2000; Jacobs and Winslow, 2003). TANF encouraged rapid linkage to work, limited education, and work-training activities, which created barriers to postsecondary education.

\section{Barriers to Postsecondary Education}

The ability of low-income parents to pursue postsecondary education has become increasingly more difficult with the passage of PRWORA (Butler and Deprez, 2002; Imel, 2000; London, 2004). The literature has identified multiple obstacles as barriers to the transition from welfare to postsecondary education. Around the country, welfare recipients are abandoning or altering their dreams of obtaining a college degree and becoming economically self-sufficient because of the welfare reform laws (Kahn, 1998; Wolf and Tucker, 2001a). Current data indicate that in 1995, 136,000 welfare recipients were enrolled in postsecondary institutions, but after PRWORA, only 54,000 were engaged in educational activities, 
including postsecondary education (Jacobs and Winslow, 2003). An analysis of the Urban Institute's 1997 and 1999 National Survey of America's Families revealed that nationally welfare recipients with a high school diploma were 13 percent more likely to attend college than other low-income women prior to welfare reform in 1996. However, by 1998 , welfare recipients were seven percent less likely to attend college than other low-income women (Cox and Spriggs, 2002). The data also suggested that African American women that lived in states with harsh "work first" requirements were least likely to attend college. Kates (1998) found from 1995 to 1997 there was a 46 percent decrease in the number of welfare recipients enrolled in community colleges. Similarly, between 1997 and 1998 there was a 33 percent decrease in the number of welfare recipients attending Eastern Washington University (Karier, 2000).

Current welfare recipients face multiple barriers in accessing and persisting in postsecondary programs. These barriers include the competing demands of family and school, TANF work requirements, the cost associated with attending school, and the lack of family and community support (Austin and McDermott, 2003-2004; Brown and Barbosa, 2001; Golonka and Matus-Grossman, 2001; Stone, 
Nelson, and Nieman, 1994; The Education Resources Institute [TERI], 1997). Kahn and Polakow (2000) found that welfare recipients were routinely required to miss class in order to attend job skills training class to meet TANF requirements and were sanctioned if they did not attend the training sessions. The study also revealed that information regarding financial aid eligibility, work requirements, work-study, and sanctions was often incorrect or intentionally withheld by welfare caseworkers. Similarly, Carnevale, Reich, Johnson, and Sylvester (2000) found that community college students in California did not apply for financial aid believing that the receipt of financial aid would count as income, thus reducing or eliminating their welfare benefits.

The reauthorization of TANF as part of the Deficit Reduction Act of 2005 created new barriers for welfare recipients. The final rules published by Health and Human Services define work and education explicitly. Education is defined as vocational education leading to a job and is limited to a twelve-month period. Recipients can no longer attend postsecondary institutions to earn a four-year or advanced degree. States are required to have a plan in place by october 2007 to meet the new TANF requirements (Sargent Shriver National Center on Poverty Law, 2006). 
What happens to the students who are attending a four-year institution or needs more than twelve months to complete an educational program? The implication is that these students will be faced with yet another transition that will have a major impact on their lives. Students may be forced to change their educational programs, or drop-out of school to take a job with low wages, limiting the possibility of becoming economically self-sufficient.

\section{Purpose}

This study explored and identified the coping strategies used by welfare recipients attending postsecondary institutions. A review of the research literature examined the history of welfare and welfare reform, and the impact of TANF regulations on welfare recipients attending postsecondary institutions, an overview of Schlossberg's transition theory, and the research literature on transition theory. The overall research question was: What are the coping strategies used by welfare recipients attending postsecondary institutions?

\section{Significance of the study}

Previous studies document the hardships of women on welfare, and the negative impact of welfare reform on 
college attendance (Cox and Spriggs, 2002, Karier, 2000, Kahn, and Polakow, 2000); however, there is little to no research that examines the coping strategies used by welfare recipients who continue in their educational programs in spite of the barriers. This study seeks to broaden the knowledge area related to the use of coping strategies by welfare recipients attending postsecondary institutions and provide a better of understanding of the transition process.

This study is also of importance to postsecondary institutions. Increasing numbers of students enrolling in colleges and universities are low-income adults. According to Horn (1996), $4 \odot$ percent of all undergraduate students are age 25 or older and almost half of them are low-income students. Anderson (2003) argued that as the number of adult students attending college increases, so does the diversity of the student population. These changes create a number of challenges for colleges and universities. Colleges must provide programs and services to students whose age, background, and socioeconomic status are varied. Each student comes with a variety of learning styles and attendance patterns. To address these complex issues, and to provide programs and services that meets the needs of all students, postsecondary institutions must be aware of 
and understand the coping strategies used, and the obstacles faced by this particular student group. Welfare recipients comprise a distinct student population; however, issues and barriers they face are similar to the barriers most adult low-income students face. The information from this study can be used to assist other students in transition. Evans, Forney and Guido-DiBrito (1998) argued that given the limited research that examines the transition experiences of college students more research is needed. This study sought to expand the knowledge regarding the coping skills of students in transition as they move in, through and out of the college setting.

\section{Conceptual Framework}

Schlossberg (1984) developed a transition model to assist in the understanding of adults in transition. The model provided a framework for researchers to analyze the transition process. The transition model is often referred to in the literature as a theory and is categorized as an adult development theory (Evan, Forney \& Guido-DiBrito, 1998, pg 108).

Goodman, Schlossberg and Anderson (2006), Schlossberg (1984), and Schlossberg, Waters and Goodman (1995) presented a model for counseling adults in transition that 
provides a framework for addressing the academic and personal needs of adult students. The model is a framework for understanding the perceived demands and coping strategies used by individuals in transition. Transitions alter our relationships, roles, and beliefs. The balance of the individual's assets and liabilities determines the outcome of the transition. Schlossberg, et al (1995) argued, "the transitions differ, but the structure for understanding individuals in transition is stable" (p. 26).

Schlossberg (1984, ) defined a transition "as any event that results in a change in relationships, routines, assumptions or roles with the setting of self, work, family, health and/or economics"(p. 43). There are three types of transitions: anticipated, unanticipated, and nonevents. Anticipated transitions are major events that are expected, such as graduating from high school or college, marriage, or starting a career. Because the events are normative, an individual can anticipate and plan for the event. Unanticipated transitions are unexpected life events that disrupt the normal routine, and typically involve a crisis and the inability to plan for the event, such as a sudden death or car accident. Nonevent transitions are expected transitions that do not occur, such as not receiving a promotion, not getting married, or 
not getting a job. Goodman, et al. (2006) indicated that the realization that the event will not occur may alter the way one sees him/herself, or the way in which one responds.

The foundation of the transition model is that personal appraisal of the change determines the meaning of the transition. How recipients respond to the changes in the welfare rules regarding college attendance, and how they adapt to the change depend on their previous coping strategies. To understand the meaning of the transition, one must consider the type of transition, the context of the transition, and the impact. According to Goodman, et al.(2006), Schlossberg (1984), and Schlossberg, et al. (1995) there are four major factors that influence how an individual copes with the transition: situation, self, support, and coping strategies, known as the 4 S system. The 4S System provides a framework to identify the resources individuals have to cope.

Situation refers to the type of transition (anticipated or unanticipated), the context in which the event occurs, and the impact of the transition on the individual's life. Self refers to personal and demographic characteristics (age, gender, ethnicity, health, and socioeconomic status) which impact perception of the event. Each individual also brings psychological resources such as 
self-concept and self-efficacy, which determine worldview. Support helps to mobilize the resources necessary to share or eliminate stress. The types of supports needed to handle a stressful event may include family, friends, institutions, and community resources. Strategies refer to the coping strategies each individual uses to prevent, alleviate, or respond to stress. Goodman, et al,(2006) argued that how an individual responds to a transitional event depends on the interaction and balance of situation, self, supports, and strategies.

Each transition is different and perceived differently by each individual; as a result, individuals appraise the same events in different ways. The appraisal of an event or nonevent is determined by the timing, control, role change, duration, previous experiences, or concurrent stress that precipitates the transition. Previous experience with a similar transition determines how effectively a person copes with the current transition.

\section{Research Questions}

Using Schlossberg's transition model as the framework, this study examined the specific coping strategies used by welfare recipients currently enrolled in postsecondary institutions. Within the parameters of this study, the 
following research questions were:

1. What are the personal and demographic characteristics of the study participants?

2. How do study participants view their current situation?

3. What support systems do the study participants perceive to be available?

4. What strategies do the study participants use to solve problems?

\section{Definition of Terms}

The following definitions apply for the purpose of this study:

- Transition: any event or nonevent that results in changed relationships, routines, roles, or assumptions .

- Coping: any response used to prevent, alleviate, or respond to an event or stressful situation.

- Stress: the result of a struggle to re-establish homeostasis following change

- Event: any incident or activity that is disruptive, or life altering in such a way 
that it causes a change in the person's normal day-to-day routine.

- Welfare recipient: a person receiving TANF funds, or food stamps and medical assistance.

- Student: anyone currently enrolled full-time or part-time in a postsecondary institution. 
CHAPTER II

\section{LITERATURE REVIEW}

This study sought to explore the coping strategies used by welfare recipients attending postsecondary institutions. Because only limited research exists on the coping skills of welfare recipients, I examine the history of welfare and welfare reform, and the impact of welfare reform on welfare recipients attending college, and nontraditional college students. The last section examines the primary tenets of Schlossberg's transition theory that provide the conceptual framework guiding this study and prior research using Schlossberg's theory on transition.

\section{History of Welfare and Welfare Reform}

The Mothers' Pension movement emerged during the Progressive Era (1890-1920). Social reformers argued that providing monetary assistance to single mothers was the responsibility of the government. The reformers also argued that cash assistance would reduce the need for mothers to work and allow mothers to raise their children in their own home. The 1909 White House Conference on Dependent Children 
prompted Illinois to establish the "Funds for Parent Act" in 1911. By 1934, forty-eight states had some form of mothers' pension law (Gordon, 1994; Neubeck and Cazenave, 2001; Piven and Cloward 1993; Skocopol, Abend-Wein, Howard, and Lehmann, 1993). Although state law established the programs, the law did not require local communities to participate, consequently, only a few states provided funding at the local level. As a result, very few motherheaded households received financial assistance (Abramovitz, 2000). The amount of money provided was so low that most mothers still had to supplement their income with low paying jobs. It was common practice to provide financial assistance only to widowed, native-born white mothers (Abramovitz, 2000).

In response to the Great Depression of the 1930s, Congress passed the Social Security Act of 1935 that transferred the responsibility of public social welfare from the states to the federal government. The Social Security Act included five public programs: Aid to Dependent Children (ADC), Old Age Assistance (OAA), Aid to the Blind ( $A B)$, Unemployment Insurance, and Social Security. Under the Social Security Act and ADC, the federal government paid each state a portion of the cost for providing cash assistance to needy families with 
dependent children (Abramovitz, 2000; Neubeck and Cazenave, 2001; and Piven and Cloward, 1993). The intent of the ADC program was to provide for a small number of widows to care for their children at home. Grants were restricted to $\$ 18$ a month for the first child and \$12 for each additional child, and no funds were included for the caretaker. According to Abramowitz (2000), the amount of the ADC grant remained at the same level until the early 1960's.

In 1962, the Social Security Act was amended and ADC became Aid for Families with Dependent Children (AFDC) and expanded financial assistance to adults by providing caretaker grants. With the liberalization of the welfare laws, the welfare rolls grew from 800,000 to 3.5 million between 1960 and 1974(Besharov and Germanis, 2000, and Shaw, Goldrick-Rab, Mazzeo, and Jacobs (2006). According to Shaw, et al, 2006, the welfare rolls grew nearly 17 percent per year from 1967-1972. With the increase in the welfare rolls, the perception of welfare recipients changed. Society viewed the welfare recipient as a never married black female with multiple children born out of wedlock (Patterson, 1996; and Quadagno, 1994). Similarly, Abramovitz (2000) indicated that negative attitudes toward welfare were fueled by the belief that most poor people came from the African-American community. However, data 
indicate that in 1995 African-Americans represented 37.2 percent of all AFDC cases, down from 44 percent in 1983, while whites represented 36.6 percent of all cases, down from 42 percent in 1983.

With the increase in welfare recipients, came the increased cost of the welfare program and a general concern that welfare promoted out-of-wedlock births. The perception of those on AFDC affected whether society believed recipients were deserving of assistance. As a result, in 1967 Congress amended the Social Security Act creating the Work Incentive Program (WIN) as a part of AFDC. WIN required that welfare recipients work or participate in employment training. To remain eligible for financial assistance mothers with children over the age of six were required to participate in work or job training (Abramowitz, 2000). Recipients were allowed to keep part of their earnings and all of the welfare cash benefits as an incentive to participate in WIN. Recipients could keep the first $\$ 30$ in earnings, and one-third of any additional amount earned (Goodwin 1995). In 1967, participation in the WIN program was voluntary; however, in 1969 participation became mandatory. Approximately 850,000 mothers registered for work, but only 140,000 entered the workforce from 1967 1982 (Farel and Dobelstien, 1982). 
In 1973, Public Law 93-203 created the Comprehensive Employment and Training Act (CETA) that expanded the WIN program. CETA promised to improve vocational training by providing on-the-job training and computerized job banks. According to Shaw, et al. (2006) CETA was an attempt to eliminate poverty by creating public jobs and provided the training needed to fill the jobs. Unhappy with the idea of job creation by the government, Public Law 97-300.29 created the Job Training Partnership Act Goodman, et al. 2006 (JTPA) in 1982 eliminating CETA. JTPA emphasized job training in the private sector rather than job creation in the government sector. JTPA reflected the human capital approach to workforce development and the growing belief that training and skill building were vital to eradicate poverty.

In 1988, President Reagan amended the Social Security Act by creating the Family Support Act (FSA). The FSA enacted Public Law 100-485 creating the Jobs opportunities and Basic Skills Training Program (JOBS). JOBS required all states to develop an employability plan for every adult welfare recipient. Each plan would include details regarding job training, education and job placement (Rodgers, 1990). JOBS required all "employable" adults receiving welfare to seek employment. Parents with children 
over age three were also required to find employment, participate in educational training or job skills training (Schram, 1995).

For the first time, education became a viable option for welfare recipients. A number of state programs encouraged recipients to earn a high school diploma or attend college classes. To encourage participation, the JOBS program provided assistance with childcare, transportation costs, as well as covering other workrelated expenses (Besharov and Germanis, 2000). Welfare recipients were also eligible to receive federal financial aid, food stamps, and Medicaid without reducing or losing welfare benefits. As a result, by 1995 approximately 500, 000 welfare recipients received student financial aid (Haveman, 1997).

The JOBS Program was not without problems. Frequently, enrolling in college without prior approval from the JOBS caseworker resulted in penalties. Penalties included reduction in the monthly welfare check, a reduction or loss of Food Stamps, or loss of childcare assistance. Those attending college with the approval of the caseworker faced a different set of barriers. AFDC, the Food Stamp Program, and federal financial aid all had conflicting eligibility criteria that sometimes resulted in a loss or reduction of 
food stamps, particularly if the student received a student loan (Kates, 1993; Rice, 1993).

The emphasis on education and training in exchange for benefits was short-lived when President Clinton signed Public Law 104-93, the Personal Responsibility and Work Opportunity Reconciliation Act (PRWORA) in 1996. PRWORA created Temporary Assistance for Needy Families (TANF), which ended AFDC and the JOBS program. TANF required work in exchange for financial assistance and shifted control of the TANF program back to the states. The passage of PRWORA was the result of thirty years of pressure to replace welfare in the form of cash grants with employment. The U.S. Department of Health and Human Service (1998) outlined the three major elements that directly affected welfare recipients: work requirements, work activities, and a fiveyear lifetime limit for receiving welfare. Under TANF, all welfare recipients were required to go to work within two years of becoming welfare recipients. By fiscal year 1997, 25 percent of the welfare caseload of each state were required to be working or no longer receiving cash assistance. That figure increased to 50 percent by fiscal year 2002. Additionally, single parents were required to work 20 hours per week in the first year, increasing to 30 hours per week by fiscal year 2000. All two-parent families 
were required to work by July 1, 1997. Recipients were required to take part in subsidized or unsubsidized employment, on-the-job training, 12 months of vocational training, or provide childcare for recipients who were participating in community service. All welfare recipients had a lifetime limit of five cumulative years of welfare cash assistance. TANF gave states the option to limit cash assistance to less than five years.

The Center for Women Policy Studies (1999) noted that TANF's final regulations did not specifically define work activities and gave states permission to use funds to provide financial support and services to assist recipients in their pursuit of education. This flexibility in meeting the work requirement resulted in variation among the states in defining work activity. Fourteen states approved postsecondary education as a stand-alone activity to meet the TANF work requirement, while 24 states approved a combination of work and postsecondary education to meet the work requirement. Eight states did not count postsecondary education as meeting the work requirement. Four states provided work guidelines and allowed each county to define work activity within the state guidelines (See Table 1). After several years of extensions, TANF was reauthorized as part of the Deficit Reduction Act of 2005 (DRA). The 
Table 1

Education Counted as a Work Activity

\begin{tabular}{|c|c|c|c|}
\hline $\begin{array}{l}\text { Stand-Alone } \\
\text { Activity }\end{array}$ & $\begin{array}{l}\text { Combined } \\
\text { with Work }\end{array}$ & $\begin{array}{l}\text { Not } \\
\text { Counted }\end{array}$ & $\begin{array}{l}\text { Set by } \\
\text { county }\end{array}$ \\
\hline Alaska & Alabama & Connecticut & Colorado \\
\hline Florida & Arizona & Idaho & Montana \\
\hline Georgia & Arkansas & Mississippi & New York \\
\hline Illinois & California & oklahoma & Ohio \\
\hline Iowa & Delaware & Oregon & \\
\hline \multirow[t]{2}{*}{ Kentucky } & District & South Dakota & \\
\hline & of Columbia & Washington & \\
\hline Maine & Hawaii & Wisconsin & \\
\hline Minnesota & Indiana & & \\
\hline Nevada & Kansas & & \\
\hline Pennsylvania & Louisiana & & \\
\hline Rhode Island & Maryland & & \\
\hline Utah & Massachusetts & & \\
\hline Vermont & Michigan & & \\
\hline \multirow[t]{12}{*}{ wyoming } & Missouri & & \\
\hline & Nebraska & & \\
\hline & New Hampshire & & \\
\hline & New Jersey & & \\
\hline & New Mexico & & \\
\hline & North Carolina & & \\
\hline & North Dakota & & \\
\hline & South Carolina & & \\
\hline & Tennessee & & \\
\hline & Texas & & \\
\hline & Virginia & & \\
\hline & West Virginia & & \\
\hline
\end{tabular}

Source: State Policy and Documentation Project, July 2000 
reauthorization decreased the flexibility of states to define work participation, increased work participation rates, mandated uniform reporting requirements, and required verification of work participation. Each state's work participation rates increased in 5 percent increments, increasing to 50 percent in 2006 . In 2007 , the rates increased to 55 percent, to 60 percent in 2008, to 65 percent in 2009, and to 70 percent in 2010 (Communications Workers of America, 2006). The DRA directed the Department of Health and Human Services(HHS) to issue regulatory definitions by June 2006 that would provide direction on how to count and verify allowable work activities, as well as clarify who is required to work (Frank, 2006; Wider Opportunities for Women, 2006).

Interim DRA rules were published in June 2006, with an effective date of October 2006. The definitions of work, as written, were narrow and more restrictive than previous definitions. Each state must meet a 50 percent work participation rate for all welfare families, with twoparent families calculated separately at a 90 percent rate. To meet the criteria, recipients must participate in countable work activity. For single-parent families the criterion is 30 hours a week and 35 hours a week for twoparent families. The new definitions for work participation 
gave states less flexibility in defining work activities (Sargent Shriver National Center on Poverty Law, 2006). Vocational education continues to be limited to twelve months and must be "directly related to the preparation of individuals for employment in current or emerging occupations requiring training other than a baccalaureate or advanced degree" (Federal Register 45 CFR \$261.2i). In addition, homework and studying can no longer count toward the work participation requirement unless it is a supervised study session. By October 2007, states were required to have a system to document the number of hours reported for study time or educational activities. The number of hours reported must be the actual times worked (Sargent Shriver National Center on Poverty Law, 2006).

In summary, in 1996 when the nation's welfare system was overhauled, single mothers were expected to work and cash assistance was no longer an entitlement. The "work first" ideology seeks to move recipients into work to reduce welfare caseloads. The reauthorization of TANF in 2005 narrowed the definitions of allowable work activities, increased work requirements, and eliminated postsecondary education as an option for welfare recipients. The additional shift in policy will create almost insurmountable barriers for welfare recipients currently 
attending postsecondary institutions. Welfare recipients who are currently attending college are more likely to be in part-time or short-term programs rather than degree granting programs (Jacobs and Winslow, 2003; Shaw et al., 2006). States are still in the process of making the necessary changes to implement the new regulations. States were required to draft a state plan to meet the new requirements by September 20, 1996, and have a federally approved plan by october 1, 2007. The impact of the new rules on current students is unfolding; however, there is current research that documents the impact of welfare reform on welfare recipients attending college over the last ten years.

\section{Impact of TANF Regulations on Postsecondary Education}

According to Shaw et al. (2006), it is difficult to provide an accurate assessment of the effects of welfare reform on college enrollment among welfare recipients. There is no systematic collection of data at the federal, state, or institutional level. The implementation of TANF eliminated the majority of reporting requirements, including college enrollment and educational training, because it was not an approved work activity (Jacobs and Winslow, 2003). Reports indicated a decrease in the number 
of welfare recipients enrolled in postsecondary institutions with the implementation of welfare reform (Jacobs and Winslow, 2003).

Cox and Spriggs's (2002) analysis of the data from the 1997 and 1999 surveys of the Urban Institutes National Survey on American Families indicated a twenty-point decrease in college enrollment of welfare recipients. Similarly, Greenburg, Strawn, and Plimpton (2000) found that the number of welfare recipients in college declined from 172,176 to 58,055 in 1998. City University of New York (CUNY) experienced a 77 percent drop among welfare recipients (Applied Research Center, 2001). Massachusetts' community college system experienced a 46 percent decrease from 1995 to 1997 (Kates, 1998). Similarly, in Michigan, one college reported a 60 percent decrease and six others reported a 50 percent decrease in the attendance of welfare recipients (Kahn and Polakow, 2000).

The financial aid application is an additional source of information regarding college enrollment. For the academic years 1996-1997 and 1998-1999, the number of applicants that reported TANF funds as income fell from 580,000 to 359,000 (Shaw et al., 2006). According to Carnevale, Reich, Johnson, and Sylvester (2000), in 1995, 408, 000 independent welfare recipients accessed the Pell 
Grant to cover tuition and fees. However, by 1998, that figure dropped to $290,000$.

Pandy, Zhan, Neeley-Barnes, and Menon (2000) surveyed 32 states and found great variation among the states regarding support services and postsecondary education for welfare recipients. Eighteen of the states allowed recipients to attend two and four year institutions and to receive subsidized childcare while in class. Fourteen states provided transportation for students attending college. Wyoming allowed recipients up to four years of education, and to work at least 32 hours a week during the summer. Students also were required to maintain a $\mathrm{C}$ average and complete 30 credit hours each academic year.

In an effort to understand the effects of welfare reform, Karier (2000) studied welfare recipients attending Eastern Washington University (EWU) a comprehensive fouryear institution. The study found that all welfare recipients attending EWU in August 1997 were allowed to remain in college until June 1998 if the student had an educational plan, and the plan was approved by November 1997. Students who did not complete their program by June 1998 were eligible to continue taking classes; however, they received no childcare assistance while in class and had to meet a 20-hour a week work requirement. 
Karier also found that 16 hours of work-study could count toward the 20-hour per week work requirement, but unpaid internship hours did not count toward meeting the work requirement. Monthly cash benefits were reduced by 40 percent if the work requirement was not met. In addition, no new educational plans that included two or four-year degree programs were approved.

Wolf and Tucker (2001a) conducted in-depth interviews with 12 welfare mothers attending college in Washington D.C. The women had difficulty combining work and school and the added pressure of the TANF time limits. They also experienced problems with negative feedback from caseworkers and had difficulty scheduling re-certification appointments. Welfare caseworkers saw attending college as an "outside interest" and in an effort to move recipients into employment, recipients became victims of the "don't ask-don't tell" policy. Caseworkers intentionally did not give recipients information regarding benefits that would assist them with their educational pursuits. Cash benefits were reduced if recipients failed to meet the 20-hour per week work requirement.

Christopher (2005) conducted in-depth interviews with 17 welfare recipients attending the University of Louisville. For nearly half of the participants perceived 
that the welfare caseworker supported college attendance, while the remaining half reported having had problems with the caseworker. Findings also indicated that caseworkers were frequently unable to provide information about pursuing a college education.

Illinois Welfare News (1999a) indicated that in 1999 Illinois made postsecondary education an option for welfare recipients. Any welfare recipient attending college fulltime could count college attendance as meeting the TANF work requirement. The lifetime eligibility clock stopped while attending college if students maintained a 2.5 grade point average (GPA). Students who maintained at least a 2. 00 GPA could remain in college, but they were required to work 25-hours per week to earn the clock stop benefit. All part-time students were required to work twenty hours per week at a regular job or work-study. However, if part-time students worked 25 hours per week they also earn the clock stop benefit. Time in school was not counted against the lifetime TANF limit.

Later the same year, the Illinois Department of Human services issued an amendment regarding welfare recipients and postsecondary education. Prior to the local welfare staff approving postsecondary education as an option to meet the work requirement, the recipient had to demonstrate 
the ability to finance tuition and other expenses, and to arrange transportation and childcare (Illinois Welfare News, 1999b). Both criteria were nearly impossible to meet when the financial aid package was not approved until midsemester and childcare could not be arranged until the recipient had a class schedule.

Michigan adopted the 10/10/10 Program for students in their second year of an associate's degree program or the final year of a bachelor's degree program. Students in oneyear certificate programs or single mothers with children age six or older were also eligible for the 10/10/10 program. Students could meet his/her TANF work requirement of 30 hours by working ten hours per week, attending class or lab for ten hours per week and studying ten hours per week. Similarly, single students with children under six years of age and in the final year of their educational program could meet their TANF work requirement of 20 hour a week by working ten hours and studying ten hours per week. Students in all cases had to enroll in programs designed to lead directly, upon completion, to a job in demand, as determined by the local Workforce Development Board. Ironically, there were no formal guidelines to determine which jobs were in demand (Kaufmann, Sharp, Miller, and Waltman, 2000). 


\section{Childcare}

Issues with childcare are closely related to the problems in meeting the work-study and work requirements. Childcare is essential for moving women and families off welfare and lack of childcare is a reoccurring problem for welfare college students.

The "work first" ideology seeks to move welfare mothers into work without considering that 62 percent of all welfare recipients have children under the age of six. The passage of TANF increased the funding for childcare, but the guarantee that childcare would be provided for welfare families was repealed as a part of the welfare reform laws. Instead, funds previously used for childcare became part of the Child Care and Development Fund (CCDF), a block grant available to states to fund childcare. The block grant made funds available to all families that earned up to 85 percent of the state's median income as well as low-income families. Welfare recipients were required to work but also had to compete for childcare subsidies with all low-income families (Adams and Rohacek, 2002). States had tremendous flexibility in designing policies and determining eligibility, provider rates, copayments, and service priorities. The cost of childcare 
varied based on location, the type of provider, and the age of the child. Co-payments are on a sliding fee scale and vary state-to-state by family size, and cost of childcare. In 24 states, providers charge additional fees above the required co-payment if the provider rates exceeded the state reimbursement level. For many welfare recipients the cost and availability of childcare poses an insurmountable barrier .

Kaufman et al. (2000) found that many of Michigan's public institutions have on-site childcare programs; however, the spaces are limited and the costs are high. There are a limited number of scholarships, but scholarships are rarely available. Welfare students must compete with faculty and staff for the available slots. The rate for full-time pre-school is $\$ 100$ to $\$ 168$ per week. Students also have a difficult time finding affordable, quality childcare in the community. Full-time childcare for preschool averages $\$ 800-\$ 900$ per month, while full-time infant and toddler care can run as high as $\$ 1200$ per month. They found that the average cost of childcare was $\$ 460$ per month. While student financial aid packages can cover childcare costs, typically, the cost is underestimated and the financial aid package does not cover the full cost. The underestimation is a result of the difficulty of finding 
affordable childcare. In 1993, Michigan had 442,649 children under six in need of childcare and the estimated capacity of licensed providers was 215,267 . Because of the high cost and shortage of available childcare slots, welfare students were more likely to leave school due to the lack of childcare or had to find unlicensed or use familial childcare arrangements.

Kahn \& Polakow (2004) found that students that were able to gain childcare subsidies in Michigan often had problems with denials or reduction in payment, slow or late payments, and inaccurate calculation of the subsidies. Findings also indicated that only 19 percent of the income eligible population of 600,000 children received a childcare subsidy. Additionally, in April 2002 Michigan increased the work requirement to $4 \odot$ hours a week for every parent receiving welfare cash assistance, further complicating the childcare issue.

\section{Transportation}

Closely related to the childcare issue is the problem of transportation to and from work and school. Transportation is a prerequisite for work as well as school. Half of all welfare recipients live in urban areas and since 1970 most new jobs have been created in suburbs 
rather than the inner city. Thus, transportation poses a challenge for welfare recipients. Bania, Coulton, and Leete (1999) found that from 1991 to 1996, the number of jobs in Cleveland fell 1.6 percent, and jobs in the suburbs increased by 121 percent. Seventy-eight percent of Cleveland's welfare recipients reside in the city. The General Accounting office (1998) also found in surveys in 1995 and 1998 that transportation was a major barrier for welfare recipients. The 1995 survey found that only 6 percent of welfare families had cars; however, by 1998 the number had increased to 20-30 percent. Under AFDC, families could not accumulate resources over $\$ 1000$, and a car could not be worth more than $\$ 1500$. Consequently, if families owned cars, they generally were not reliable. Families frequently relied on public transportation. Bania, et al. (1999) also found that public transit systems were inadequate. Many entry-level jobs were in the outer suburbs beyond existing transit lines. If commuter rails were available, they were expensive and did not provide direct access to employment sites. Transit trips were frequently long and required transfers, and the schedule did not meet the time needs of the welfare recipient. 
Financial Aid and Federal Work Study

Most welfare students face many obstacles in their pursuit of self-sufficiency and postsecondary education, one obstacle being financial aid. To be eligible for a Pell Grant the student must be making progress toward completion of a course of study. TANF requires that the course of study be work related, however, classes are often not offered in the sequence needed, or not offered at times that the student is available to take the class. Consequently, students have difficulty demonstrating progress toward a degree (Strawn, 2000). Demonstrating progress toward a degree is also difficult if the student needs to take developmental classes that carry no credit and do not count toward degree completion. To be eligible for federal financial aid, students are required to take credit-bearing classes. Eighty percent of all public community colleges allow developmental courses to qualify for financial aid; however, the student must be eligible to take a credit-bearing course along with the developmental course. According to Strawn (2000) and Freidman (1999), federal student aid is a flat rate, and there is no adjustment for family size; as a result, welfare recipients are more likely to have family expenses that are not covered by financial aid. 
According to Carnevale, et al. (2000), many welfare recipients simply did not apply for financial aid. In California, 96, 000 community college students were eligible for federal financial aid but did not receive financial aid. Many believed that financial aid would count as income, thus reducing or eliminating their welfare cash assistance. Some students were not aware that they are eligible; for others, the local welfare office mistakenly reduced their welfare grants.

Wolf and Tucker (2001a) found that students frequently waited in long lines and financial aid packages were not approved in a timely fashion. In one instance, a student applied for financial aid for one semester and did not receive approval until the following semester. Similarly, one student was not determined to be ineligible for financial aid until mid-semester. Interviews with students also revealed the information regarding financial aid eligibility often came from community-based agencies rather than postsecondary institutions.

Kahn and Polakow (2000) documented similar problems in a study of welfare-to-work recipients in Michigan. The study followed ten welfare recipients in four counties in southeast Michigan between 1997 and 2000. The participants in the study revealed that information regarding 
eligibility for financial aid, work requirements, sanctions, and work-study was often incorrect or withheld. Students were routinely required to miss class in order to attend job skills training and were sanctioned if they chose to go to class rather than the jobs skills training session.

Johnson and Kaggwa (1998) found that in 1995 federal funds were provided to higher education institutions to create jobs for low-income students who needed financial assistance to meet college cost. California earmarked \$34 million for work-study positions at community colleges. Kentucky set aside $\$ 1$ million to colleges to promote workstudy positions to enrolled welfare recipients. In both states the work-study position met the TANF work requirement. Many colleges have found it difficult to finance new work-study positions for welfare recipients using federal funds only. The allocation formula that requires matching funds tends to favor higher cost institutions. Community colleges, as well as other lower cost public institutions, that are more likely to enroll welfare recipients, often have insufficient funds to serve all eligible students. Federal Work-Study, like the Pell Grant, required that students take credit-bearing courses to be eligible. 
Nontraditional College Students

Horn (1996) defined the nontraditional student as those who fall into one or more of the following seven categories: (a) delayed college enrollment, (b) those attending part-time, (c) financially independent from financial support, (d) work more than 34 hours outside of the home, (e) caring for dependents ( may be a child or an aging parent), (f) single parents that are primarily responsible for the child, and (g) may not have a standard high school diploma. Horn also suggested that students who faced one of the seven characteristics are considered to be minimally nontraditional. Students meeting two or more of the characteristics are considered to be moderately nontraditional and students meeting four or more of the characteristics are considered to be highly nontraditional.

Horn, Cataldi and Sikora (2005) found that students that delayed entry into college were more likely to come from low-income families, to be single parents, to be African American, Hispanic or American Indian or first generation. Similarly, Mingle and Birkes (2004) discussed the barriers that adult learners face in southern states. The barriers included lack of preparation, scheduling, time and lack of finances. 
Macari, Maples and D'Andrea (2005-2006) compared student development in nontraditional and traditional college students. Findings indicated that nontraditional students scored lower on the development of establishing and clarifying purpose. Nontraditional students are more likely to engage in responsibilities off campus and to avoid extracurricular activities due to these responsibilities. They are also less likely to engage in career planning and cultural activities and other types of events on campus.

Cross (1981) identified three barriers to completion of college for nontraditional students as situational, institutional and dispositional. Situational barriers relate to the person's life and include time constraints, family and work responsibilities, and low-income. Institutional barriers are those barriers that may deter a student from attending. These barriers typically include policies and procedures regarding class locations and time, officer hours, or lack of information about programs or procedures. Dispositional barriers, sometimes referred to attitudinal barriers, are those which the individual has about themselves as a student. The barriers may be expressed as a lack of confidence in one's ability to learn, non-participation in campus activities, low self- 
Finally, given the flexibility to design their own welfare programs, some states created barriers that were more punitive than federal legislation. Other states developed programs that supported education as a method of meeting the federal work requirements. Both options presented a variety of barriers such as time limits, inadequate childcare assistance, misinformation, financial aid problems, conflicting appointments, and complex welfare guidelines. Faced with balancing work, family, classes, and bureaucratic barriers, many recipients abandoned their goal of earning a college degree (Johnson and Kaggwa, 1998).

Reducing the welfare rolls and putting recipients to work continues to be the primary thrust of welfare reform. The current reauthorization eliminates the ability of welfare recipients to attend four-year institutions, and limits education and training to twelve months. Recipients currently attending four-year institutions may be required to experience an unanticipated transition, including a significant change in their educational program. Each transition is a process and how the student responds depends on how he or she views the transition.

Both nontraditional students and welfare recipients attending postsecondary institutions possess similar characteristics. These may include, delayed entry, age, 
single parents, multiple responsibilities and low-income, and exposure to multiple situational, and dispositional barriers that place them at risk of persistence.

\section{Transition Theory}

The definition of transition grew out of crisis theory; Moos \& Tsu (1976) described a crisis as short periods of time when problems arise and a person has to work out ways of resolving or handling a problem. Parkes (1971) used the term "psychosocial transition" to describe any change that necessitates " the abandonment of one set of assumptions and the development of a fresh set to enable the individual to cope with the new altered life space" (p. 103). Similarly, waechler (1974) argued that transitions contribute to psychosocial development because they involve change or adaptation across the life span. Bridges (1980) described transition as "the natural process of disorientation and reorientation that marks the turning points of growth" (p. 5). Brammer and Aberego (1981) described transition as any change involving personal awareness and the assumption of new behavior. The process begins long before it happens, and may continue well beyond the actual event. In a similar fashion, Mercer, Nichols, and Doyle, (1989) defined transitions as "turning points, a 
point of reference from which a person's life course takes new direction requiring adaptation or change" ( $p .2)$. Bridges (1980, 2003) described transition as a three-stage psychological process of letting go of old ways and identities, understanding what comes after letting go, and making a new beginning. Bridges contends that the phases are not separate and that the individual may find himself or herself in one or more phases at any time.

Sugarman (1986) described a seven-stage transition cycle that takes place when an event or nonevent results in a change of one's behavior and relationships. Movement through the transition cycle is neither smooth nor continuous, and the individual fluctuates between the different phases. While each individual responds differently to a transition, the stages are a recognizable sequence of responses. The first phase, immobilization, is characterized by a sense of shock and being overwhelmed. The intensity and duration increases by the suddenness and negative interpretation of the transition. Reaction, the second phase, is depicted as a sense of elation or despair, denial or minimization is dependent upon the individual's appraisal of the event. The reaction provides relief from the event and is followed by self-doubt, which may be manifested in feelings of anxiety, anger, or depression. 
Self-doubt is followed by letting go; the reality of the change is accepted. Brammer \& Abergo (1981) indicated that letting go may be traumatic. Letting go requires courage to let go of the past and plunge into the unknown. Sugarman (1986) described letting go as a coping mechanism, the point at which one can begin to convert the transition into growth points. Letting go allows the individual to consider and test new options, which is the fifth phase. This is an experimental period, alterative options are considered as the individual begins the process of putting the past behind and searches for new meaning. The sixth phase, reflective thinking is an attempt to make sense of what has happened. During the final phase, integration, the individual feels at home with the transition and takes on new behaviors that result in lifestyle changes.

Bridges (1980) argued that what the individual brings to any transitional situation is the style that he or she has developed for dealing with endings ( $p .15)$. Bridges (1991, 2003) described managing transitions as helping individuals through three phases: endings, the neutral zone, and new beginnings. A transition begins with an ending, the letting go of old ways and identities. After letting go, an individual enters the neutral zone, a psychological realignment. It is an in-between stage when 
the old is gone, but the new is not operational due to the process of psychological realignment. During the final stage, the individual completes the transition and makes a new beginning. Bridges (2003) described this three-stage transition as a psychological process of letting go of old ways, and making a new beginning. An individual experiences change within the context in which the individual resides; hence, Schlossberg's transition theory provides a framework to examine the coping skills of the individual in transition.

\section{Schlossberg's Transition Theory}

As one moves from a period of relative stability to a transition, the response differs dependent upon the individual's appraisal of the change. Schlossberg (1981) made the point that "a transition is not so much a matter of change as of the individual's perception of the change. A transition is only a transition if is so defined by the person experiencing it." (p. 7). "The more the event alters an adult's roles, routines, assumptions, and relationships, the more he or she will be affected by the transition" (Sargent and Schlossberg, 1988, p. 58).

There is increasing recognition among psychologists that stress, life events, and how one responds to the life 
events is important in understanding coping behavior. Goodman, Schlossberg and Anderson (2006), Schlossberg (1984), and Schlossberg, Waters and Goodman (1995) presented a model for counseling adults in transition that provides a framework for addressing the academic and personal needs of adult students. The model is a framework for understanding the perceived demands and coping strategies used by individuals in transition. Schlossberg, et al. (1995) indicated "the transitions differ, but the structure for understanding individuals in transition is stable" (p. 26).

Schlossberg (1984) defined a transition "as any event that results in a change in relationships, routines, assumptions or roles with the setting of self, work, family, health and/or economics"(p. 43). There are three types of transitions: anticipated, unanticipated, and nonevents.

Anticipated transitions are expected normative events, such as graduating from high school. Because the event is normative, an individual can anticipate and plan for the event. Unanticipated transitions are unexpected life events that disrupt the normal routine, typically involving a crisis and the inability to plan for the event. Nonevent transitions are expected events that do not occur. 
Goodman, et al. (2006) argued that the realization that the event will not occur may alter the way ones sees him or herself, or the way in which the individual responds.

Appraisal and response to change is the foundation of the transition model. The personal experience of the change determines the meaning of the transition. How recipients respond to the changes in the welfare rules regarding college attendance, and how they adapt to the change depend on their previous coping strategies. To understand the meaning of the transition, one must consider the type of transition, the context of the transition, and the impact. According to Schlossberg (1984), Schlossberg, et al. (1995), and Goodman, et al. (2006), there are four major factors that influence how an individual copes with the transition: situation, self, support, and coping strategies, known as the 4 S System. The 4 S System provides a framework to identify the resources individuals have to cope.

\section{Situation}

Each transition is different and perceived differently by each individual; as a result individuals appraise the same events in different ways. The appraisal of an event or nonevent is determined by the timing, control, role change, 
duration, previous experiences, or concurrent stress that precipitates the transition. Previous experience with a similar transition determines how effectively a person copes with the current transition. A stressful life event is any event that exceeds an individual's capacity to respond effectively (Lazarus and Folkman, 1984). Welfare reform represents a complex, large-scale event in the lives of welfare recipients that potentially challenges each individual's coping skills. The appraisal of any transition is dependent upon the context in which the event occurred and the impact on daily life activities. Transitions are a process over time and assimilation and appraisal are continuous (Schlossberg, 1984).

Cognitive appraisal is the process by which an individual attempts to evaluate if an incident or event is relevant to his or her well-being and in what ways. According to Lazarus and Folkman (1984), cognitive appraisal determines if an event is stressful or nonthreatening, the meaning, or the importance of the event, and the options available. According to Compas and Orosan (1993), during primary appraisal, the individual determines if he/she has a stake in the event and asks, "Am I okay or am I in trouble?" The individual looks at the relationship between self and the environment and determines if the 
event is threatening, non-threatening, or positive.

During secondary appraisal, the individual evaluates if anything can be done to overcome the event, prevent harm, or improve the outcome (Lazarus and Folkman, 1984). The extent to which an event is viewed as harmful depends on the meaning or significance. A single stressful event may not place great demands on coping ability; however, multiple problems can leave one feeling helpless, and the perceived inability to cope.

Rattner (2004) working as a welfare rights advocate in New York documented the stories of women with whom she worked with who were welfare recipients attending the City University of New York. One student described being on welfare as being "stuck." The student felt helpless and had a great deal of anxiety regarding time limits and the inability to handle the pressure of home, school, and work requirements. No longer able to handle the stress, the student was admitted to the mental health unit of the hospital. Other students expressed a sense of desperation and flattened expectations in response to the demands of welfare reform.

McPhee and Bronstein (2003) found that the recipients worried about the impending loss of benefits. They also viewed the policies as limiting their independence and 
viewed education as a way of gaining access to economic independence and respect from society. Similarly, Grabowski (2006) found that the welfare recipients complained about the restraints of the TANF system. One primary concern was that the "system" treated all clients the same without regard for the individual needs of each client.

Welfare reform represents a threat of the loss of financial resources, a sense of stability, and a negative impact on school attendance (Jarrett, 1996). Because of the punitive nature, the welfare system is viewed as a means of controlling and regulating the lives of welfare recipients.

Self

Self looks at an individual's assets and liabilities. What does the individual bring to the transition? Reaction to any event varies according to the factors related to self. Self involves two categories: personal characteristics and psychological resources.

Personal characteristics include socioeconomic status, gender age, stage of life and ethnicity that in turn influence worldview. Pearlin and Schooler (1978) defined psychological resources as the "personality characteristics that people draw upon to help them withstand threats" (p.5). Psychological resources include 
locus of control, ego development, values, and selfefficacy .

Personal characteristics affect how a person views life. Two persons may experience the same transition, but approach it differently dependent upon their level of maturity and frame of reference. According to Parker (1994), psychosocial coping resources, including a sense of control, help to buffer the effects of stress and contribute to economic self-sufficiency.

Welfare recipients bring to the educational setting a wide variety of experiences that shape them as individuals. They bring the experiences that include their educational history and their responsibility to family and friends. They come with multiple identities but share some common characteristics that place them in an "at risk" category. Welfare recipients are most likely to be a first generation student with poor educational skills and tentative family support. Current welfare policies place emphasis on quick transitions from welfare to work assuming that all recipients are equal and without giving any consideration for their psychological status.

McPhee and Bronstein (2003) in a multiphase study interviewed thirty-nine women participating in a program designed to move them from welfare to self-sufficiency. The 
participants gave negative descriptions of the interactions with welfare workers and other professionals associated with the welfare system that were similar to the finding of Colbry (1995), Ross (1992), and Sentson (1989). The women described other women on welfare in terms of the popular welfare images in the media. However, they did not attribute the same descriptions to themselves. Goodban (1985) and Kerbo (1976) found that welfare recipients were ashamed of being on welfare and blamed themselves for their situations. Seccombe (1999) found that some welfare recipients distanced themselves from other welfare recipients by identifying with middle class values and not internalizing the welfare stereotypes. According to Sercombe, this form of denial creates negative psychological consequences for recipients.

McPhee and Bronstein (2003) found that the participants in the study expressed a strong sense of self and had ambitious personal goals. Yet what was missing from their discussion was the skills and resources needed to accomplish their stated goals. The program had done a wonderful job with the women helping to develop positive self-images, but it had not helped them develop realistic goals. Individuals who are not equipped to gain the resources necessary to fulfill their identified goals are 
particularly vulnerable to stress.

Welfare recipients are more likely to experience

stress because they are faced with the loss of financial

resources and a sense of instability given the current

welfare reform changes. Jarrett (1996) found that mothers

on welfare felt threatened by the potential loss of welfare

benefits. Wolfe and Tucker (2001b) found that recipients in

college feared the threat of being sanctioned, of having

their benefits cut or of losing benefits entirely for

failing to meet the TANF requirements.

Browne, Salomon, and Bussuk (1999) explored the

relationship between partner violence and work over time.

The findings indicated that partner violence and a women's

ability to hold a job over time interferes with the ability

to escape poverty. The study also found that practical

supports such as childcare and childcare subsidies increase

the likelihood of women to maintain work over time. In

addition, high levels of psychological distress were

associated with low-income women's capacity to maintain

employment for more than a twelve-month period. Parenting

stress is a barrier to successful employment for parents to move off welfare into work.

Parker (1994) argued that a sense of self-control in the midst of a crisis is a coping resource for welfare 
mothers. Bandura (1997) argued that an individual's perceived self-efficacy influences how the individual thinks about him/herself and motivates behavior. If one believes that he/she has no power to influence event, the individual does not try. Conversely, effort is put forth to influence the event if the individual believes that he/she can influence the outcome. Kunz and Kalil (1999) using the data from the 1970 through 1994 surveys of the National Longitudinal Survey of Youth sought to determine if family background (self-esteem and self-efficacy) were related to welfare use as young adults. The self-efficacy data was collected in 1979, and the welfare data was collected between 1985 and 1992. Multivariate analysis of the data found a robust association between self-esteem and welfare use, but not between self-efficacy and welfare use. The results found that prior to entering the welfare system participants had lower scores on self-efficacy and selfesteem. Self-esteem was a significant factor related to welfare use. When controlling for background risk factors, those that scored one-half of a standard deviation above the mean on self-esteem were 16 percent more likely to have received welfare that those who scored one-half standard deviation below the mean. The findings suggested that low self-esteem might directly influence welfare use in early 
adulthood. Goodban (1985) and Jarrett (1996) found that long-term use of welfare benefits diminished self-esteem and self-efficacy because of the stigma related to being a welfare recipient.

Support

Social support is emotional or tangible assistance that individuals receive from their circle of family and friends when confronted with a stressful event. Support systems help to mobilize the individual. Support may extend outward to include social institutions, and community. Kahn and Antonucci (1980) developed the concept of convoy of support in which each person moves through life surrounded by a group of significant others giving and receiving support. Caplan (1976) indicated that support systems help the individual to mobilize psychological resources and master burdens. Support systems may also share financial resources, may share tasks and information, and may provide guidance on handling stressful situations. Thoits (1986) described social support as a buffer that assists the individual by providing resources that reduce the stress and the impact of an event. Kahn and Antonucci (1980) identified three functions of support: affect, affirmation, and aid/assistance. Affect provides support through respect 
or care. Support that is affirming expresses agreement or understanding of the individual. Aid or assistance provides tangible assistance that is necessary to resolve the crisis or transition.

Brown and Barosa (2001) studied a group of fifteen women participating in a welfare-to-work program that provided job-readiness skills. The study identified obstacles to self-sufficiency: lack of childcare, lack of self-esteem related to school, lack of support from family and friends, limited life options, criminal history, program quality, and lack of training for non-welfare recipients.

Participation in the program resulted in a loss of social support for some of the study participants. The decision to participate in the program changed their roles as well as their relationship to family and friends. Ebaugh (1988) found that leaving behind a role and incorporating the old role into a new identity is often threatening to significant others. One participant that had been the primary caregiver for her extended family lost the support of her family when she was no longer available to meet their physical and emotional needs. Some participants made the decision to enlarge their circle of support to reduce the stress of the transition. To make a successful 
transition to self-sufficiency required the participants to develop new and stronger support systems with staff and peers. The participants that were unable to navigate the role change did not expand their circle of support and were not successful in the program. According to Schlossberg (1984), any role change is accompanied by some degree of stress.

There are times when individuals in the circle of support have different functions. D'Ercole (1988) found that for one group of mothers emotional support came from a small group of supportive friends. However, family members and neighbors provided task related support.

Support may not always be positive. Wijnberg and Reding (1999) found that negative social networks included threats of abuse from a former spouse or partner, as well as family members that were highly critical. Wijnberg and Reding indicate that in relationships where the same person is both supportive and critical represents a special complexity. The relationship is characterized by ambivalence and pain, yet the recipient of the criticism is dependent upon the relationship.

Stone, Nelson and Nieman (1994) studied the primary sociological belief factors of low-income mothers attending college. The primary sociological factor that affected 
academic success was the emotional support and encouragement received from family members. The support of peers also played an important role. Peer support was more emotional and came in the form of "feeling understood," "being encouraged" or "providing feedback and information."

In a study by Wijnberg and Weiger (1998), the participants acknowledged receiving practical support more frequently than emotional support. Practical support was in the form of childcare, transportation, or housing assistance. However, the participants expressed a stronger need for emotional support to assist in the coping process. As the individual evaluates the transition, the response is determined by the available social supports. Kalil, Born, Kunz and Caudill (2001) argued that it is important to help welfare recipients to extend their social networks and social communities to assist them in making the transition from welfare to work.

\section{Strategies}

Coping strategies include the individual's response to the transition. Pearlin and Schooler (1978) define coping as "any response that serves to prevent, avoid, or control emotional distress." Schlossberg's transition model endorsed Pearlin and Schooler's belief that coping 
responses fall into three categories:

1. Responses that control the meaning of the problem by cognitively neutralizing the meaning to avoid the stress.

2. Responses that attempt to modify the situation by helping the individual to accommodate the stress without feeling overwhelmed by the event.

3. Responses that help to manage the stress after the feelings of stress have occurred. This response helps to trivialize the importance of the stress by selectively ignoring, denial, or passive acceptance.

Lazarus and Folkman (1984) described a process model of coping that examines the dynamics of a person's thoughts and behaviors within a specific context. They acknowledge that coping is complex and involves a number of factors, including the timing of the stressful event and the place in the life cycle. Lazarus and Folkman argued that coping is an attempt to control the situation, and it may involve changing the meaning of the situation, altering the environment or managing the individual's emotions and behaviors. The effectiveness of the coping strategy depends on whether the strategy used is appropriate for the 
situation. An effective coping strategy eliminates or reduces stress.

Coping strategies are a repertoire of behaviors utilized by the individual to reduce stress. Individuals who believe that outcomes are dependent on their own personal behaviors use more problem-focused coping strategies. Problem-focused coping strategies take direct action to relieve the stress, and may include confrontation, social support, and planning. Individuals who believe outcomes are beyond their control typically use emotion-focused coping strategies. Emotion-focused coping behaviors attempt to minimize the stress and may include distancing or escape/avoidance. Lazarus and Folkman (1984) emphasized that the selection of the coping strategy depends on if the situation can or cannot be changed.

Lazarus (1984) found that individuals who cope effectively use both problem-focused and emotion-focused strategies. Individuals typically cope by seeking information, taking direct action or taking no action or using intra-psychic behavior (such as denial, dreaming, or distortion). The ability to cope is a dynamic process that constantly changes throughout the process of appraisal. The type of strategy used depends on whether or not the situation can be changed. Individuals are generally faced 
with a variety of transitions and stressful events, consequently, a particular coping strategy is not effective in all situations.

Thomas (2002) studied former welfare recipients and found that 86 percent of the women used prayer and talking to mentors and friends as a method of coping. The women frequently sought out friends or other single mothers who were also pursuing the same goal. Negative coping behaviors included drug and alcohol abuse, isolation from others, dysfunctional relationships, eating and sleeping disorders, and perfectionist behaviors. McClary (1990) indicated that as adults enter a learning environment "their ability to cope with frustration, pressure, positive and negative life event is often an important aspect of their success." ( $p$. 66)

Gill (2001) studied the levels of distress among women making the transition from welfare work. The study also examined factors associated with increased distress and the coping strategies used to reduce the levels of stress. Gill found that the distress experienced by the participants was often related to day-to-day hassles of living rather than the number of benefits checks remaining. Many of the women combined periods of employment with periods of using welfare benefits. The women used the strategy of saving 
some months of benefit eligibility in the event of an emergency or unexpected unemployment.

Edin and Lein (1997) found that welfare recipients were not able to cover all their monthly living expenses with their welfare check. In response, many of the women developed other strategies to produce additional unreported income. Strategies included income from babysitting, cleaning houses, taking jobs that paid cash only and, in some instances, prostitution.

Arthur and Heibert (1996) studied the coping strategies of students during their first year of college. In response to familiar demands, the students used coping strategies they had used in the past. At times, the strategies were not effective, but the students continued to use what was familiar and were unable to develop new coping strategies.

In summary, transition is a process and each person completes the process differently and the outcome is different for each person. How one successfully accomplished this task of integration is contingent upon four factors: situation, self, support and the effective use of coping strategies. This balance of resources and liabilities determine why individuals react differently to the same type of transition and why the same person 
responds differently at different times.

Research Using Schlossberg's Transition Theory

Schlossberg, et al (1995) offered a model for counseling adults in transition. The model's framework provides a systematic approach for helpers to assist persons in transition. The transition framework locates where the individual is in the transition, identifies the resources an individual has to cope, and demonstrates new coping strategies.

Pearson and Petitpas (1990) used Schlossberg's theory as the conceptual framework for studying injured and retiring athletes. The study found that the participants experienced a great deal of stress related to unexpected injuries or being cut from the team unexpectedly. Identifying the individual athlete's perception of the transition and the available supports were helpful in athlete's making a healthy transition. Personal identity as an athlete, the inability to make the necessary preparation for retirement, and the timing of the injury or retirement were all barriers to making a successful transition. The researchers recommended developing a preventative program for athletes making career transitions.

Using in-depth interviews, Anderson (1993) studied the 
reaction of students and their families to the student not being promoted to the next grade. The results identified seven coping resources that fell into three categories: the characteristics of the individual, the characteristics around the retention and the individual's environment. Seven coping resources influenced the individual's retention experience. The coping resources included selfdefinition, previous experience with retention, feelings of empowerment connected to the decision, retention philosophy of the individual, feelings of empowerment regarding the retention decision, reasons for the retention, and the support system available to the individual. As pointed out by Goodman, Schlossberg and Anderson (2006), the transition process occurs over time as reactions change, perceptions of the situation change.

Goodman and Pappas (2000) developed a survey instrument using Schlossberg's 45 model to survey fiftyfive retired college professors. The study found that control and timing were important aspects of the perceived satisfaction with retirement (situation). There was also a correlation between life balance and retirement (self). The retirees voiced a lack of university support at the retirement planning stage (support). No major themes were identified that related to coping strategies (strategies). 
Schlossberg (1995) indicated that retirement is a transition that often results in a perceived or actual loss of goals or structure and those retiring must find balance and feel challenged and supported as they move into a new life phase.

Rock (2002) studied how students from an elite private school and a public school in an urban setting approached the college admissions process over a five-month period. Schlossberg's theory on transition provided the theoretical framework for the study. The results suggested that the students from the private school were more confident, used key coping strategies, and were more familiar with the admissions process. The students from the public school lacked self-confidence, had limited support systems, and were not familiar with the strategies needed to gain admission. The findings support the notion that transition theory can be useful in assessing and preparing students to transition from high school to college.

Research related to Higher Education using Schlossberg's Theory

Graham (1994) used in-depth interviews to study the transition process of adult undergraduate students transitioning into a public four-year institution. Graham 
sought to determine the adequacy of Schlossberg's transition framework in explaining student transition. The findings indicate that some components of the framework were more important than other parts. Self (individual) was the most important component of the transition process. Ego development, outlook, coping strategies, the event, and previous experience with a similar transition were also important to the transition process. Rodin (1990) argued that a person's belief that he/she can control the situation affects the outcome of the transition.

Bowie (2001) used Schlossberg's theory to explore the experiences of 8 women as they left graduate school. The women described the experience in various ways, and yet there were commonalities. Some described life after graduation as an up-hill climb, while others saw it as a roller coaster ride or a learning experience. Self served as the primary resource category that directed supports, situation, and strategies. The researcher found Schlossberg's framework useful for understanding the complexities of the transition.

Wiesenberg (2001) used Schlossberg's transition theory and mattering scale to study a group of graduate students taking a long distance online course. The study examined the coping responses of students as they moved through the 
program. The study also examined the student's perception of "adult student friendliness" of the institution offering the course. Participants were surveyed three times over a three-year period using the Mattering Scale for Adult Students in Higher Education and the Transition Coping Questionnaire. The Mattering Scale for Adults in Higher Education is designed to assess the ways in which adult learners feel they matter to the institution. The Transition Coping Questionnaire is a self-help tool that can be used by counselors to guide individuals through exercises designed to help identify coping skills.

The study found that at the beginning of the program, students struggled with the impact of becoming a student and the effect of the transition on their relationships and routines with family and friends. By the end of the study, students were able to manage the additional stress by using support groups to compare their situation with others in similar situations. The students primarily used coping strategies that managed the stress, or that changed the meaning of the stress. The students managed the stress of being graduate students by adapting to situations over which they had control.

Bundy (2002) tested the validity and reliability of The Transition Guide and Questionnaire-Modified (TGQ-M) 
developed by Schlossberg. The study focused on low-income rural women who experienced job loss or enrolled in the community college to obtain new skills prior to returning to work. Findings indicated there was variability in age among the women who sought immediate employment. Findings also indicated that there was a significant relationship between level of education, race/ethnicity, and the women who enrolled at the community college. The researcher also found that there was reliability of the subscales of the TGQ-M across two administrations.

Evans, Forney and Guido-DiBrito (1998) emphasized that Schlossberg's theory places emphasis on the individual's perspective and that individual's situation, making the theory applicable to the integration of cultural and individual differences.

\section{Conclusion}

This chapter began a brief history of welfare in the United States from the late 1800 s to the passage of welfare reform in 1996. The second portion provided an overview of the impact of welfare reform on welfare recipients attending postsecondary institutions. The literature documented the implementation of welfare reform and its impact on welfare recipients attending college. The 
literature also identified the barriers faced by welfare recipients attending college. The barriers included childcare, transportation, financial aid, and work study jobs. The next section provided a brief description of nontraditional college students. The barriers faced by nontraditional students and welfare students were similar. The discussion identified the similarities between the two populations .

The following section described transition theory and the transition process, which lays the groundwork for Schlossberg's transition theory, which is the conceptual framework for this study. Schlossberg's transition theory, the fourth section, describes transition as any event that results in the change in an individual's roles, routines, and assumptions. Schlossberg identified four factors that influence how an individual copes with transition: situation, self, support, and coping strategies. The studies cited in these two sections are helpful in understanding the transition process and how Schlossberg's theory can be applied to welfare recipients.

The next section provided and overview of the studies using Schlossberg's transition theory in an array of situations outside of the educational setting. This 
overview shows the flexibility of Schlossberg's theory and how the theory is applicable to a variety of transitions. The final section discussed the use of Schlossberg's theory in educational settings and provided the support for the use of Schlossberg's theory as the conceptual framework of this study. Because the theory places the emphasis on the individual's perspective, the perception of the change determines what coping strategies the individual uses to alleviate the associated stress. This individual

perspective makes the theory applicable to a variety of situations. 
CHAPTER III

METHODOLOGY

Introduction

Using Nancy Schlossberg's (1995) transition model as the framework, this qualitative study examined the coping strategies used by welfare recipients currently enrolled in postsecondary institutions. This chapter discusses the research design and the rationale for a qualitative design. The chapter then describes the sample size, human subjects, participant recruitment, and informed consent. Next, the data collection process is described followed by field notes, data analysis, document analysis, validity, reliability, and researcher bias. Finally, the chapter provides a brief description of the participants, the context/limitations of the study, and participant demographics presented in tables.

\section{Research Design}

This study was descriptive and exploratory and focused upon the collection of data to examine the use of coping strategies by welfare recipients attending 
postsecondary institutions. This qualitative study utilized a case study design. The case study design is the study of a bounded system or case (multiple cases), over time, through detailed in-depth data collection involving numerous sources and rich in context, in order to present a substantive picture of the case (Creswell, 1994, 2003 ). The case study method is the most appropriate strategy when "how" and "why" questions are the focus, and when the focus is on a contemporary phenomenon, within a real life context (Yin 1994, 2003). Merriam (1998) indicated, "a case study design is employed to gain in-depth understanding of the situation and meaning of those involved" (p. 19). The process may describe the study participants in the context of the study or the process of events. The use of multiple cases to do a comparative analysis enhances the validity of the study. Maxwell (1996) recommended the use of a theoretical framework to help assess the purpose of the study, as well as the development of realistic and appropriate research questions. Maxwell described the use of existing theory as "coat hooks in the closet; they provide places to 'hang' data, showing their relationship to other data" (p. 33). Yin (2003) indicated that the use of theory helps to delimit a case study, and the use of theory is essential for generalizing the results of the 
study. Creswell (2003) stated, "the use of theory provides a lens to guide the researcher as to what issues are important to examine" (p. 131). For the purposes of this study, a multiple case study approach was used to explore and understand the coping strategies of welfare recipients currently enrolled in college using Schlossberg's (1995) transition theory as the framework. The themes that emerged from each case and across each case helped to provide an understanding of their collective realities.

\section{Rationale for a Qualitative Design}

Merriam (1998) described qualitative research as an "umbrella concept covering several forms of inquiry that helps us understand and explain the meaning of social phenomena with as little disruption of natural settings as possible" (p. 5). Similarly, Creswell (1994) defined qualitative design as "an inquiry process of understanding a social or human problem, based on building a complex, holistic picture formed with words, reporting detailed views of informants, and conducted in a natural setting" (p. 1). Maxwell (1996) proposed that the strength of qualitative research is derived from "its inductive approach, its focus on specific situations or people, and its emphasis on words rather than on numbers" (p. 17). 
Maxwell identified five research purposes for which qualitative research are especially suited: (a) understanding the meaning for participants in the study, (b) understanding the context, (c) identifying unanticipated phenomena and influence, (d) understanding the process by which events and actions take place, and (e) developing causal explanations. Padgett (1998) proposed that some topics are better suited for qualitative inquiry: when the researchers explores a topic about which little is known, pursues a sensitive or emotional topic or wants to capture the lived experiences from the perspective of those who live it, and create meaning from it. Qualitative research is evolving and flexible, responding to the changes as the research progresses. The sample is typically "nonrandom, purposeful, and small" (Merriam, 1998, p. 8). Finally, the researcher is the primary instrument and spends a significant amount of time with the research participants in their natural setting .

\section{Sample Size}

For the purposes of this study, the sample size was seven. Patton (1990, 2001) pointed out that the size of the sample depends on what the researcher wants to find out and 
how the findings will be used. Padgett (1998) and Merriam (1998) argued that there is no concrete answer to the question of the number of subjects to include in a case study, but what is needed is an adequate number to answer the research question. Similarly, Seidman (2003) argued that there are two criteria to determine when the researcher has enough participants: (a) when there are sufficient numbers to reflect the range of participants, and (b) when there is a saturation of information and the interviewer is no longer hearing new information. Glasser and Strauss(1967) and Lincoln and Guba (1985) also discussed the point at which the interviewer is no longer hearing new information.

\section{Human Subjects Committee}

The study proposal was submitted to the University of Louisville Institutional Review Board (IRB) in the Human Subject Protection Program Office. Approval was given to proceed with the proposed research (Appendix G).

\section{Participant Recruitment}

Purposeful sampling was used to recruit the study participants. Patton (2001) indicated that the "logic and power of purposeful sampling lies in selecting information- 
rich cases for study in depth. Information-rich cases are those from which one can learn a great deal about the issues of central importance to the purpose of the inquiry" (p. 230). Additionally, Creswell (1994) suggested that "purposefully" selected participants are chosen as those who can best answer the research question. Lecompte and Preissle (1993) described criterion-based sampling as a means to obtain a purposeful sample. In criterion-based sampling, the researcher develops a list of attributes that are essential to the study and recruits participants that meet the criterion. If enough participants are not recruited, current participants will be asked to refer other persons they know to the study. Merriam (1998) described snowball sampling as a form of purposeful sampling, in which other groups/individuals refer the research to other people who would be study participants.

To recruit participants the researcher enlisted the assistance of the director and coordinator of three programs serving welfare participants, and requested assistance in identifying study participants. The researcher provided the directors and program coordinators with a letter of introduction that included a description of the research project (Appendix B). The information was provided in electronic format so that the directors and 
program coordinators could e-mail the program participants. The e-mail asked the participants to contact the researcher if they were interested in participating in the research project. This method generated three participants. The researcher obtained permission to present the research project to a support group meeting for homeless women. The presentation generated two study participants. The final two participants were generated through referrals from the women participating in the research project.

The racial/ethnic make-up of the study participants included six African-Americans and one Iranian/Caucasian. Attempts to recruit a more racially/ethnically diverse group were unsuccessful. During the presentation to the group of homeless women, the researcher stressed the need and importance of having racially diverse participants for the study. At least 25 women expressed interest in participating in the program but only two participants followed up by contacting the researcher. Of those that expressed interest, at least 15 were of Caucasian descent. The interviews took place July 2007-0ctober 2007. The participants of this study included students who were currently enrolled in a postsecondary institution, the parent of at least one child, and currently receiving TANF cash grant, or food stamps and a medical card. 


\section{Informed Consent}

As each participant agreed to be interviewed for the research project, the researcher emphasized that the interviews were confidential and their identity would be protected. The researcher attempted to put each participant at ease by telling them about her experience as a welfare recipient and the purpose of the study.

Each participant was given two copies of the Informed Consent Form (Appendix A). The researcher explained the purpose of the three interviews, and that the first two interviews would be audio-taped, transcribed, and analyzed for themes and categories. Participants were advised that the third interview would not be audio-taped, and the researcher would provide a written transcript and a profile based on the first two interviews. The third interview would give the participant the opportunity to review the transcript and the profile, and to give feedback to the researcher. Each participant would be asked to sign a member check form that confirmed the participants were given the opportunity to review the transcripts and profiles. (Appendix F).

Each participant was paid $\$ 10$ after each interview. All participants were advised that they could stop at any 
time. All seven participants completed all three interviews.

\section{Data Collection}

Schlossberg's (1995) model for counseling adults in transition provided the theoretical framework to guide data collection. The primary research method used to collect data were in-depth, semi-structured interviews (Appendix C). Merriam (1998) pointed out that “interviewing is necessary when we cannot observe behavior, feeling, or how people interpret the world around them," (p 72). The interview questions were semi-structured, allowing the researcher and the participant flexibility in addressing the research topic.

The researcher met with each participant three times from July 2007 to October 2007. Interviews were scheduled at the participant's convenience for approximately 90 minutes each. The interviews occurred in the participant's home or in the researcher's office. The initial interview was designed to collect demographic data about the participant (Appendix D), and a brief overview of the participant's life.

Each interview was audio taped. Each audio tape was transcribed verbatim prior to beginning the follow-up 
interviews. The transcripts were analyzed for understanding, and generated new or follow-up questions for clarification during the next interview. After the second interview, each participant was asked if there was anything she thought the researcher should know about her experience as a welfare recipient.

Prior to the third interview, the researcher developed a profile of the participant based on the transcribed audio tapes. Each participant was given the opportunity to review the transcript as well as the profile. Participants were given the opportunity to add to the profile, delete, or correct any information. The participants made some corrections and additions to the transcripts and profiles, but no deletions were requested. Each participant signed a Member Check Form (Appendix E) and approved the transcript and the profile.

\section{Field Notes}

Field notes were kept during each interview. The notes included the researcher's observation or a reminder to go back and ask for clarification. These notes were made in the presence of the participant and were often shared with the participant as we neared the conclusion of each interview. The notes served as a reflection of the 
researchers' ideas and observations and functioned as an audit trail of the research process.

\section{Data Analysis}

Merriam (1998) suggested that data collection and data analysis is a simultaneous process. Marshall \& Rossman (1998) defined data analysis as "the process of bringing order, structure, and meaning to the mass of collected data, (p. 112). According to Marshall \& Rossman (1999) analytical procedures fall into six categories: (a) organizing the data, (b) creating themes, categories, and patterns, (c) coding the data, (d) testing the emergent understanding, (e) searching for alternative explanation, and ( $f$ ) writing the report, ( p.151).

Data gathered for this case study were analyzed simultaneously with data collection, data interpretation, and the writing of the report. Categories and themes emerged through constant comparative data analysis. The analysis of multiple cases occurred in two stages, within case analysis and cross case analysis. Each case was analyzed individually and then across cases to search for differences, patterns, themes and linkages. The analysis was inductive, moving from the specific to the general in a systematic fashion. "A qualitative, inductive, multiple 
case study seeks to build abstractions across cases" (Merriam, 1998, p. 195). The transcribed tapes were manually coded, and sorted by patterns, themes, and linkages. The researcher began with line-by-line coding of the interview transcript during the data collection. Bracketing was used to identify themes and handwritten notations in the margins. After reviewing the bracketing and notations, the researcher made a list of the codes that could be grouped together. Those that did not fit into one of the identified categories were listed independently or subcategories were created. As the researcher continued, the coding and categorizing, patterns and themes began to emerge. These themes are presented in chapter IV.

\section{Document Analysis}

For the purposes of this study, the researcher analyzed welfare guidelines and income eligibility guidelines for childcare assistance. The documents were from the state TANF office. The documents provided data that the researcher used to compare with the interview data. The data obtained also enhanced the validity of the study . 


\section{Validity}

There is always a question about the validity of qualitative research and if the findings of the research match reality (Merriam, 1998). The researcher used several techniques to enhance the trustworthiness and rigor of qualitative research findings. Strategies identified by Maxwell (1998) and Creswell (2003) were used to enhance internal validity:

1. Triangulation was achieved through multiple sources of data, document mining, and researcher notes.

2. Member checking was achieved through verbatim transcripts of the audio-taped interviews that were shared with each participant during the third interview session.

3. Clarification of the bias of the researcher was accomplished by a discussion on researcher bias.

4. Prolonged time or repeated observation was achieved by multiple interviews. Each interview was 60-90 minutes. 


\section{Reliability}

Reliability in qualitative research is similar in meaning as that of quantitative research, can the study be replicated. However, reproducing social phenomena is almost impossible because it is difficult to replicate the original conditions under which the data was collected, or to control for variables that affect the findings. To increase the reliability or trustworthiness of the data, the researcher provided rich descriptions so that the readers can see how closely the narrative matched the data analysis. Providing an audit trail that described in detail how data were collected, how the interviews were coded and categorized, and how decisions were made increases reliability (Merriam 1998). Similarly, Patton (2001) suggested that the rigor of qualitative research is increased by including the instances and cases that do not fit with the pattern. These cases provide the opportunity to revise and fine-tune the analysis.

\section{Researcher's Bias}

No research is entirely without bias. The researcher brought to the study her own experience as a former welfare recipient. The researcher was careful not to bias the 
study. To limit bias, the researcher recorded her thoughts and perspectives as an observer throughout the study. The researcher also shared the transcript and coding summaries with a colleague familiar with the welfare system and welfare recipients to corroborate the logic of the researchers' interpretation of the data.

\section{Participants in the study}

The following paragraphs provide a quick snapshot of each study participant. Each participant is identified by a pseudonym to protect the identity of the participant.

Ann

Ann is a 37 year-old African American female with one child, age four. Ann has never been married and is currently pregnant with her second child. She was an accounting major at a community college and enrolled in six credit hours. She had earned 66 college credits and plans to transfer to a four-year institution.

\section{Lisa}

Lisa is a twenty-three year old African-American single parent with two children ages one and two, and is currently pregnant with her third child. The fall semester will be 
her second semester in college. Lisa planned to begin her first semester in medical coding which is a certificate program in the fall.

Celeste

Celeste is a 29-year old African American single parent with a six-year old child. Celeste lived in a threebedroom townhouse in a public housing unit. Celeste needed two classes to complete an Associate in Applied Science in medical assisting.

Mary

Mary is 25 years old and is of Iranian/Caucasian descent. She has two daughters ages four and five and has never been married. Mary attended a four-year research institution and planned to graduate at the end of the semester with a bachelor's degree in political science.

Sarah

Sarah is a 41-year-old African American female with one child who is four years-old. Sarah has never been married. Sarah is a full-time student at the local fouryear institution. Sarah was enrolled in 12 credit hours, and hoped to be admitted into the nursing program. Sarah had completed 44 credit hours. 
Trina

Trina is a 32 year old African-American single mother with two sons ages 8 and 12. Trina recently transferred from a community college to a four-year research institution. Trina was working toward a bachelor's degree in criminal justice.

Desiree

Desiree is a forty-two year old African American divorced mother with two sons ages fourteen and three. She was completing her undergraduate degree in social work and planned on entering a master's program in social work the next spring at the time of the study.

The tables that follow present participant data. Table 2 presents the participant demographics. Table 3 presents college enrollment and number of credit hours completed, and Table 4 presents the interview schedule.

\section{The Study in Context/Limitations}

The study is limited to six never married and one divorced welfare recipients residing in an urban area. Because welfare benefits vary state to state, the issues identified by this study may or may not be representative 
of all women that are welfare recipients attending postsecondary institutions.

Table 2

Participant Demographics

\begin{tabular}{llccc}
\hline Age & Race & $\begin{array}{c}\text { Number of } \\
\text { Children* }\end{array}$ & $\begin{array}{c}\text { Age of } \\
\text { Children }\end{array}$ & $\begin{array}{l}\text { Martial } \\
\text { Status }\end{array}$ \\
\hline 23 & $\begin{array}{l}\text { African } \\
\text { American }\end{array}$ & $2^{*}$ & 1,2 & Never Married \\
25 & $\begin{array}{l}\text { Iranian/ } \\
\text { Caucasian }\end{array}$ & 2 & 4,3 & Never Married \\
29 & $\begin{array}{l}\text { African } \\
\text { American }\end{array}$ & 1 & 6 & Never Married \\
32 & $\begin{array}{l}\text { African } \\
\text { American }\end{array}$ & 2 & 8,12 & Never Married \\
& $\begin{array}{l}\text { African } \\
\text { American }\end{array}$ & $1 *$ & 4 & Never Married \\
41 & $\begin{array}{l}\text { African } \\
\text { American }\end{array}$ & 1 & 4 & Never Married \\
& $\begin{array}{l}\text { African } \\
\text { American }\end{array}$ & 2 & 3,14 & Divorced \\
\hline
\end{tabular}

${ }^{*}$ Currently Pregnant 
Table 3

Credit Hours Completed, Institution Type and Major

\begin{tabular}{|c|c|c|c|}
\hline Participant & $\begin{array}{l}\text { Credit Hours } \\
\text { Completed }\end{array}$ & $\begin{array}{c}\text { Institution } \\
\text { Type }\end{array}$ & Major \\
\hline Lisa & 10 & $\begin{array}{l}\text { Community } \\
\text { College }\end{array}$ & $\begin{array}{l}\text { Medical } \\
\text { Coding }\end{array}$ \\
\hline Sarah & 44 & 4-year Public & Nursing \\
\hline Celeste & 63 & $\begin{array}{l}\text { Community } \\
\text { College }\end{array}$ & $\begin{array}{l}\text { Medical } \\
\text { Assisting }\end{array}$ \\
\hline Ann & 66 & $\begin{array}{l}\text { Community } \\
\text { College }\end{array}$ & Accounting \\
\hline Trina & 90 & 4-year Public & $\begin{array}{l}\text { Criminal } \\
\text { Justice }\end{array}$ \\
\hline Mary & 115 & 4-year Public & $\begin{array}{l}\text { Political } \\
\text { Science }\end{array}$ \\
\hline Desiree & 125 & 4-year Private & $\begin{array}{l}\text { Social } \\
\text { Work }\end{array}$ \\
\hline
\end{tabular}


Table 4

Interview Schedule

\begin{tabular}{lccc}
\hline Participants & $\begin{array}{c}\text { Interview } \\
1\end{array}$ & $\begin{array}{c}\text { Interview } \\
2\end{array}$ & $\begin{array}{c}\text { Interview } \\
3\end{array}$ \\
\hline Celeste & $07 / 30 / 07$ & $08 / 06 / 07$ & $08 / 13 / 07$ \\
Mary & $07 / 31 / 07$ & $08 / 07 / 07$ & $08 / 28 / 07$ \\
Lisa & $08 / 04 / 07$ & $08 / 09 / 07$ & $08 / 30 / 07$ \\
Desiree & $08 / 29 / 07$ & $09 / 07 / 07$ & $09 / 11 / 07$ \\
Sarah & $09 / 26 / 07$ & $09 / 27 / 07$ & $10 / 02 / 07$ \\
Trina & $09 / 26 / 07$ & $10 / 03 / 07$ & $10 / 05 / 07$ \\
Ann & $09 / 28 / 07$ & $10 / 05 / 07$ & $10 / 08 / 07$ \\
& & & \\
\hline
\end{tabular}




\section{CHAPTER IV}

\section{RESULTS}

I want to be working so that I can provide for them. I want the house, the little car, the American dream. You know, I just want that. I'm still trying to hang in there. I'm waiting on the lottery or something (laughter)! I don't even play the lottery. ( L: L 514)

This chapter presents the research findings. The first section provides a review of the purpose of the study and a restatement of the research questions. The second section provides and a in-depth description of each study participant. In the final section, the findings are presented based on the research objective and the identified themes and categories.

\section{Purpose}

The purpose of this study was to identify the coping strategies used by welfare recipients attending postsecondary institutions. The objectives of the study were to: (a) to examine the student's view of their current situation, (b) to identify the level of support, and (c) to identify the coping strategies used to alleviate stress. 


\section{Research Questions}

Schlossberg, Waters, and Goodman (1995) presented a model for counseling adults in transition. The model provides a framework for identifying and understanding the perceived demands and coping strategies used by individuals in transition. Using this model, the following research questions guided this study:

1. What are the personal and demographic characteristics of the study participants?

2. How do the participants view their situations?

3. What support systems do the study participants perceive to be available?

4. What strategies do the study participants use to resolve problems?

\section{$\underline{\text { Participants }}$}

Celeste

The interviews took place in Celeste's home. Celeste lived in a three-bedroom townhouse in a public housing unit. The apartment was neatly furnished and Celeste proudly asked the researcher to be seated on the sofa. Celeste is an African American single parent with a daughter that is six years-old.

Celeste described her childhood as relatively normal. 
After graduating from high school celeste continued to live with her mother, worked full-time, and attended classes part-time at a four-year public institution. Celeste attended part-time for approximately two-years until she became pregnant and withdrew from classes due to rapid weight gain and symptoms of asthma. The campus is very hilly, which made walking difficult. Celeste was able to continue working because her job did not require walking or lifting. When her daughter was approximately seven months old, Celeste moved into her own apartment. At age 22, Celeste applied for TANF but was only eligible for food stamps and medical card because of her employment. Her job was intermittent; there were short periods of unemployment. When she was not working, she was eligible for unemployment benefits. The frequent changes in her job status also meant that there were frequent changes in her welfare status. As a result, the TANF caseworker frequently called Celeste at work to verify her work hours. Celeste explains:

I was given the food... that's just food stamps, not the check. The caseworker would call me at my job a lot like they didn't have enough information about my work hours. I was in a program that was for college students. It was a telephone interview position. The work was intermittent but the work was steady, unless we just had a shortage of work. Then you might be off for a week or two. If I would try to get some income for the time I was off a week or two, she gave it was a lot of riff-raff back and forth. 
They were calling the job, always needed more information. Always needing verification, and what you were getting mad at me because I didn't want to just take off for a piece of paper when I could mail it. I took off some time sometimes to go to a meeting for them. But, I always tried to go at 8:30 rather than taking off work. I was generally late for work if I had to go to the TANF office. (C: L 49)

Celeste had attempted to combine work, school, and welfare at various times in the last six years. She had completed 24 credit hours at a four-year institution and had enrolled at least twice since the birth of her daughter. She finally transferred to the community college.

After I had her, I found it a little easier to attend the community college. I like the smaller classroom, the closer student, and professor involvement. At the community college, you get a lot more professors that will stay after class immediately for extra time. I believe the school must pay them to stay, because at the university you had to make an appointment to meet with the professor. At the community college, you don't have to do that, they just stay after class. Tutoring is free. You can go in there, do your homework, and be there all day because the teachers rotate out. After I had my daughter I realized the setting I liked better, but attending the community college is not going to allow me to grow the way I want to grow, so I will eventually have to go back and "bite the big apple'. (C: L 544)

Celeste had completed the Medical Coding Program and was enrolled in the Medical Assisting Program that offered an Associate in Applied Science. She had completed all of her classes with the exception of the two externship 
classes. Celeste had planned to graduate in May 2007, but had two obstacles to overcome. The first obstacle was a tooth extraction that resulted in oral surgery. After the extraction, the pain and swelling increased rather than decreasing. Several trips back to the dentist did not relieve the pain and swelling. Frustrated, Celeste went to an oral surgeon. An x-ray showed a piece of metal from a broken dental instrument was the cause of the problem. As a result of the infection and subsequent oral surgery, Celeste missed a month of classes. Unable to make-up the assignments, she dropped her classes. Celeste stated:

On the day I should have graduated, I was in the bed on pain pills. I should have been walking the aisle. (C: L 442)

The second obstacle was the Externship Coordinator. The Externship Coordinator was responsible for finding placements for all students in the externship class. The Coordinator failed to find a placement for Celeste. In fact, she did not find a placement until several weeks after the end of the semester. Because the coordinator did not find a placement, Celeste had requested that she be allowed to take the class again at no cost. She was able to verify that she had made repeated contacts regarding her placement. She was waiting on a response from the Dean. If the request is not granted, she will have to pay for the 
class again. Celeste needs two classes to finish the program.

I only have my externship to complete. The way the program is setup, they setup the externship. It never got done. No matter how many times I talked with her she never set it up. I only have two classes to finish. I paid for that class and was never given an externship. She waits until I have been out of class for a month to call me to set up at externship. By that time, I was sick and couldn't start. So I should have been finished in the spring semester and now I have to go back this fall to finish the last two classes. (C: L 777)

Unable to balance school and the TANF work requirements of 20 hours per week, Celeste made the decision not to receive TANF cash benefits. She opted to use school loans as income, thus making her ineligible to receive a monthly check. However, she remained eligible for food stamps and Medicaid. In addition, Celeste had been sanctioned for not meeting the work requirement and was no longer eligible to receive the caretaker portion of the TANF check. She received $\$ 139$ a month in TANF assistance for her daughter, \$285 in food stamps, and Medicaid.

I still got food stamps and Medicaid. So, it puts me on the basic food stamp program. What food stamps said if you get the school loan money it is not counted as income. So, I get the maximum allowance of food stamps available, but I had to totally forfeit my TANF check. So, I had to reapply if I wanted cash assistance. It's a mess (C:L 250)! 
Celeste described several problems related to childcare. Celeste arranged for a neighbor to meet her daughter at the bus stop in the afternoon and watch her until Celeste returned from class.

I had one babysitter that I used as a personal babysitter that I used that lived around the corner. She would watch when she got off the bus, and there were a few times that she was not at home when got here. With my mother working next door to the apartments, my daughter would walk over there, that's how I found out that the babysitter wasn't home. And my mother would call my cell phone and that's how I found out. I depend on my cell phone at lot when I am not here. So she actually had to cross the street, she walked about two blocks. She was only five, so that stopped. (C: L 137)

On another occasion, Celeste never received a message at work that the daycare provider had a family emergency and closed the daycare for the day.

I was at work and got a phone call that my boss did not relay to me about my daughter. The day care provider's dad become suddenly ill, she went to the emergency room and she called to let me know that my daughter was going to be at my mother's. However, I didn't know this because I never received the message. I was on the telephone doing an interview. Well, I called to check on her and no one answered. I called for three straight hours and no one answered. Lo and behold, this message was sitting on my boss's desk. I called my mother's house and there was no answer there. So in the middle of my work day I don't know what's going on with my child, I don't know why no one is answering the phone. So they let me off to find out about my daughter. She lived all the way out on the other side of town. I'm panicking, no one is at the house. I'm going Oh my God, Oh my God, something has happened to 
my kid, something has happened to my kid. I go home and they are not there. I had previously called my mother's house and no answer. They had left, no one called me. I finally was able to track down my mother. She didn't call me because the daycare provider told her that she had left me a message. I had to go into work the next day and talk with them not passing the message to me. My boss and me were at odds all the time, we were just not getting along. So I felt she held the message on purpose. So I took it to her boss. So I explained, I know that if I'm on a phone interview you can't interrupt me, but if it is about my daughter you got to give me the message. I don't care if you give me a post-it note and tell me to save the call until after I finish my interview and then go call.(C: L 484)

Celeste also had problems with the childcare assistance program. To receive childcare assistance, the TANF recipient must be working. There were times when there was a conflict between the number of hours of attendance required by the childcare assistance program, and the number of hours of attendance required by the childcare provider.

Now some daycares have a minimum amount of time that the child is required to be there too. Like one daycare might say that they have to be there a minimum of 25 hours. They might say we won't keep them if they are not here a minimum of 25 hours. But the program might say that 25 hours is more than part-time so we are only going to pay this 20 hours. If the program and the daycare don't agree, then I have to pay the overage. So the program may have a minimum allowed time and the daycare has a minimum allowed time so there were times that I actually had to take her when I was in school and I was working when I really didn't need them. When she was at daycare full- 
time, it took away time that we got in the evening to study and everything else. It cut into dinnertime it cut into all that. (C: L 189)

Problems balancing work and times they wanted her to be daycare. I don't deal with them anymore because they cut me off when I went to work. So I don't fool with them anymore. I haven't dealt with the childcare program since my daughter started kindergarten a year ago. Once I figured out how to "cater my schedule I didn't worry with them. I was paying $\$ 80$ a week, $\$ 160$ per pay period. So when she started going to school. I "catered" my classes around the times she was in school. I was paying $\$ 160$ because I was working and was no longer qualified. (C: L 756)

Right now, I will only need after school care and a lot of daycare don't provide transportation. They charge more if they do provide transportation. (C: L 772)

Celeste found parenting, working, and going to school as stressful and had difficulty finding time for herself and for her daughter.

Being a parent is stressful (laughter)! I feel like there is no down time especially if I'm working. I don't have any down time until I pass out and go to sleep (laughter)! If I'm in school and working, which I tried that. It didn't work out to well after I had my daughter. Before I had her it wasn't a problem. I withdrew from classes initially. (C: L 637).

Right now, I only need after school care and that's a problem because I will be in class when she gets out of school and some daycare don't provide transportation. If they do, they charge more. (C: L 772)

If I'm in school and working, which I tried that. It didn't work out until after I had my daughter. 
Before I had her, it wasn't a problem. I found that juggling work, school, and parenthood was just too much. I withdrew from classes initially, but kept working. The idea of taking out the school loan came from my cousin. Prior to that, I had not thought about it. When I took out the student loan, I left work and went to school full-time.

(C: L 644)

Celeste spoke about feeling guilty and the need to

find time for her daughter and time for herself.

We'll do something, we might go to a movie, might have a day at Chuckie Cheese, go out to dinner. we do a date, a dinner and a show. Or we'll take... after a heavy semester we went to the aquarium We'll do things like that together. We don't do the date thing often. When I have school and there is financial aid, I usually have money; we might do it every two-weeks. We'll do things like movie night-popcorn, pizza. We just do little things to spend time together. I own a lot of DVD movies. It might cost money like the aquarium or it might not cost anything. She is happy just spending time together. It's a big thing to her. There have been times that I just been so busy that she will just come and interrupt what I'm doing. I could be doing homework. There were times that I would just ignore that, but I realized that she really needs you'. She might say 'Mommy you haven't talked to me or she'd say 'Mommy you are always doing this, you're always doing homework'. So I stop what I'm doing, it might not last but 30 minutes, we might watch a quick TV show. I feel like at that time she needs her mom and I stop. (C: L 719)

Sometimes I try and find time for myself. I might... I find me time after she is asleep, so I might stay up late, I might watch a movie. I might take a nice quiet bath and paint my toenails. Watch a favorite TV show, but I feel guilty because I'm not studying. I squeeze it in somewhere. (C: L 748) 
I should have dinner done by this time, her in bed by this time.... different things will happen. When we've been busy all day I think I have to stay up later because I haven't seen my child all day. You know, I put her to bed and I should go straight to the books, but I'm so tired, I go to bed. I need to start finding my limits. I keep saying...well we're going to make up this time on the weekend or we'll have movie night Friday night. So, with it being just me and her so long and if I were are really busy for a couple of weeks, I feel really guilty like I'm neglecting her. I miss her on top of that so I'm over compensating by spending time with her when I should be studying for a test. (C: L 395)

Celeste described herself as easily distracted by her relationship with a boyfriend or family members. She believed that she allowed them to have too much control over her time and emotions.

I am always getting distracted and getting sidetracked by arguments with a family member. I can be in a good mood, but certain family members, I love them to death, but we get into arguments way too much. I still allow sometimes others to control me, and my attitude.

(C: L 371)

My number one distraction is dating when I'm in college. Dating, and that's why I always try to stop dating. But dating and...... I start giving up time that I really don't have especially if my daughter is in activities. I usually try and keep her in activities and keep the home life. I need to learn how to balance time better, and that I need to do all around. I think my life distractions... I'm not giving everything time limits. (C: L 385)

Or, he asked for a date and I just need to get out the house-but I should be studying. So I need to be more stringent on those limits. (C: L 405) 
Celeste felt like she is in full control of her life only when she is able to set goals and meet those goals. She described being in control when she is worked fulltime, came home and cooked dinner, spent time with her daughter, and not dating.

Celeste perceived that she had the support of her mother and stepfather and a circle of friends. Typically, her parents provided financial support and childcare, while her friends provided emotional support. She has also used other sources in the community when she needed assistance.

I call my mom and my step-dad if I need something. They provide mostly money, and some childcare. They don't watch her too much anymore. Primarily on an emergency basis, like I went to a job fair today. My stepfather was available to keep her today, he just happened to be home. He actually was supposed to be out of town today. (C: L 523)

I have a couple of friends that I share my personal life with, but I don't ask them for money or nothing. They are there to just listen and provide emotional support. A lot of times, that give me other ideas to solve problems. (C: L 630)

I have been going to the Trustee's office for assistance on my utilities, and I've been to a Food Kitchen before. I could call my daddy, he would probably say no, but I'd call him anyway. If we need it, we need it, so I'll try. (C: L 573 )

In response to the questions regarding coping and 
problem solving, Celeste gave the following responses:

I pray about it and then I deal with it. I do what I feel like I need to do to deal with it. I start searching for solutions. Problem resolution!! (C: L 592)

Even if it looks like I can solve the problem, I still look for other means. If it's money and my mother don't have it, if there is a bill I might see if there is something the Trustee's office will pick up or sometimes they will help with utilities and stuff like that. Most of my problems are financially related. (C: L 596)

If it can't be resolved I wait, pray on it, and see what comes about later. I am aware that it exists and I've beat my head, I set it to the side and say maybe the Lord will send something else, so I start doing other things that might need to be done. I still have a house that needs to be taken care of. I still have a kid that needs my attention and stuff like that. I don't act like it doesn't exist. I might put it off for right now. For example, if I have to pay my rent and my mother and they don't have it, I call and see if there are others ways that I can get it. If I've made phone calls and nothing is available I might leave messages for a trustee worker. I might call my caseworker to see if there are other programs or I might call the office themselves to let them know I am having trouble getting the money and see if there are other options I can take. Once I leave a message, I give them a day or two to get back with me and I am working other things. There may be other things that I might have to need, but I am still...in my conversations with people I might ask, 'Do you know where I can get help with...' They might say no, but I am continuing with other things that might have to deal with. (C: L 612)

Celeste's dream was to return to the university and earn a degree in psychology. 
Lisa

The interviews took place in Lisa's home. Lisa resided in a one-bedroom apartment in public housing. The apartment was sparsely furnished with a television, chair, coffee table, hutch, and full-size bed in the living room. Lisa apologized for the bed being in the living room and appeared to be embarrassed. Lisa described the bedroom as small and hot this time of year. Even though this was a scheduled appointment, Lisa asked if she could feed the children before the interview started. I agreed to wait and played with the children while she warmed their food in the microwave. She fed the children in the living room. She moved a high chair into the living room for her daughter, and her son ate at the coffee table. Lisa sat on the bed to begin the interview. The researcher asked permission to sit next to Lisa on the bed rather than across the room. Lisa smiled often, but frequently would not make direct eye contact with the researcher.

Lisa is a twenty-three year old African-American single mother with two children ages one and two, and is pregnant with her third child. She attended a local community college. Lisa withdrew from summer classes due to problems finding adequate childcare. During the spring semester, Lisa took business classes but decided to change 
her major. Fall semester will be her first semester in the medical coding program. Lisa changed her major to medical coding because the program required only two semesters. Because she believed that the medical coding program was two semesters it would be a quick fix to her financial problems and child care problems. Lisa believed that medical coding would allow her the opportunity to work from home. Lisa did not have a computer at home, but believed that she would have one when the time comes.

There are places where you can buy a computer for $\$ 29$ a month or a free laptop. I've seen the ads on TV and stuff, you know. I'm not worried, I will have it when I need it. I have to take everything as I can get it. ( L: L 290)

Lisa had lived in the same city most of her life. Lisa became ill during her senior year in high school and did not graduate. After leaving high school Lisa obtained a job at a fast food restaurant, became the manager and moved into her own apartment. At age 20, Lisa became pregnant with her first child and decided to obtain her high diploma. Needing only a math credit to graduate, Lisa enrolled in an adult education program.

I had to take algebra that year and I taught myself algebra. That was the hardest thing. ( L: L 25)

Near the end of her pregnancy, Lisa went on maternity leave from her job with no pay. Unable to pay rent, she 
moved back home with her mother. Lisa described her relationship with her mother as volatile and tentative.

Me and my mom we don't have a real good relationship, and she had not been a real good supporter or provider. It wasn't a healthy relationship like it was supposed to be. ( L: L 35)

It was in this environment that Lisa's mother attacked her physically when she was nine months pregnant. Bruised and battered, Lisa was rushed to the hospital by ambulance and had an emergency caesarean section.

With no place to go after the birth of her son, Lisa moved in with her boyfriend's aunt for about a month. Lisa again became the victim of verbal and physical abuse by her boyfriend. During one incident, her boyfriend physically beat Lisa as she held their son. Lisa sustained bruises and a broken thumb and her son was hit in the head during the attack. When she sought medical treatment for herself and the baby, the hospital called Child Protective Services (CPS). The baby was released to her custody with the stipulation that there be no contact with her boyfriend.

Homeless again, Lisa and the baby moved in a homeless shelter for several days. Lisa was not comfortable at the shelter, and when her boyfriend came to pick her up, she went with him even though she had been warned by CPS to stay away from him. Lisa was afraid of what he might do if 
she did not go with him. Lisa left her son with her brother while she and her boyfriend moved into a motel room. Lisa picked up her son and other belongings and went back to the motel. Using the car seat to hold her son, Lisa placed the car seat on a chair in lobby of the motel, but did not fasten him in the car seat. Because he was not fastened in, he slid out of the car seat onto the floor in the motel lobby. Fearing the child had been injured, the motel clerk called for an ambulance. The ambulance arrived at the motel accompanied by the police. Knowing that she was not supposed to be with her boyfriend, Lisa was afraid to hand her baby over the police and paramedics to be checked for injuries.

I know that I am not supposed to be at the hotel with his dad, but we had nowhere else to go. I was really nervous and stuff and I didn't want them to take my baby from me. I asked to ride in the ambulance and they said no. I was fighting and when went around for about an hour and they took my son from me and put me in jail. I was in jail for five days. They told that I had neglected him. I didn't give him medical treatment when he needed it or something. Because I wouldn't hand over my baby. I just wouldn't hand over my son to anyone. So, I went through that and they took him away for maybe 9-10 months and I was only allowed to see him two times a month. I was breast-feeding at the time. (L: L 97)

Lisa's son had no injuries, but he remained in foster care. To regain custody Lisa had to participate in domestic 
violence and parenting classes. She was also required to obtain a job, an apartment and furniture, a car, and arrange for childcare. Lisa returned to her former job at the fast food restaurant and met all the requirements outlined by Child Protective Services (CPS). Just prior to his return home, her son was diagnosed with diabetes. He has been home approximately 18 months.

While her son was in foster care, Lisa became pregnant with her second child. That pregnancy was the result of multiple rapes by an acquaintance. After each rape, the rapist would apologize. Lisa did not report the rapes because of her prior experience with the police and CPS. Lisa feared that any police involvement might prolong her son's stay in foster care.

By the time I built up my courage that I was not going to deal with it anymore I was already pregnant with my daughter. I did a lot of things to myself because I didn't want the baby. There were times that I prayed she would die. ( L: L 450)

Lisa, emotionally devastated, attempted to put the baby up for adoption, and worked with an adoption agency. It was not until she gave birth that the agency told her that she would need the father's signature to terminate parental rights. Lisa believed that the agency deliberately waited until after she gave birth because they feared she 
might have an abortion. Lisa refused to contact him and did not sign the termination papers. Lisa struggled with whether or not to allow her daughter to visit her father if he ever requested visitation. She recognized the importance of a father in a child's life, but she feared for her daughter's safety and she wondered if she can trust him. So, I'm like, I was crazy, it wasn't brutal, it was a date rape, but I got... this child. ( L: L 467)

Lisa continued to struggle with the reality of the rape, but saw her daughter as a blessing.

Lisa applied for welfare benefits after the birth of her daughter. She received $\$ 288$ a month in cash, $\$ 300$ a month in food stamps, and a medical card. Lisa stated,

Food stamps are not enough to feed them. Because my son is diabetic, $\$ 300$ a month often does not cover the entire cost of meals. My son needs to eat six meals a day, three snacks and three meals, to make his blood sugar stays level. He is insulin dependent, and his meals must be balanced and sometimes it requires that I buy some special foods that have higher prices. I fix the same meals for both of them so that he doesn't feel different.

(L: L 175)

The medical card is both a benefit and a medical necessity

The medical card covers the entire cost of the insulin and pays for 150 blood test strips per month. Because my son is insulin dependent I have to test his blood sugar five times a day. The medical card will only cover a 30 day supply. If 
there are more than 30 days in the month, or if he gets sick, I have to purchase the extra stripes. I usually have to pay about $\$ 50$ for the extra test stripes. He is to be sick more often in the winter than the summer. ( $L: L$ 182)

Lisa received a six-month exemption from the TANF work requirement after her son came home from foster care. The exemption gave her time to readjust to her son living in her household, learning to give the insulin shots, and the birth of her daughter. A month ago, Lisa told her welfare caseworker that she had several job interviews scheduled and requested childcare assistance. Lisa had also located a childcare program that would administer her son's insulin shots. The daycare also needed an $\$ 80$ deposit to hold the day care slots. Lisa's request for childcare assistance was denied because she was not working. With no childcare assistance and no one to watch her children, Lisa missed her job interviews.

I have a work history and a decent resume, if I didn't I wouldn't be getting the interviews. Well, how am I supposed to go to a job interview or get a job without child care? I told them I have three job interviews. I also told them I was going to school, but they don't honor school and they won't give me childcare. (L: L 206)

Frustrated, Lisa took her children with her to a meeting at the welfare office. After a month of multiple requests, the caseworker approved Lisa for childcare, but 
gave her a week to find childcare. The welfare office had contracted with an agency to administer childcare payments. Lisa had difficulty making telephone contact with the agency and had already become frustrated by the difficulty in making contact with the provider.

Lisa worried about the short time frame to find a child care provider because she wanted to take her time to find the appropriate provider. She had a scary experience during the spring semester with someone who provided childcare for her children. Lisa worked full-time at hotel as a banquet server and also took classes. The job paid well, but required long, irregular hours. Lisa hired a nanny to stay with the children. The nanny was also diabetic, so Lisa felt comfortable knowing that the nanny could give the insulin injections and recognized the importance of giving her son his insulin shot. She was wrong; the nanny forgot to give an insulin shot, and her son was hospitalized for several days.

I know I was gone a lot, but I was trying to take care of my family. If it was too much for her she should have told me. ( $L$ : L 161)

Lisa quit her job to take care of her children. This was the second time a caregiver had forgotten to give the insulin shot. Lisa's sister also failed to give her nephew 
his insulin. Luckily, Lisa was not gone for very long, and he did not need hospitalization.

Lisa was concerned about finding a childcare provider that knew how to give insulin shots and check her son's blood sugar. Lisa also recognized that finding a provider that could meet her son's medical needs would be difficult.

My challenge is everybody won't take him or they have no experience giving insulin shot or don't want to deal with it. (L: L 239)

Lisa located a childcare provider that agreed to check her son's blood sugar levels before each meal, but would not administer the insulin shots.

I am hoping that my class and work schedule will allow me to give the insulin shot the 7:15 am and the 5:30 pm shot. If my schedule is 8:00-4:00, my plan will work. My class schedule will work, but I don't know my work schedule and don't I know what hours I will be working. If I can't get the schedule I need from my job on campus I will to go back to a working fast food job that has flexible scheduling. ( $L$ : L 309)

Lisa was pregnant, and scheduled to have a caesarean section in late December, but had no childcare plan in place. Lisa planned to be back on her feet and attend classes during the upcoming semester.

I have to; I have to make it work. I don't have a "go to" person. I don't speak to my mother or my sister. I don't have a person, and that makes it difficult. I don't have someone that I can say 'hey I need some help can you help me out.' (L: L 314) 
Lisa described herself as her own support system. She sought out information from others, but had no close friends. Lisa believed that her current pregnancy was the result on having no one.

Not having someone to talk to gets me into to trouble (pointing to her stomach). ( $L$ : L 316)

Lisa was aware of and used community supports. She was given a list of community resources when her son was placed in foster care and she used that list as a reference when she had a need. She used a community agency for diapers when she ran short, and churches or the food pantry when she ran low on food.

Lisa wanted to move out of public housing and was on the waiting list for the Section 8 rent subsidy program. She will also be attending classes on budgeting in preparation for the homeownership program. In the past, Lisa attended several churches in the neighborhood but found them cold and unfriendly.

I pray, I just don't go to church. They looked at me like I wanted something or didn't belong, so I don't go anymore. I think about going back some time ( $L: L$ 340)

Lisa viewed the welfare system as unfair and controlling.

They are controlling my life because I'm on assistance. If I move the wrong way or don't go by the guidelines... it's totally unfair. If I don't find childcare in a week it probably means that I have to start all over again. If I don't 
do the work requirement they will take my benefits. I don't see how I am supposed to be negligent for what she's asked me to do when I've been asking for a month. ( $L$ : L 331)

The welfare office doesn't give you any information to help you. You find out from somewhere else and they say, you should have asked about that long time ago. They don't try to help you. It's like they want to see you fall. I know they have been working there a long time and they see a lot of people that don't want anything. ( $L$ : L 521)

Lisa had great difficulty expressing how she coped with problems. She stated, "I ask a lot of questions."

Mary

The interviews with Mary took place in the researcher's office because it was the most convenient for Mary. Mary is twenty-five years old and is of Iranian/Caucasian descent. She has two daughters ages four and five, and had never been married. Mary described her early life as a series of unfortunate events. Her parents divorced when she was about four. The divorce resulted in a nasty custody fight. Mary's mother feared that her exhusband would kidnap Mary and take her back to Iran. Mary and her mother went into hiding for two years. They left the state and to conceal Mary's identity, her name was changed. After several years, they moved back to their home state. 
Mary's mother became involved with a man whom she eventually married. During this relationship, Mary was physically and sexually abused for six years by her mother's significant other. Mary's mother was aware of the abuse but did nothing to protect her daughter. When Mary was approximately 12, her mother ended the relationship with the abuser.

Her boyfriend at that time sexually and physically abused me. They were together for nine years and that happened for the duration while they were together. They got divorced when I was 12. I was really angry as you could imagine, because my mom knew too. So it kind of pissed me off a little bit. (L: L 17)

Mary's mother became involved with an apostolic church and was ordained as a minister when Mary was about 14 years old. Mary's mother became involved in a relationship with Mary's Sunday school teacher and became pregnant. The Sunday school teacher was married and the pastor's nephew. Once the pregnancy became public knowledge, Mary and her mother were 'thrown' out of the church. Mary responded by rebelling, shoplifting, and dropping out of high school.

I am sorry, I know it is kind of crazy. Yeah, we got kicked out the church and I just started rebelling by shoplifting, running away from home, breaking into people's houses, and smoking. I was just really kind of crazy for a little while. That lasted about 6 years until I was about 20 . Shoplifting was my thing, that's what I did and I just kind of professionally started boosting and 
selling things. Especially when I went away. I went away to school when I was 17. I actually dropped out of high school at 15 to take care of my mom's baby that she had. I took care of her for a year, I went back, I went an alternative program, and I finished in a year. I graduated a year earlier than I should have. I graduated in 1999 and I was supposed to graduate in 2000. I thank God for that. (M: L 27)

Encouraged by a family friend, Mary applied to a fouryear institution located approximately two hours away. Mary was accepted and moved on campus.

I wanted to get away from my mom. My best friend's mom filled out my FAFSA for me. So it was a combination of being bullied into going and wanting to get away. I just, I never really like school, so it was never for me. I liked to learn, but school, I didn't think it was for me so I just used it in the beginning just to get away. (M: L 276)

Mary left for college but continued shoplifting.

Because of her relationship with her boyfriend and his family, Mary became involved in selling drugs. While Mary was in college she was arrested several times. The last time she was arrested she was seven months pregnant with her first child. When she appeared before the judge for sentencing, the judge was sympathetic, and sentenced her to two years probation rather than a year in jail. The judge warned Mary that if she came back to court she would serve a year in jail, and she would not see her child. She 
described the judge's threat as a turning point in her life.

That was all I needed, something finally clicked. I just stopped, nothing is worse than me missing out on my kid, you know a day in her life. I just changed my life around, not immediately, but I stopped doing all illegal things. (M: L 54)

Now I'm here, almost done. I turned my life around, all the way to God. I am really involved in my church and $I^{\prime} m$ going to seminary when $I^{\prime} m$ done. (M: L 126)

Mary moved back home and planned to go back to school

after the birth of her child.

I stayed with my mom for a little bit, and then I went to a shelter. I went to a homeless shelter. I was there only 1-2 nights. Because it the dead of winter and it was so cold. I asked them what I could do with my babies' bottle-could I put them in the refrigerator. They said everybody just keeps them in the windowsills. It was that cold in the room; the milk was still cold as if it had been in the refrigerator. I couldn't do it. I slept in my car for a little while. I was homeless for...I wasn't homeless I had my car and I had places I could go to, but I just didn't want to go because I had a lot of pride. I got an apartment when my daughter was 7 months. (M: L 79)

A couple of months after giving birth to her first child Mary realized that she was pregnant again. Her children are eleven months apart. Instead of returning to college, Mary went to work as a temporary employee. Afraid that she might lose her job because of her pregnancy, she attempted to hide the pregnancy. She later found out that 
everyone knew she was pregnant. Mary continued to work for a year and decided that she wanted to return to college. Just before her youngest daughter's first birthday Mary returned to school.

In 2004, I quit my job because I had tried to work part-time. I tried to consolidate them. It was a full-time accounting job and I tried to work 25 hours a week and go to school full-time in the summer. I started the summer 2004 and I just realized that I really couldn't do it. No way, I was getting overloaded at work, stressed with school work and the kids. I realized that it would be easier, I would get more benefits if I went on welfare. I wouldn't have co-pay anymore for my daycare because I would be eligible for 4Cs. They would pay for my daycare and I also heard about the benefits you could get while being on welfare and in college. Even though those benefits are gone now thanks to DRA (Deficit Reduction Act), but.... (M: L 133)

Mary applied for TANF and received \$262 in cash, food stamps, medical, and $\$ 60$ a month in transportation assistance. The transportation assistance has increased to $\$ 100$ per month. TANF also provided $\$ 400$ per year for textbooks. If you did not have scholarships or grant money for the summer, there was also the possibility of receiving $\$ 1800$ tuition assistance. The summer tuition assistance was limited.

Initially, my work requirements were 20 hours a week, but you could use 10 credit hours to meet 10 hours of the work requirement. So you only had to work 10 hours a week. Your first year, you didn't have to work at all. There was no work 
requirement for the first year. Now for people with children ages 5 and under your work requirement is 20 hours a week you cannot apply your course credit hours. That's in addition to going to school full-time as well because that's what I do. For those mother's whose children are 6 and over, their work requirement is 30 hours per week in addition to going to school fulltime. If you don't make your work requirement, which is almost impossible. I don't know how anyone can work $30 \mathrm{hr}$ a week, go to school fulltime, and have children that you have to take care of as well. But, if you don't make your work requirement you will lose your medical for your children and you, and, you will get a reduction in food stamps and you will totally lose out on your TANF check. (M: L 166)

Mary spoke about the difference in the requirements

for recipients attending two-year and four-year institutions.

Well not having the book vouchers has impacted me a bit. Well, for me and for everybody, tuition is going up and my loan money is going down. I'm almost maxed out on loans. Thank God, I'm getting out. That's the way that I pay my bills, I'm not in subsidized housing. I pay my bills. I pay my gas, which is crazy, it's so high now. Everything is through my loan money. I live off my loan money, that's how I pay my bills. Then I can focus on going to school, working my work-study job. Otherwise, it would not be possible. I also have the book vouchers and the summer tuition money as well. I've been fortunate enough to have just enough loan money to get by, but that summer tuition. Like I've said the work requirements really have not affected me, but I have seen other people affected tremendously. I have seen people who have had to quit school because of it. (M: L 242)

If you are in a two-year college, or vocational training school you still get all those benefits. You still get your book vouchers; you can still 
use your course credit hours for your work requirements. You can even use a study group as part of meeting your work requirements. But can't if you are in a four-year college. You have to fulfill your work requirement and not be able to count study time. (M: L 191)

My current work requirement is 20-hours a week, my youngest child is four. Thank God, I'm getting out of here before she turns six If she was six, I would have to work 30 hours a week. You would also have to provide verification, like check stubs. It's impossible to work 30 hours a week and go to school. I don't know how people do it. I know one lady that sanctioned herself off of the cash check, but kept her medical, so she would not have to meet the work requirements. She ended up leaving here, going to the community college, and eventually dropped out because she just couldn't do it. (M: L 262)

Mary's only problems with childcare related to the amount of time it took for recertification of eligibility for child care assistance. Recertification at times, caused her to miss classes or have to leave class early.

I have to go tomorrow and I will have to leave class early. Because if you are on TANF it's a walk-in on Monday's and Wednesday's and that's just not convenient for me. Because I have class 9-11 Monday to Thursday and I'm going to have to leave early to get signed in and you have you have a long wait. Or you can do a phone interview, but you have to be available for call backs. Or you can set up an appointment. It's just hard to get in touch with your 4 'cs worker, it's almost impossible. So I just go up there and walk in and you are there for a few hours. It's time consuming because it is not easy to get in touch with your worker. It's easy once you get there, get back there to meet with your worker, it's nothing, just signing a few papers, that's it and telling where your kids are in daycare. It's very easy for me because I'm on TANF. But 
once I get off TANF in December it's going to be harder. I'll show to show all these materials, proof that you are working this much and how much you are making and they have to figure it all in, it's just ridiculous. (M: L 726)

Mary found support both on and off campus. Mary sought counseling assistance on campus and currently was involved in a support group for adult survivors of childhood sexual abuse. Mary's best friend and her mother provide financial and emotional support. When Mary's car stopped running, her best friend transported Mary's children to day care until Mary could replace her car.

Thank God for my friend, because if she didn't pick up my kids and take them to school I would have been taking 4-5 buses a day just trying to get them to their daycare and myself to school. (M: L 514)

I don't ask for money often, but if $I$ need it, they can help me. (M: L 531)

I'm still in therapy... I just started back up, you know I'm saying---I don't need it, need it. I don't know I just go and talk. I do that here. I've been doing that for a year and a half now with the support group that they had last year for the fall and spring. That was really good, I really grew a lot from that. Originally, the group was for victims of childhood sexual abuse and then it turned into any kind of trauma you may have had, but most of the participants are victims of childhood sexual abuse. The group leader has been wonderful, it was really good. (M: L 637)

Balancing the children, work, school, and church activities kept Mary busy. 
I get up in the morning, get the kid up, get their clothes on, breakfast, take them to school. We get up about 7:00. It only takes an hour. We have bath and showers the night before so I fix them breakfast, get their clothes on, do their hair and drop them off. I try to get out of the house by $8: 15$, usually $8: 25$. Daycare is about 10 minutes away. I have class from 9-11, then I go to work from 11:30 to 4:45, but it been a little more flexible because I am working in my church on the leadership team for a college age ministry that we are starting up. So I've been going there a couple of days a week. Then I go pick my kids up. I have to get there by 5:30. Then on Monday and Wednesday I come back to church. Mondays I have rehearsal and they have rehearsal, the kids do at 6 , so I try and get them something to eat from somewhere. If I know that I don't have any money, I try to get them early enough to go home and fix something to eat. Then we go back out, we go to church. We usually get out of church by 9:00, go home, bathe and go to bed. Then I study after they go to sleep, usually. I have homework that I have to do online, I don't have internet at home so I have to do homework here on campus, at work, or at church. (M: L 285)

Another source of stress for Mary was her current

financial situation. Mary did not budget her loan money appropriately this semester, and her work-study assignment was 12 hours a week instead of 20 . All of Mary's bills are overdue.

Right now I have financial stress-but I'm not really worried about it so-Well, I haven't paid my car note. I got a new car in January. It's the first time I've ever had a car payment in my life, because my car finally conked out on me.... I didn't pay my LG\&E for two months, my phone is cut right off, I didn't make my car payment for July. I told them I would pay July in August. I'm waiting on my school check really to get my bills paid. I can't pay my rent for August until I get 
my school money... I don't have any money, I've got about 20 bucks in the bank, so that's not going to pay my bills and I'm not getting any money to pay my bills. I'm only working, and I've only be allotted $12 \mathrm{hr}$ a week work-study, I can't meet my work requirement. My worker does not know that and I will not tell her that. She thinks I'm working 20 hours a week, there's no way I can work 20 hours a week because the work study money is not there. So, I am working 12 hours a week at $\$ 7$ an hour and that's nothing, that's gas money. (M: L 311)

Well, my landlord don't know that I can't pay my rent for August. It's not in my name. It's in my best friend's mom's name and she knows that I can't pay my rent. So, she's trying to help me, like pay it, and I'm going to give her the money back. (M: L 344)

Mary's coping response to her finances and her problems reflected her religious faith, and her belief that all problems were temporary.

I just try to give everything to God and I don't worry about it cause I don't have the money to pay for it. There's nothing I can do about it. (M: L 318)

I'm just thankful that we have food stamps so we always have food. If my kids can eat fine! They have a roof over their heads, that's not going away where, clothes that they can fit, shoes that they can fit. (M: L 338)

I'm not going to let it get that bad. Through some kind of way I'm going to get the money and I'll have to pay it back when I get my school money in a couple of weeks, so. Money will be disbursed on the $13^{\text {th }}$ and $I^{\prime} m$ hoping by the $17^{\text {th }}$ I'll have my money. (M: L 357) 
Like with school, I have very big dreams, I always have, even as a kid, that was the only thing that kept me going and I just know that even when I hit a rough patch or I'm having a bad day, a bad, week, or even a bad month, I know that it is temporary. I always know that my situations are temporary, it's not going to be forever. That's just what keeps me going. That's the only reason why I am where I am now, I mean physically here on earth. Why I haven't tried to commit suicide or anything, I mean I have, but I here and I know that. As a kid I always lived in my head. I dreamed of a better life, of one day being happy and having money and you know. I don't know how I got there. I have no idea of where I got these dreams from. The only thing that I can say that God kept me and gave that to me. I can't really explain it. (M: L 382)

Mary's response to the question regarding control also echoed her religious faith.

I don't feel like the world is in control of my life. See I don't, see, my responses may be a little different because I feel like God has control over my life. I've allowed him to have control over my life finally. I don't appreciate some of the things he wants me to do or some of the things he leads me to do, but I do them out of obedience. So, do I have control over my life, official yes, I can choose to do whatever I want to do. But I just believe that God is always in control and I'm allowing him to lead me right now, choosing consciously to do that so...... I don't know. (M: L 425)

Desiree

Desiree is a forty-two year old African American

female with two sons ages fourteen and three. Desiree lived 
in an urban area in a three-bedroom house. Desiree described herself as:

A recovering addict, a felony offender, a victim of domestic violence, and a welfare recipient. (D:L 205)

Her spiral into the world of drugs and addiction began when she left for college in 1985. Desiree's introduction to drugs came from first husband. She was in active addiction from 1985 to 2000. According to Desiree, when she left for college in 1985 she knew very little about drugs and their addictive qualities. What started out as an innocent birthday celebration resulted in 15 years of addiction and felony offenses.

I had my birthday down there. Drink a little Maddog 2020, smoke a little reefer. How about these pills? Have you heard about this thing called cocaine? How about a little crack? That's all she wrote. I didn't know that Holly Springs, Mississippi was so fast. (D: L 22)

We ended up enrolling in another college in Illinois. I've always been in school, if it wasn't for nothing but the loans. We used the loans to buy drugs, sell drugs, and survive. Do drugs, sell drugs, and have a place to stay. (D:L 39)

Desiree and her husband divorced in 1996. She remarried and continued her drug use during her second marriage.

I was in active addiction from 1985 to 2000. I was an avid crack smoker. I smoked crack every 
day. I was into real estate, and people lost houses and were set out on the street because I didn't make the mortgage payments, they were renting from me. (D: L 8)

I always had money that I can't tell you what I did with it, but smoke it up (D: L 86)

I stole cars because I did not believe in prostitution, I couldn't see it. A friend said let's go out a turn a trick and get $\$ 20$, I said let's go steal a car and take it to the chop shop. I really wanted to get high. I thought that was really important. That's what I did. That was my racket, stealing cars and selling them to the chop shop. The chop shop told us or you could look at the rims. Now it would be a little bit harder to do it because of all the alarms on the cars. Ironically, I got into trouble for the complicity to theft and only did a year in jail. Out of all the things that I did I only did a year. I had a variety of warrants on auto theft, drug paraphernalia, drug trafficking, and traffic violations. I did 6 months here, 6 months there. out of all the felonies that I acquired, earned honestly, I've only done one full year. I've been in and out of jail and if I added it up I honestly do not know, 3 months here, 4 months here, 2 more here. However, I have only done one consecutive year. By the time I got the complicity to theft I was considered a persistent felon, 3 time felon. I don't know how it worked, but it was the grace of God. (D: L 211)

Desiree had been married twice and indicated that both spouses were physically abusive. She also indicated that all of her relationships with men have been abusive. She was not involved in a relationship with anyone at the time of the study.

My first and second marriage and any relation in which I was involved there was physical abuse. As 
a result I suffer from a herniated disk( L5) which sometimes does impair me and is hard to deal with because I am a recovering addict...I can't take pain medications. I use a tens unit (electrotherapy) to alleviate my pain or I get a cortisone shot. But I don't do that often because it messes with your bones. I'll also do meditation and water therapy and just kind of rotate stuff. Then I pray and sometimes look crazy and holler at everybody and my mom will say hey there's "Zena" again. (D: L 8)

Desiree did not receive a cash grant from TANF, but received \$284 per month in food stamps and a medical card. To complete the practicum hours for her degree Desiree worked for Americorps, which provided a living allowance. The living allowance provided by Americorps was counted as income, making Desiree ineligible for the \$285 monthly TANF check. The practicum with Americorps also affected daycare assistance. TANF did not count Desiree's hours at Americorps as meeting the work requirement that made her ineligible for daycare assistance.

I had a big problem when I went to Americorps TANF did not classify Americorps as a work activity so I ended up going to Americorps Daycare. Now that Americorps is over, I don't have day care now. The lady (TANF caseworker) suggested that to keep childcare assistance that I do my Americorps hours, and work at McDonald's for 20 hours a week. I asked her if she was crazy and was there a 24 hours a day daycare provider. (D: L 486)

When they canceled my daycare payment, they did not notify me, the daycare provider told me. Yes, she was real upset about it and said TANF sent 
her a letter canceling daycare payment. I didn't know anything about it and I never got a letter. (D: L 511)

Desiree described her problems with the TANF caseworker as a nightmare.

TANF has been a nightmare because of all the appointments I have had to make, waiting for absolutely, like I don't have to go to school. Then I'm supposed to have 20 hours of volunteer work and I'm sitting in this office waiting for the TANF worker to see me and that's not counting toward the 20 hours. Then the frustration of having the paperwork, the caseworker has lost the paperwork or forgotten to tell me things I might need. Like, I went in to apply for food stamps and she didn't tell me to bring in the electric bill because food stamps count electric bill and rent. So, for a whole 3-4 months, they did not have my electric bill because I didn't know. So I happen to go in for a recertification and she mentioned that she did not have my electric bill. You can get more food stamps because they count that. You could have told me that before. (D: L 527)

My worker was not familiar with Americorps and she goofed all that up as far the daycare situation goes. That was the direct result of not knowing what Americorps was and not taking the time to find out. Even after she found out she goofed, it was water under the bridge, and nothing changed. Americorps paid for daycare for me. Let me tell you what happen to me after I was in Americorps. She knew I was in Americorps and didn't put me on the work experience program so I lost book vouchers, car vouchers, all that stuff for me because I was supposed to have a transitional period and it wasn't turned in. (D:L 554 )

I have an interview with her supervisor, and I explained that I understand that everybody is overloaded I'm not familiar with the programs that the agency is supposed to offer. If the 
caseworker doesn't know, she doesn't ask, but when we find about them there should be some kind of back-up plan where things can be rectified. Just don't take my stuff away from me and that's what they did and the worker got very frustrated and angry with me. I had to explain to her that I'm not here to take your job or get you fired, but I'm not here to suffer the consequences because you don't know information. It is a lot of information for them to know. It was kind of left up in the air. I got frustrated and finally said I have to go another route because if I can't stay up here and be in this office fussing and acting crazy. I can find another way to be motivated and just solve the problem.

(D: L 573)

Desiree described a circle of support with family and

friends and in the community. Her mother, father, step-

father, and brother assist her whenever there is a problem.

I have the kind of support system that everyone will pitch in to make sure everything is covered. (D: L 357)

I have the same friend that I have had since seventh grade. I have one, she's my best friend. When I was in active addiction, I didn't hang around her. I could call her and say I need this and she would wire me money, we never lived in the same state. I counted up over the years how much money she sent me and said I was going to pay her back and she didn't want the money and she said, 'just seeing you clean is enough, I don't need the money'. She's the type of friend that I don't talk to everyday, but she'll say I know you are a single parent. She is also a single parent but she is a schoolteacher and she owns her own condominium and her own home. She will call me around November, and ask if I have everything I need to get the kids for Christmas. If you don't I have an extra $\$ 400$ that you don't have to pay me back. One Christmas I took her up 
on it, Christmas two years ago. Other times I've told that I didn't need it. (D: L 323)

My brother and I have a wonderful relationship.

He is a great source of support even though he is younger than me. If I run into a financial situation I can ask him. (D: L 295)

When I'm having problems with my back and I have to lie down I can call my mother and ask her to watch my son. ( $D$; L 359)

During Desiree's years of active addiction, her oldest son lived with her parents. At the time of the study her son continued to live with her parents and visited Desiree daily. Desiree lived one block from her parents. When she decided to attend the local community college, her parents agreed to pay the tuition for one year to show their support. Desiree did well and transferred to a private 4-year institution. The staff and faculty were so impressed with Desiree that, when her application for financial aid was denied because of unpaid school loans, Desiree was allowed to attend for a year without paying tuition. The staff began a letter writing campaign to the Department of Education requesting that she be eligible for the Pell grant. The request was successful and Desiree received financial aid.

I found university staff to be very helpful. Professors provided emotional support and creative support on how to manage my practicum last year. I was also the President of the Student Social Work Association and as President; 
students came to me with problems. I used the faculty as a resource, but I also became a resource for the students. I would sometimes relay the problems to the faculty and make suggestions. All of my professors know that I am a recovering addict and felony offender and sometimes they would ask me if a chapter was accurate or if my experience had been the same. I would respond, no...that's textbook stuff.

(D: L 385)

Desiree had a very strong opinion regarding welfare reform, and the impact of welfare recipients.

I've had to take a lot of twists and turns to meet the long range goals. What makes me angry is they talk about self-sufficiency, but they don't allow you enough room to become self-sufficient. You have to choose between low pay all these hours or stay on the system and be termed as lazy. There's no middle where we can work together. You make $\$ 23,000$ that is not a lot of money. Day care can potentially be 50 percent of your monthly income. They are creating a subsistence level, a permanent class of people in poverty. Numerous challenges and you have children. You might make to McDonalds in 5 years. You really need more time. They need to provide some secondary support (D: L 639)

Desiree became ill the previous semester because of her many responsibilities and poor time management. She was working part-time, had a practicum, classes, and took care of her children. Realizing that she was doing too much, she asked for assistance from her parents with transporting her son to daycare. Getting sick also forced her to learn more about taking care of herself.

My time overlapped tremendously. What I did, I learned not to do that now. What I did was get 
sick. But my mother was very instrumental, wherever I had to be, either my stepfather or my mom picked up the kids. My mom had to really go back and teach me how to eat and impressed upon me the need for vitamins, you're older. I didn't know how to do that. I thought damn I quit doing drugs, so everything is going to be cool now. But I found out that it wasn't. I found out that I still need to take care of myself like the other women who have never used drugs. Things you don't know when you live a different lifestyle. (D: L 14)

Desiree enjoyed the slower pace this summer and tried to spend more time with her sons. She learned to cook and tried out new recipes to surprise her sons. Cooking was a new adventure for Desiree and she viewed it as something she was doing for herself as well as her children. She and the boys also spent time together going to the park or the zoo. She tried to spend as much time as possible because she knew that once she started graduate classes she would not be able to spend as much time with them.

Desiree's primary coping strategy was writing down her problems so that she was not overwhelmed. She also sought advice from her parents or a close friend.

My major coping strategy for so many years has been for me to use drugs. So a lot of times when it comes to resolving things my coping skills are inadequate to some degree so I write it down. I'm a big writer, I write it down and $I$ to do that to make sure that it is just one problem. A lot of times, it might be two or three problems, and I might look at it as one which would overwhelm me. Then I talk to my mother and ask if my perception of the problem is correct and how she 
would solve the problem. I also might call my friend from the $7^{\text {th }}$ grade or my biological father. It's good to have him and mother because they are so different. $\mathrm{He}$ is streetwise and my mother is the nurturing homebody. It's good to have them to bounce off of. (D: L 400)

I know that there will be a problem that I can't resolve. I found that it's not that I can't resolve the problem, it's that I don't want that answer. When that happens I backup and look at the pros and cons. I understand that I do have a perception problem because of all the years of drug use. So I'll look at the pros and cons and I just accept that I can't do it this way now, and I say NOW! (D: L 425)

Sarah

Sarah is a 41-year-old single African American female with one child that is four years-old. Sarah has never been married. Sarah described her biological family as dysfunctional with "lots of divisions and separation." Sarah has seven siblings, and she is the youngest female. She described her mother and youngest brother as "chronically depressed". Sarah believed that she and all of her siblings experience periodic bouts of depression.

Sarah's mother worked second shift (3:00pm-11:00pm), she rarely saw her mother. Her mother was asleep when she left for school and was leaving for work when she returned home from school. The primary caregiver for Sarah and her seven siblings was her mother's alcoholic and abusive boyfriend. He was physically abusive and beat Sarah and her 
siblings often. Her mother's live-in boyfriend also sexually molested Sarah from age seven to age nine. Because she felt no real connection to her mother or her siblings, she initially saw the molestation as affection and acceptance .

My mother was never home or she was sleep, my older siblings stayed out in the streets as long and as often as possible. There was no one to tell so I got to the point that I didn't have anyone that I felt comfortable telling what was going on so I dealt with it. The one thing I remember thinking is maybe he likes me, maybe he will stop hitting me. (S: L 294)

"Now when I look back at it, I allowed it to happen because it was a sensation for me that I didn't understand, it was pleasurable. I was in a situation where everything seemed to be wrong. I don't know, as bad as it was it was still pleasurable. I allowed it to happen, I was 7 years old, but I didn't know it was wrong for him, I knew it was wrong for me." (S: L 279)

As she grew older, Sarah recognized that what was happening to her was wrong, yet she felt like she had no one to tell. Sarah believed that her mother was aware of the molestation or at least the frequent beatings, because as soon as her mother received a financial settlement from a lawsuit, she moved out of state with the five youngest children. The two older siblings were no longer living at home. Sarah did not tell her mother or siblings about the sexual molestation until she was in high school. While Sarah received some support from her sisters, she described 
her mother's response as "mild". The relationship with her mother continues to be a very strained relationship.

Sarah participated in a school to work program during her senior year in high school. She remained employed at various jobs after high school for approximately ten years. She remained at one organization for seven years.

I used to pray a lot, 'Lord you know I am unhappy', I'm getting my work done, but I'm not feeling any kind of...I put everything into what I do. I prayed about it...I prayed on it and I got a 'you can leave', so I left. (S: L 55)

Feeling unappreciated, Sarah left and worked as a temporary worker for approximately two years before taking a permanent job. Sarah again became dissatisfied with her job.

I became disgruntled, but not unhappy. I guess my identity has always been what $I$ do and now I'm in another position where I'm doing something, I'm getting paid but, I'm not being fulfilled by it and that wasn't going to change. I recognized that that was where my head was. I was in a relationship with an individual who, by the time I got pregnant I realized that I did not know this individual and I cut my losses. I was 37 and I like deciding, I do have a job, I can support myself, I guess I can support a child by myself, so I will have this child and we will be a family. You know it was "What have I done, I'm an adult, I've done stuff that teenagers do." I kept thinking, what have I done? It took me some time to sit back and say, ok. It's going to be ok, I'll make it work. But the more I went on through my pregnancy and the more I thought the things that I wanted for this child, that job I was working, was not going to cut it for me. I wanted 
her to experience things that I didn't experience. (S: L 100)

Shortly after giving birth to her daughter at age 37

Sarah decided to quit her job and enrolled in college.

Sarah developed a financial plan prior to quitting.

What I did when I left my job.... I have a really good retirement plan which made it very hard to leave my job. The $401 \mathrm{k}$ plan that they set up we put in a certain amount and they put in a certain amount, they matched it. I think they doubled what we put in. So, it was hard to leave that because I had $\$ 16,000$ in there fairly quickly. I worked for them for 6 years and I think they started that they started that in maybe 3 year, I had $\$ 15,000$. I pulled that out; I of course lost some of that because I pulled it out early. But it was enough for me to pay off my car, move into cheaper housing. It was enough to get me established because my financial aid wasn't approved yet. I bought my own books first. It took care of all the preliminary things that needed to be taken care of. It gave me enough to do that plus put some aside. I also filed bankruptcy prior to leaving work because I had a lot of credit card debt. I kept my car for transportation and as a means for staying employed. I refinanced the car and paid it off. Now I have been going to school since 2004 and I have only just recently, last semester, depleted what was left in that account. So, it took me quite a ways. I was afraid to spend it and it not be there. I am one of those people that keep a nest. I'm not going to say that $I^{\prime} m$ a great saver, but I do spend money frivolously, but when I know that it money that I need (emphasis), I keep a nest. I have a nest now but it's like this (indicating that it's small) but I'm going to allow it to grow periodically with small deposits, but I can't afford to do any more. I'm just afraid that if something happens and $I^{\prime} \mathrm{m}$ left with no money, huge school bills. What happens and I don't get through nursing or 
something happens and I don't make it to the upper division? What if something happens and my financial aid runs out before I get out of school? I have to have something. ( $\mathrm{S}$ : L 531)

Sarah, like many welfare recipients, did not receive cash benefits from welfare to extend her lifetime eligibility and to circumvent the work requirement. She lived on school loans, 20-hour a week work-study job, and child support payments. To ensure that her child support was received on time, the payments were made through payroll deduction. Sarah cancelled her medical assistance and food stamps during the summer, but reapplied when classes started. Sarah worked as a Certified Nursing Assistant (CNA) during the summer to see if she wanted to be a nurse before she reached the upper division of the nursing program.

Over the summer, I worked as a CNA. I wanted to work so that I could see what...because I want to be a nurse and I have never been totally introduced to the field of nursing. I was like, do I really want to be a nurse? So I said I am going to work this summer and see what happens. God is good, because he knows me better that I know myself. I enjoyed it to the point of 'ridiculousness'. I was wiping people's butts, but I loved it. Now that I'm back in school I can't do it. I tried working just a day or two but it was too hard. (S: L 218)

Sarah used a childcare program that was subsidized by United way funds. Sarah found the provider while she was 
working and the provider had a sliding fee scale based on income. Sarah only paid \$30 per week. Sarah was not eligible to receive childcare assistance because she was not employed and did not receive TANF funds.

If I used the childcare assistance through TANF I would be required to work 20 hours a week. Me working 20 hours a week is costly in time and with me having difficulty in reading and picking up stuff really quickly. (S: L 593)

Academically, Sarah struggled with what she described as reading and math difficulties, which had been present all her life. Sarah had never been tested for a learning disability; however, she was having trouble keeping up with the reading assignments as they became more difficult. According to Sarah, in the past she had been able to skim and glean the meaning from the text, but as new, unfamiliar concepts were being introduced, skimming no longer worked.

For Sarah, the concept of having a support system was new. Sarah had always felt little or no support from her family. Because she worked and had no children until she was 37, Sarah did not see the need for a support system. Even as she quit her job three years ago, she left with a short-term plan for self-sufficiency. She withdrew the money from her $401 \mathrm{~K}$ plan, paid off her car, moved to cheaper housing, and enrolled in college. Sarah finally depleted her savings on 2006. Once the money ran out, 
Sarah's plan fell apart and she eventually lost her apartment. She and her daughter now live with one of her sisters. Her sister did not charge her rent and made no financial demands on Sarah. To pay her back, Sarah helped with household chores and gave her sister money whenever she had extra cash.

Another sister gave Sarah cash periodically to help her out. Sarah gave her sister any food stamps that she did not spend. In return, for the food stamps, her sister gave her cash. For example, if she gave her sister $\$ 80$ in food stamps, her sister might write the check for $\$ 60$. Occasionally, she gave Sarah $\$ 120$ for the food stamps as her way of showing support.

While her two sisters provided basic support Sarah could not discuss school or school problems with her sisters, and the same was true with the rest of her family. While all of them indicated that they supported her decision to go to college, they refused to discuss school.

I have a large family and one of the divisions I see is that if I talk about school it's like, shut-up I ain't trying to hear that. I can sometimes feel them quietly sitting back and waiting for me to fail. (S: L 190)

In addition, Sarah had not developed any meaningful relationships on campus. 
I have no one that I can sit and study with or just to talk about school. I don't have anyone that I talk to on campus other than people at my work-study job. (S: L 189)

Sarah viewed her faith in God and her church

affiliation as an important part of her life. She attended church on a regular basis and was an usher.

That has been a real, real testimony my entire life. When I was a kid I was around a house full of people, but I never felt so alone. That is all I knew feelings of loneliness because I really didn't connect with my family. When I did it was because I was getting a boat connected to my head or something. I don't remember us going to church very often. Mama read her bible and she told us about God. I remember SEEKING HIM, SEEKING HIM, not because I needed him. Not because I wanted to let me see if this worked. I needed him, I needed to know that there was a God in my corner. I saw him at a very early age. I don't know if my knowledge of God came from her (mom) or watching evangelists on TV or where it came from. But I sought him out and he was there. There have been times in my childhood, throughout my whole life, but I think visually more in my childhood. Where I know, somebody was there helping me. Umm, Praise God!! An example is when we got away from I didn't pray to get away from him like that, I can't say that I prayed and it happen. But I leaned on him so much, certain things that happen were just too doggone incidental. had never ever penetrated me during the time I was being molested by him, but he was changing. It was right around the time he hid my shoes that he was trying to do more. I don't remember what the noise was but, I was down in the basement doing laundry. He wouldn't molest me for the whole time and he would do it for a little while and go somewhere and do something. I would do whatever I could to be the farthest away from him wherever he was at. I went to the basement washing my laundry; it's always been dark down there. I think one of my sisters came home from 
school, I think that's what the noise was. He comes down there and he decides to pull out his 'johnson' and tells me to come over and sit on him and that was the first time I was really scared. I can't say that I was really scared before because I couldn't do anything about it. But when he did that I felt scared and it was like that was a trial run. I started getting really scared, I don't want him to do that to me. It was the first time I knew for sure, that I can't let this happen. Who can I go to? We moved shortly after that, we got away from him. It was an answer to my prayer. I don't know how to explain it when I needed him most in my childhood he was there. My momma wasn't always there, my family was never there, but he was always there. I don't,... I use that as a testimony many times, but I don't know how to articulate it well enough to let you know that I knew his presence was there. Not just in miracle that was there when I needed him, not when I wanted him... I did not literally have conversations with somebody that I was talking to that I could see, but in my mind and in my heart I knew that I was communicating with God. (S: L 810)

My relationship with God tends to remain pretty much similar today.... He has always been an integral part of my life, but there's that doubt in my head during my adulthood. Well what if that really wasn't God, what if it was really something else?" (S: L 980)

.... Besides praying about it and asking God for guidance and asking him to help me know what to do. I really can't honestly tell you what else because every time I have done that he has come through for me. When I got,... I applied for, things would happen for me, especially with school that it be before I would get down on my knees and ask for it specifically. Like I'm running through some financial difficulties like crazy, I'm struggling, I made through this year cause I'm not getting these funds anymore God. I've said this ever since I started school, you brought me this far, so whatever I going through I am going to keep moving because that is the 
direction you want me to go in. Because you want me to go on it, I know you are not going to allow me to fail. If something happens and it doesn't work out then I know it is because God has something else for me. I just leave it at that. As I am going through situations, he makes a way. Right now, living with my sister, to me this is a miracle. I mean the way it's worked out it's like a miracle. Me getting that scholarship for $\$ 4000$ when I needed it the most. I just didn't get it and it was like free money, it was when I needed it the most. Those types of things have happened throughout my life. I refuse to believe that that much coincidence can happen. (S: L 992)

Sarah acknowledged that the sexual molestation she experienced as a child had affected all of her personal relationships.

In my personal relationships I would not allow anyone to touch me for God knows how long.... I just don't want to hate my mother anymore...one thing I know that I have done in the past dealing with people, if I can't fix it soon, I cut them loose. I have someone right now that I've had to cut loose. I don't have the time. I am real product oriented. When I am most happy with me is because I have completed a goal." (S: L 412)

Sarah tried to evaluate each situation individually and make a decision after she had time to think about the problem. Sarah had a three-step process she used to resolve problems.

When things go wrong I do three things. First, I sink down, I get lost and allow them to get a little worst at first because I'm stressing over it. I will stress over a situation and while I'm sitting there stressing something else pops in and something else and something else and things 
start getting bigger. When I get to a point where I feel it's like point of no return, then this regulator comes on and it's like, hey we got to stop this. Second, I start analyzing the situation. Where are you? What happened last time? There are some things you can do to pull this out. Here are some things that help you do whatever. I have to go through this process or I can't function. Third, I will try different things, different strategies until one of them work. When I do that it is 'gung-ho'. I pray to God that one works before it is too late and it usually does. (S: L 380)

Right now I have a time management problem. I analyze what I do a lot and that helps me figure out my options or a better plan. Sometimes it takes me a while. I have done this my whole life, particularly if I'm in a funk, a depression. My family won't admit it, but my mom raised a bunch of depressed kids. Once I recognize that I am depressed I am able to get through it. (S: L 343)

Sarah felt the need to be in control of her life and that she was in control most of the time.

I've gotten to the point that I know what life is like when you feel you don't have any control. I refuse to be in that situation now. I freak out when I feel like I am not in control of me. I don't need to be in control of everybody else, just me. (S: L 371)

Trina

Trina is a 32 year old African-American single mother with two sons ages 8 and 12. Trina's parents were divorced when she was approximately four years old. Her parents shared custody and Trina lived with her mother during the week and with her father on the weekends. Trina did not 
like going to her father's home on the weekends because there was drinking, fighting, and drug use. Trina's father also lived with his girlfriend and her children. The girlfriend encouraged Trina and her siblings to fight with other children in the neighborhood and encouraged sexual activity between Trina's sister and boys in the neighborhood. Because Trina was younger, she was not forced to participate in the sexual activity or fighting initially.

I was just kind of hanging by, watching, and looking at everything. As I got older, she started on me. She would hook us up. Her son always had his friends that would be there smoking and drinking. The guys were all about the sex. (T: L 16)

Trina made excuses not to go to her father's because she did not want to participate in the sexual activity. Trina never told her mother because she did not want to get her father in trouble. She did not tell her father because he and his girlfriend were always fighting and telling would have caused another fight.

Trina always knew that her parents expected her to attend college. After graduating from high school, Trina attended a local community college for a semester. Her sister attended a local 4-year university and encouraged Trina to transfer so they could attend college together. 
Trina transferred to the 4-year institution, but was eventually dismissed because of poor grades. In addition, Trina became pregnant with her first child.

I wasn't serious about school then and I did a lot of partying and not going to class. So, I was dismissed because of poor grades. ( $T$ L 33)

Trina worked two jobs during her pregnancy. After giving birth, Trina applied for welfare benefits and re-enrolled part-time at the community college. Trina did not like being a welfare recipient and she soon went back to work. She became an assistant manager at a retail store and was later promoted to manager. She continued taking classes at the community college part-time and earned an Associates in Applied Science, and Associates in Arts. Trina was terminated after working for the same company for six years.

I lost job after 6 years. I got fired and I filed a wrongful termination suite and won that. I was fired because an ex-boyfriend was stalking me and kept calling or coming to my job causing problems. They paid me a year's pay and I went back to school. ( $\mathrm{T}$ : L 196)

After getting fired, Trina decided that she needed to return to college and petitioned to for re-admission to the university. Her petition was granted and she returned in the fall of 2007 .

I wanted to take five classes a semester so that I can get out quick. I started the semester with 
five, but had to drop the two harder classes and I picked up walking, swimming, something easier. I picked something easy because I have to focus on the harder classes. I have to keep a certain GPA and I didn't want to put a lot on me and I was feeling like I couldn't handle it and I didn't want to be thrown out. So now I'm taking two classes that don't count for nothing and three core classes. At the community college I was taking three classes and I could handle it, but I got over here I have five and the advisor had me in 15 hours, and people (appeals committee) said I could only take 13 hours. How am I going to do this? I went the first week and I knew it was too much. (T: L 105)

My walking class is Tuesday and Thursday and it clears my head. Then the three classes I'm ready to focus on. ( $T$ : L 110)

Trina received $\$ 282$ in cash grant, $\$ 300$ in food

stamps and a medical card. She also received transportation assistance to help cover some of her transportation costs. Because Trina attended a four-year institution TANF required that she work 30 -hours a week to meet the TANF work requirement. She had a 12-hour a week work-study job, as well as 20 -hour a week to meet her TANF work requirement. Trina believed that she was blessed because both of her jobs were on campus. Trina also used childcare assistance for after school care and had not had any problems with their services. The problems she experienced had been with her TANF caseworker.

The worker does not return calls and only responds if I go to the office. I just go up there and every time I go up there, she does what 
she is supposed to do. She's got a lot of other cases, she says she is overwhelmed and has a lot of cases. That's okay, but if you say the paper is due on the $10^{\text {th, }}$ and I turn it in on the $3^{\text {rd }} \ldots$. I do every compliance and I don't understand why I can't get my money. She just had to send $\$ 282$ that she owed from the summer that I just got. She still owes me a $\$ 100, I^{\prime} m$ just like, I have to go up there she quit answering the phone. ( $T$ : L 45)

As a TANF recipient, Trina was eligible for $\$ 100$ a month transportation assistance but her payments are often late.

I down there today (10/03/07) and she accused me of not turning in papers, the computer showed what date I had turned them in and my copy showed the same date. Whenever we turn something in the date is entered into the computer. Even when the computer shows that I turned it in, she can't find the paper. ( $T$ : L 296)

Because the caseworker frequently accused Trina of not turning in paperwork on time, Trina always made back-up copies. She always had two copies date stamped by the welfare office so that she had one to give them and one for her own records. To receive the transportation assistance Trina had to have each instructor and each tutor sign a calendar to verify attendance.

Sometimes they don't want to sign, or they ask why. I don't have the heart to tell them it's for welfare. I just kind of mumble something and they sign it most of the time. It is already October and I was told today that they will send the August check, but the September check will be four hours short because I forgot to get a 
signature. If I can come up with a signature for those four hours, I can get paid. It's a mess ( T: L 201)

Trina believed that she had only had half of her lifetime eligibility for TANF left. Last year she used a student loan for living expenses and did not receive a TANF check. Her eligibility clock for TANF stopped whenever she did not receive cash assistance. She reapplied for TANF this summer.

I try to manage it because I don't know how long it will take me to finish school. I do it for 2-3 months and I cut it off, I do it for 2-3 months and I cut it off. I just keep going back and forth, I'm sick of that too. The months that I'm not on TANF I live off my student loan. I still have my work-study money. I use my student loan to pay my mortgage up and pay my bills up to the next semester. So my work-study money I pay the phone bill or LGE, bills like that. ( $T$ : $L$ 182)

Trina described her typical day as hectic and recognized the need to make some changes.

Normally I get home about $3: 00 \mathrm{pm}$. I have to pick up my sons, put dinner on, help them with their homework and by then it is time for football practice. We go to the field, come back, do baths, and I try to do homework which never works. Once I leave campus, it doesn't happen. I'm more able to concentrate about 11:00 pm. So, I'm up from 11:00pm to $1: 00$ am doing homework. Then I get up a 6:00 am to get the youngest son to school because he is a car rider. I'm trying to rework that whole thing. I can't study until 11:00 pm when they are in the bed. Like, I was up until 12:00-12:30 am last night, and then $I^{\prime} \mathrm{m}$ sleepy this morning. I start making them take baths and shutting it down at 9:00 pm. They have 
to be in the bed by $10: 00 \mathrm{pm}$. We get back from football by 8:30 pm, and they still have to eat. If they didn't finish any homework they are doing that and then they take their baths, then bed. They practice Monday-Thursday. (T: L 82)

As a previous victim of domestic violence and stalking, Trina wanted to provide a peaceful environment for her children. She believed that as she had matured, and she tried to think things through without yelling and arguing .

Trina planned to get married shortly. Her boyfriend and his 13-year-old son recently moved into her house. The combining of the two families had become a source of stress and conflict. Trina felt like she had the most control when home, school, and children were in order.

When the house is crazy, my relationship is everywhere, it takes time from my studies. ( $\mathrm{T}:$ 125)

I think with us moving into together. We argue about petty stuff. Because he had his own, and I had my own. I think with us moving in together, we thought it was a great idea. But he has set things he likes to do. He has his ways and I have my ways. So we are trying to adjust to each other's ways. His son lives with us also, so we have an 8,12 , and 13 year old boys living in the house with us. My pastor is doing sessions, counseling session with us. It's really helping with the counseling sessions. (T: L 128)

Trina typically tried to think through problems, but also tried to avoid confrontation. 
I just hold it in. I'm thinking about it and if $I^{\prime} m$ angry $I$ used to just fly off the handle right then and there. Now I don't want confrontation. I don't want my kids to be in an abusive home like I was. I don't want them to think it's okay for all this ranting, raving, fighting and calling the police. I just don't want that in my life anymore. I was with my son's dad for 12 years. When we separated, I ended up in two abusive relationships back to back. They would come in the room and hold me down, try to choke me out. I would have to call the neighbor or anyone to call 911. My son's father was not abusive, he didn't finish high school, didn't want to work, didn't want to do nothing. I just knew that I wanted more for myself. It was a good relationship, but financially I was the sole supporter. I couldn't have me being on welfare and I'm trying to help him, it was just too much. (T: 171)

I was in a relationship that was abusive and I decided to get out of it, but he didn't want to the relationship to be over. He broke into my house, followed me, and called me constantly at home and at work. I had to take out an order of protection. They told me to report anything that he did that I thought was harassing, no matter how small. I ended up being fired because of all the mess he did at my job. I found out when I was moving that he had been living in my basement. We only used the basement for storage so I didn't go down there often. I found his stuff hidden in a corner out of view. I don't know how long he had been living there without my knowledge. There were times that I thought I heard a noise, but in a old house you always hear noises. He did jail time for stalking me. (T: L 250)

Trina saw her will to succeed as her greatest

motivation. Trina felt that she had to succeed because she did not get any emotional support from her family.

Once I accomplished by associates I was proud because everybody said I wasn't going to be able to do it. Now I'm here trying to get the four 
year degree. They say I've been in school for 100 years, but they don't understand. You hear the negative about you been in school so long, you ain't gone never graduate. My mother says that to me all the time and she's not very encouraging, but I know she wants the best and I want to make her proud. She didn't understand that I was working full-time, and only taking one class a semester that's why it was taking me so long to accomplish that. ( $T$ : L 96)

While Trina felt that her mother did not understand, her mother provided support in other ways. Trina's mother was always willing to assist with transporting the children to and from school, and football practice, and to care for the children while Trina studied. Trina's boyfriend also assisted with transportation, and assisted financially by taking care of some of the household expenses. In addition, he encouraged her to attend school and entertained the children while she studied.

A childhood friend from ninth grade provides a great amount of emotional support; she is someone that I can always talk too. ( $T$ : L 150)

Trina had also used resources in the community for assistance with paying utility bills, and a homeownership program. Lisa recently purchased her home through her participation in the homeownership program.

Section 8 helped me buy my own house about a year ago so I haven't had a rent subsidy since then. I was working full-time, I got promoted at work and when I got the promotion I was in the middle of buying the home. When I went back for 
recertification, they saw my new income was $\$ 33,000$ and threw me off Section 8 and I had to do the closing by myself. They should have helped me with the closing. ( $T$ : L 188)

Trina had difficulty articulating what coping strategies she used other than avoiding confrontation.

Ann

The interviews with Ann took place in the researcher's office. Ann is a 37 year-old African American female with one child age four. Ann had never been married and is currently pregnant with her second child.

Ann and her brother grew up in a family affected by domestic violence. Ann's stepfather drank heavily on the weekends, and was physically abusive to her mother when he was drunk. In an attempt to shield her children from the abuse Ann's mother sent them to stay with relatives on the weekends. Ann would go to her grandmother's and her brother would go to an aunt's home.

The plan to protect Ann from abuse failed. Ann became a sexual abuse victim. An uncle who lived with her grandmother molested her. The molestations began when she was nine and continued until she was 14 years old. Her uncle would sneak into her bedroom at night. Ann initially thought she was dreaming or it was her imagination. One night she awoke during the molestation but pretended to be 
sleeping. Eventually, her uncle knew that she was aware of the sexual abuse and he threatened to kill her if she told anyone. Frightened, Ann told both her mother and her grandmother but they did not believe her. Both her grandmother and her mother accused her of lying and trying to get attention. Feeling she had no one to protect her, Ann felt totally abandoned and endured the sexual abuse until she was about 14. She began to find ways not to spend the night at her grandmother's house.

I would find friends to stay with on the weekends or just stay home and listen to my stepfather abuse my mom. Listening to the abuse of my mother was frightening; staying with my grandmother was even more frightening. I felt safer at home. (A: L 20)

At age 19 Ann was again sexually assaulted while on a date. The rapist threatened to kill Ann if she told anyone. Ann did not report the rape because of the threat and her sexual molestation as a child.

If no one believed me before who would believe me now? So I suffered in silence. My family still does not believe me (A: L 36)

Ann worked for a community agency for ten years, and was terminated when the company downsized. She received unemployment for about a year. Ann always drank alcohol socially, but after the termination, her drinking 
increased. Over the next two years, Ann's life spiraled downward.

I used to dip and dab when I was 30 and I just do it on the weekends when a friend of mine would invite me over. I was drinking, and started using cocaine and marijuana along with the alcohol. I would be out all night on Friday but I would always go home on Saturday because I wanted to go to church on Sunday. I knew that if I got high on Saturday I would be too messed up to go to church Sunday. (A: L 177)

Ann's addiction became her primary focus and she eventually lost her apartment. About the same time, Ann lost her apartment she found out that she was pregnant at age 32. Homeless, pregnant, and addicted, Ann entered a residential drug treatment program 70 miles from her home. The program specialized in the treatment of drug addicted pregnant women. While in the treatment program, Ann developed gestational diabetes and cervical incompetence and was hospitalized for 30 days. Ann was too far along in the pregnancy to have the surgery to correct the cervical incompetence, and was placed on bed rest for the remainder of her pregnancy. She also had to have insulin shots for the gestational diabetes.

Ann returned home to give birth to her son. She lived with friends and family for approximately two years. As long as Ann worked and provided financial assistance to the household expenses, she and her son had a roof over their 
heads. When the money ran out Ann moved on to the next friend or family member. Ann's drug use and destructive behavior continued. She attempted to withdraw money with a stolen ATM card and was arrested. Ann was charged with the fraudulent use of an ATM machine because she had not stolen the card. The card had been given to Ann by a friend. Ann was sentenced to 100 days of home incarceration for attempting to use the stolen ATM card.

Ann believed that she suffered from postpartum depression for approximately two years after the birth of her son.

I did some harmful things to myself so I was sent to the psychiatric unit of the hospital. After keeping me a couple of several days, I was told that my body was reacting to withdrawal from drug use rather than depression. I was released from the hospital, and referred to alcohol and drug abuse program. They refused to admit me to their residential program because my drug use was primarily on the weekends and not every day. (A: L 61)

Determined to kick her addiction, Anne decided to do it on her own.

I was getting sick and I knew I had to quit, so I went back to church and asked God to help me. I started going to bible study, and found out there were Narcotic Anonymous (NA) meetings being held at the church. I started going to the meetings. (A: L 369)

Ann had been clean for approximately two years. Recognizing that she needed to get away from her friends, 
Ann applied to, and was accepted into a housing program for homeless women. At the time of the study, Ann resided in a federally subsidized apartment provided by the program.

The program provides the kind of structure and support I need. (A: L 98)

Ann applied for welfare benefits two years ago.

I could not believe I was applying for welfare because I had worked most of my adult life, even off and on during my addiction. (A: L 90)

Ann received \$225 monthly in cash, \$112 in food stamps and a medical card. The amount of food stamps she received was determined on her income from her work-study position. Without the income from work-study, her food stamp allotment would have been $\$ 284$ a month.

Because Ann's son was not yet six years old, Ann was required to work 20 hours a week to maintain her TANF cash benefits. She had a 20-hour a week work-study position on campus that met the work requirement. She also received up to $\$ 100$ per month in transportation assistance. To receive the transportation funds recipients were required to verify class attendance by obtaining the signature of each instructor on a calendar after each class. The calendar also had to include the time of the class. If the recipient forgot to get the signature, or the time of the class is 
not on the calendar, transportation assistance was denied or delayed.

They want to know why they have to sign the calendar, or become upset because they are asked to sign. It is embarrassing and makes me wish I didn't have to have it. You get punished if they refuse to sign. Learning all the rules for welfare is hard, they keep changing. (A: L 400)

Day care and transportation were not a source of stress for Ann. The childcare assistance program paid the cost of her son's childcare. Ann no longer had to get up two to three hours early to use public transportation to get her son to and from day care, or to and from her classes. In June, Ann received a car donated by a group of local auto mechanics in the area. It is the first car that Ann has owned in ten years. Ann described the car as "a blessing".

Ann was no longer drinking and using drugs, but she continued to struggle emotionally. Recently Ann received the news from her mother that her uncle was getting married. The news of her molester's pending marriage caused Ann to have flashbacks about her childhood molestation by her uncle.

Here he is getting married and living happily ever after and I'm left with this baggage.

(A: L 400) 
The previous semester Ann tried to go to school fulltime and work, but found that she could not handle both.

$$
\begin{aligned}
& \text { I couldn't do it, which was a large part of my } \\
& \text { stress last semester, it was too much. (A:L 405) }
\end{aligned}
$$

The combined stress of school, work, and flashbacks related the sexual molestation resulted in an emotional breakdown. Distraught, Ann sought counseling. At the time of the study, Ann continued to meet weekly with the counselor. Ann described herself as not having a support system. The only person Ann felt she can might be able talk with is a mentor, but the mentor was not always available.

I save things up to talk them over with my counselor. I have friends and I have family, but they are not the supportive type. If I mention school or homework, their response is always negative. One person even commented that they liked me better when I was high. (A: L 161)

No there is nobody that if I had something going on that I can just pick up the phone and say, girl...no I don't have that. (A: L 198)

Ann believed that in addition to struggling with her addiction, parenthood had been a 'tough adjustment'. Ann was 32 when her son was born.

For so long I only had me to worry about, now I have him. I stayed with friends and family for the first two years after he was born because I needed help but did not know how to ask for help. Now that I have had two years of living on my own, I am proud of the adjustments that I have made. It ain't easy, but it's fun in a way, 
because I'm learning, and he's learning. (A: L 247)

While Ann was happy about the positive changes in her life, parenting as a single parent had not been easy.

I'm working, I'm going to school, I'm pregnant, $I^{\prime} m$ parenting, and I attend the group meetings where I live. I feel like I am being pulled in different directions and have little or no time for myself, and I have no control. Sometimes I get flustered because I have no time for me. (A: L 103)

In the past, Ann's son would spend two days a week with his father. He no longer exercised his visitation rights and Ann felt cheated because she had no time for herself.

Now the one thing that I do take the time to do is my hair. I don't let nothing stop me from doing my hair. I comb my hair before I go to bed. As soon as I wake up I wash my face, brush my teeth and comb my hair. My son asks when am I going to let my hair be messed up. But that's the only thing I do for me. (A: L 363)

Ann does not like confrontation and tended to withdraw and isolate herself when there is a problem. When Ann learned that she was pregnant a second time she denied the pregnancy for a couple of months and isolated herself. Ann's typical coping behavior is isolation.

When things go wrong I pray. (A: L 128)

I just keep to myself, I don't answer the phone, I just block everything out. I tend to my child and when he goes to sleep I write, I write a lot. (A: L 147) 
She described her writing as a way of looking at the problems and the possible solutions.

Well, my writing down the problem and me writing down what I can do to solve the problem helps me. Now if I write down a problem and I know that I really can't solve it, just something that has to pass, is just what I have to say.... Sometimes I have to put my feelings on paper, which I am used to doing because I didn't have no one to talk to, I started when I was young. (A: 250)

If it's a problem and it's not going away I try to address it properly. (A: L 263)

Ann began writing down her problems shortly after she was raped at age 19. She wrote because she felt she had no one to talk to about her problems. At the time of the study, Ann continued to feel that she had no one, so she continued to write.

Ann continued to go to church, but attended the Saturday service rather than going on Sunday.

The services on Saturday are not as formal, so my son doesn't have to sit as long. He has trouble on Sundays. I find gospel music as 'soothing' when I am upset. (A: L 138)

The previous section provided a detailed look of the study participants. The following section presents the findings of the study. 


\section{Objectives of the study}

This section presents the findings related to the research objectives: (a) to examine the participant's view of her current situation, (b) to identify levels of support, and (c) to identify coping strategies used to alleviate stress. The objectives of the study related to Schlossberg's transition theory and the four factors that influence the ability for the individual to cope (situation, self, support, and strategies). The findings are presented based on the identified themes and categories.

\section{Participant's View}

Each transition is different and perceived differently by each individual; as a result, individuals appraise the same events in different ways. The appraisal of an event or nonevent is determined by the timing, control, role change, duration, previous experiences, or concurrent stress that precipitates the transition. Personal characteristics include socioeconomic status, gender age, stage of life and ethnicity that in turn influence worldview. Pearlin and Schooler (1978) defined psychological resources as the “personality characteristics that people draw upon to help them withstand threats" ( $p$ 5). Psychological resources 
include locus of control, ego development, values, and self-efficacy. The themes that emerged that relate to the participant's personal history, welfare receipt and their view of their current situation include the following:

- Personal History

Domestic Violence, Rape, Physical, or Sexual Abuse

Drug \& Alcohol Abuse/Criminal History Work History Prior to Welfare

- Impact of TANF Work requirements/Loans Caseworker Issues

- Sources of Stress

Male Relationships

Parenting Control

\section{Personal History}

Domestic Violence, Rape, Physical or Sexual Abuse Six of the participants told stories of their victimization. Desiree, Trina, and Lisa described themselves as victims of domestic violence. Lisa and Ann were both victims of acquaintance rape, and Trina was forced into sexual activity at a young age. In addition, 
Sarah, Ann, and Mary were all victims of physical and sexual abuse as children.

Desiree briefly mentioned her history as a domestic violence victim, and indicated that both of her marriages and all of her relationships with men had been violent. As a result, Desiree had a permanent back injury. Because of her history of drug and alcohol abuse, Desiree cannot take pain medication and used alternative methods to manage pain.

When her parents divorced, Trina spent weekends with her father and his girlfriend. The girlfriend encouraged Trina and her siblings to engage in sexual activity with boys in the neighborhood. Trina did not tell either parent about the forced sexual activity because she did not want to get her father in trouble. As an adult, Trina was involved in two physically abusive relationships. When Trina attempted to leave one of the abusive relationships she was subjected to harassment at work, and lost her job because of the stalker calling her job repeatedly.

Mary's mother divorced and became involved with the person who physically and sexually abused Mary. Her mother eventually married Mary's abuser. Mary believed her mother was aware of the physical and sexual abuse and failed to 
protect Mary. Angry, Mary resorted to running away, stealing, and selling drugs.

Similarly, Ann grew up in a home affected by domestic violence. Ann was sent to stay with her grandmother on the weekends to protect her from the violence occurring in her home. Ann's maternal uncle began molesting her at age 9 . Frightened, Ann told both her mother and grandmother, but both her mother and grandmother told her she was lying and looking for attention. The molestations continued until she was 14 years old. Ann was raped while on a date at age 19. Similar to her molester, the rapist threatened to kill Ann if she told anyone. Ann did not report the rape because of the response she received as a child:

If no one believed me before who would believe me now? So I suffered in silence. My family still does not believe me. (A: L 36)

Lisa moved home to live with her mother late in her first pregnancy because she could no longer afford her apartment when she went on maternity leave. Near the end of the pregnancy, Lisa's mother physically attacked her; Lisa gave birth the same day.

Homeless after the birth of her son, Lisa and her boyfriend moved in with an extended family member. Lisa was physically abused by her boyfriend. One incident resulted in numerous bruises and a broken thumb, additionally, Lisa 
was holding her son during the attack, and he was injured. Soon afterward, the baby was placed in foster care after Lisa violated a no contact order.

Lisa's second child is the product of multiple rapes by an acquaintance. Lisa's son was in foster care when the rapes occurred; she did not report the rapes. She feared that if she reported the rape it would extend the time that her son would remain in foster care:

By the time I built up by courage that I was not going to deal with it anymore I was already pregnant with my daughter. I did a lot of things to myself because I didn't want the baby. There were times that I prayed she would die. ( $L: L 450$ )

Lisa worked with an adoption agency and initially planned to give the baby up for adoption, but backed out when she realized that she would have to contact her rapist. Rather than contact him she kept the baby.

From age nine to age fourteen, Sarah was the victim of physical abuse and sexually molested by her mother's livein boyfriend. Sarah's mother worked the afternoon shift and her boyfriend was the primary caregiver. Sarah knew that her mother was aware of the physical abuse and suspects that she was aware of the sexual abuse. Sarah did not tell her mother of the sexual abuse until several years after 
the abuse ended. Sarah described her mother's reaction as mild.

Table 5 provides a summary of the domestic violence, sexual abuse, physical abuse and rape of the study participants.

Table 5

Domestic Violence, Sexual Assault, Physical Abuse, and Rape

\begin{tabular}{lll}
\hline Participant & $\begin{array}{l}\text { Child } \\
\text { Victim }\end{array}$ & $\begin{array}{l}\text { Adult } \\
\text { Victim }\end{array}$ \\
\hline Lisa & & $\begin{array}{l}\text { Rape, Domestic } \\
\text { Violence }\end{array}$ \\
Sarah & $\begin{array}{l}\text { Physical Abuse } \\
\text { Sexual Abuse }\end{array}$ & \\
Ann & Sexual Abuse & Rape \\
Trina & Sexual Abuse & Domestic Violence \\
Mary & $\begin{array}{l}\text { Physical Abuse } \\
\text { Sexual Abuse }\end{array}$ & \\
Desiree & & Domestic Violence \\
\hline
\end{tabular}

Current research confirms the prevalence of domestic violence and sexual assault among low-income women, particularly women on welfare (Allard, 1997; Brown \& Bussuk, 1997). 
Heyman and Slep-Smith (2002) found that women who witnessed paternal violence and who were sexually abused as children were at risk of experiencing domestic violence as adults. This study supports the findings of the previous research on sexual assault and domestic violence. Trina as a child witnessed the physical abuse of her mother and was coerced into sexual activity at an early age. Trina was also a victim of domestic violence and stalking as an adult. Similarly, Ann witnessed domestic violence as a child and was the victim of sexual molestation as a child and rape as an adult.

Current research indicates that victims of sexual assault view themselves as having low self-worth and may use avoidance coping strategies as their primary coping strategy (Littleton and Breitkopf, 2006; and Schewe, Riger, Howard, Staggs, and Mason, 2006).

Emotion-focused coping strategies are more likely to be used by victims of childhood sexual abuse. Childhood sexual abuse creates a situation that is often perceived as having no control. Because the individual perceives a lack of control, Diehl and Prout (2002) argued that the individual primarily used avoidance or dissociation as coping strategies to change the meaning of events that are appraised as threatening. 
Carlson (1997) identified several barriers to selfsufficiency for low-income women that leave violent relationships: lack of housing and lack of childcare, economic loss of income, and low social networks to provide material assistance. The barriers faced by victims of domestic violence are many of the same barriers faced by welfare recipients and adult students.

Drug/Alcohol Abuse and Criminal History

Three participants provided information regarding drug or alcohol use and their related criminal history. Mary began shopping, and burglarizing homes as a rebellious teenager while she was still in high school. Mary's criminal behavior continued after she entered college and added selling drugs to the list. She was arrested several times while she was in college and was placed on probation for two years after her last arrest. Mary was seven months pregnant with her first child when she was placed on probation.

Desiree was a drug addict from 1985 to 2000 and spoke freely about her addiction as well as her criminal history. Desiree's first husband introduced her to drugs in college. She remarried and continued her drug use during her second marriage. Desiree stole cars and sold the stolen cars to 
the chop shop to support her drug habit. She found stealing cars more acceptable than prostitution. She had been arrested a number of times and considered herself as a three-time felon. Desiree eventually served a year in jail for complicity to automobile theft.

Ann always drank alcohol socially, but after she lost her job, her drinking increased. Over the next two years, Ann's life spiraled downward. Ann's drug use and destructive behavior continued until she was hospitalized during her pregnancy. After giving birth Ann resumed her drug use and was eventually arrested and received a sentence of 100 days of home incarceration for attempting to use a stolen ATM card.

Brown and Riley (2005) argued that for drug users negative social support might involve other drug users and individuals who do not support an individual's attempt not to use drugs, and may encourage continued drug use. In this study, Ann described feeling as if she had little to no support from family members. According to Ann, one family member commented "I liked you better when you were high. Brown and Riley (2005) also found that for low-income drug users the frequency of drug use decreased by $70 \%$ when the quality of the support network was positive and led to more positive employment outcomes. The drug use and 
criminal behavior of Desiree and Ann occurred prior to becoming welfare recipients. The same is true with Mary, the drug sales and arrests occurred prior to becoming a welfare recipient. The findings of this study indicate that as Desiree, Ann, and Mary changed their negative social networks, and changed locations, their drug use and criminal behavior decreased.

Work Prior to Welfare

In this study, all of the participants were employed prior to the receipt of welfare benefits. Six of the participants applied for benefits after the birth of their first child. One of the recipients applied for benefits after divorcing an abusive spouse. All of the participants have worked since applying for benefits, and strategically used work to extend the welfare eligibility limit of 60 months. Celeste felt that she was in control of her life when she worked. For Sarah, work was an important part of her personal identity.

Gilen (1999) argued that the media's portrayal of welfare recipients as lazy and not willing to work was instrumental in the passage of welfare reform laws that included mandatory work requirements. The work requirements were designed to increase the work ethic. However, a great 
deal of research that shows welfare mothers wanted to work and have worked prior to receiving welfare benefits.

Table 6 provides a snapshot of the study participants' employment history prior to applying for welfare benefits. The table does not reflect sporadic employment either full or part-time, or work-study after the participants applied for welfare benefits.

Table 6

Participant Employment History

Participant

Number of Years Worked Prior to Welfare

Mary

3

Lisa

4

Celeste

4

Desiree

4

Trina

6

Sarah

Ann 


\section{Impact of TANF}

Work Requirements \& Loans

Four of the participants used school loans to extend their eligibility on TANF, to bypass the TANF work requirement, and/or supplement their income. For example, Trina believed that she only had two years of TANF eligibility remaining. The previous year she had received a student loan and dropped her TANF cash grant. Whenever she did not receive TANF cash, her eligibility clock stopped until she re-applied for the cash grant.

I try to manage it because I don't know how long it will take me to finish school. I do it for 2-3 months and I cut it off, I do it for 2-3 months and I cut it off. I just keep going back and forth, I'm sick of that too. The months that I'm not on TANF I live off my student loan. I still have my work-study money. I use my student loan to pay my mortgage up and pay my bills up to the next semester. So my work-study money I pay the phone bill or LGE, bills like that. ( $T$ : $L$ 182)

Sarah also opted not to receive cash benefits to extend her lifetime eligibility and to circumvent the work requirement. She lived on school loans, a 20-hour a week work-study position, and child support payments. Sarah cancelled her benefits during the summer while she worked as a certified nursing assistant (CNA). Sarah reapplied prior to the start of the fall semester. 
Mary and Celeste used school loans to extend their TANF eligibility and to eliminate the TANF work requirement by not receiving a TANF check as well. Obtaining a school loans allowed each participant to attend full-time.

\section{Childcare and Transportation Assistance}

The participants in the study received $\$ 100$ a month to help cover some of their transportation cost for attending college. To receive financial assistance for transportation participants were required to obtain the signature of each instructor after class to verify attendance. Several participants expressed frustration with the requirement and found it demeaning:

They want to know why they have to sign the calendar, or become upset because they are asked to sign. It is embarrassing and makes me wish I didn't have to have it. You get punished if they refuse to sign. Learning all the rules for welfare is hard, they keep changing. (A: L 400)

The participant's frustration with childcare assistance was with the TANF recertification process. The participants that used childcare assistance expressed the following problems: difficulty getting in touch with the caseworker, the caseworker did not return calls, missing classes for recertification appointments, or not forwarding updated information to the childcare agency. The study participants also expressed frustration with having to wait 
two-three hours to fill turn in or sign paperwork that could have been completed at the front desk in ten minutes. Another frustration involved that caseworker not responding to telephone messages. The participants typically had to go to the office to get a response to their questions. Celeste and Lisa's childcare problems were related to finding a reliable childcare provider. Lisa's son was diabetic and required three insulin shots per day. On at least two occasions the child care providers failed to give Lisa's son his insulin injection. One of the incidents resulted in a three-day hospitalization. Consequently, Lisa quit her job to care for her son. When Lisa was ready to return to work she also had difficulty getting approved for childcare assistance because she was not working. After a month of repeated requests, childcare assistance was approved and Lisa was given a week to find childcare for a child with special healthcare needs.

Celeste also had to find a new childcare provider after her daughter walked three blocks to her grandmother's place of employment because the childcare provider was not home when she got off the school bus.

Similar to the participants in this study, wolf and Tucker (2001a) found that welfare recipients had difficulty 
scheduling re-certification appointment and found the caseworkers withheld needed information.

\section{Sources of Stress}

Male Relationships

Four participants identified men and their relationships with men while attending college as too distracting. Three of the four decided not to be involved romantically while attending school. Celeste and Mary's comments about dating were similar:

My number one distraction is dating when $I^{\prime} m$ in college. Dating, and that's why I always try to stop dating. But dating and...... I start giving up time that I really don't have especially if my daughter is in activities. I usually try and keep her in activities and keep the home life. I need to learn how to balance time better, and that I need to do all around. I think my life distractions... I'm not giving everything time limits. (C: L 385)

Desiree's reasons for not dating were different. She was not involved with anyone at the time of the study. Desiree described both marriages as physically abusive and all other relationships with men had been abusive. "Too many distractions, I've never had a healthy relationship so I need to figure it all out."

Trina announced her engagement during the first interview. She and her future spouse had recently moved in together and the adjustments were a source of stress: 
I think with us moving into together. We argue about petty stuff. Because he had his own and I had my own. I think with us moving in together, we thought it was a great idea. But he has set things he likes to do. He has his ways and I have my ways. So we are trying to adjust to each other's ways. His son lives with us also, so we have an 8, 12, and 13 year old boys living in the house with us. My pastor is doing sessions, counseling sessions with us. It's really helping with the counseling sessions. ( $T$ : L 128)

Lisa and Ann were both pregnant at the time of the study. Neither of them talked about their relationships with the father of their unborn children. Sarah had just ended a relationship that she described as unproductive.

Parenting

All seven participants described the feeling of being pulled in every direction due to the demands of school, work, and parenting. Finding time to get everything done and finding time for themselves was a source of frustration. Celeste's comment echoes the opinion of all the participants.

\footnotetext{
Being a parent is stressful (laughter)! I feel like there is no down time especially if I'm working. I don't have any down time until I pass out and go to sleep (laughter)! If I'm in school and working, which I tried that. It didn't work out to well after I had my daughter. Before I had her it wasn't a problem. I withdrew from classes initially. (C: L 637)

Lisa's primary source of stress was finding a
} 
childcare provider that would agree to give her son insulin injections, and do the required blood sugar checks.

All of the participants had attempted to work and attend classes and take care of the children. All of them either gave up jobs, or kept their job and attended school part-time in order to meet the time demands. Desiree and Ann both became overwhelmed and sought assistance. Desiree asked for her mother to help and Ann sought counseling.

\section{Control}

Five of the participants felt that they had difficulty maintaining control over their own lives. Celeste felt like she was in full control of her life only when she was able to set goals and meet those goals. She described being in control when she worked full-time, came home, cooked dinner, spent time with her daughter, and not dating. Celeste was currently not working, so she felt that she was not in control. Her family also influenced her sense of control. Celeste allowed her family at times to control her decisions and attitude. Sarah, on the other hand, did not like things out of control and worked to control her environment and control herself. Mary's sense of control was determined by her relationship with God and what she felt God wanted her to do with her life. She recognized 
that she could choose to control her life, but preferred to "allow God to lead her in the right direction."

Lisa and Desiree felt like the requirement imposed by TANF were controlling, unfair and did not look at each case individually, but applied the rules as if every situation was the same. Lisa was afraid that if she made a mistake or made the caseworker angry she would be punished.

\section{Support Systems}

Caplan (1976) indicated that support systems help an individual mobilize psychological resources. Support systems may share financial resources, share tasks and information, and provide guidance. The themes that emerged related to support included the following:

- Family support

- Friends

- Community

- Campus

- Feelings of no support

Family Support

During Desiree's years of active addiction, her oldest son lived with her parents. Her son continued to live with her parents at the time of the study. Rather than disrupt 
his life, Desiree rented a house a block away and her son stayed with both his mother and his grandparents. Desiree described a circle of support with parents and siblings:

I have the kind of support system that everyone Will pitch in to make sure everything is covered. (D: L 357)

Celeste also described her mother and step-father as her source of financial support and child care on an emergency basis. Lisa, Mary, Ann, Trina, and Sarah found little support from family members.

Stone, Nelson, and Nieman (1994) studied the primary sociological belief factors of low-income mothers attending college. The primary sociological factor that affected academic success was the emotional support and encouragement received from family members.

\section{Friends}

Mary credited the support of her friends as one of the reasons that she was able to attend college. Mary was encouraged by the mother of a close friend to attend college and helped her fill out her financial aid application. Mary's friend also assisted her with transportation and money when needed.

Desiree, Trina, and Celeste also described friends that provided emotional support and someone to talk to and 
share their personal thoughts and feelings. Sarah, Ann and Lisa did not describe any close personal friendships. D'Ercole (1988) found that for one group of mothers emotional support came from a small group of supportive friends.

\section{Community Supports}

All of the participants were aware of services available in the community to assist them in a time of crisis or need. Lisa, in response to an unwanted pregnancy worked with an adoption agency. Lisa, Celeste, and Trina used community agencies to obtain diapers or assistance on utilities, as well as churches and food pantries for food. Trina, Desiree, Celeste, and Lisa used their affiliation with subsidized housing to begin the process of homeownership. Trina had completed the homeownership program and purchased a home. Celeste, Desiree, and Lisa were just beginning the process and would be participating in the homeownership classes for the next several months.

Ann, Lisa, Sarah, and Mary all had been homeless at one point in their lives and had lived with family, with friends, or in a homeless shelter. At the time of the study, Ann lived in a subsidized apartment provided by a 
program for homeless women. Sarah, at the time of the study lived with one of her sisters.

Ann and Desiree, both former drug and alcohol abusers, continued to use support systems in the community related to alcohol and drug abuse.

\section{Campus Support}

Four of the participants, Ann, Sarah, Trina, and Mary had work-study jobs on campus to meet their welfare work requirement. Celeste did not work on campus, but found the environment at the community college more supportive than the environment at the 4-year institution. Celeste described classes as smaller, making student and instructor contact easier. There were also more opportunities to meet with individual faculty members.

Mary recognized that she needed to resolve some of the issues regarding her molestation and became involved with a support group on campus for adult survivors of child molestation. Mary also became involved with at least one other student organization on campus.

Desiree found support from staff and faculty at the 4year institution. She was also involved in a campus student organization and became an officer in the organization. 
Because of her involvement with both students and faculty Desiree described herself as a resource to both groups.

Sarah, Trina, and Ann talked about the work-study positions as jobs, not as a way of connecting with other students on campus. Sarah acknowledged that she had developed no meaningful relationships on campus and provided the most telling statement:

I don't have anyone that I can talk to on campus other than people at my work-study job. (S: L 189)

Schlossberg (1989) developed a theory of marginality for students in higher education. She defined marginality as a sense of not belonging. Because Sarah, Trina, Ann and Lisa, made no real connections on campus, the feeling of not belonging was evident. This sense of marginality put these students at risk of not persisting until degree completion.

Kalil, Born, Kunz and Caudill (2001) indicated that it is important for welfare recipients to extend their social networks and social communities to assist them in making the transition from welfare to work. Social ties to the community influence the individual's ability to respond to stress and resolve problems. 
No Perceived Support

Lisa described herself as her own support system and having no close friends. She also spoke of her non-existent relationship with her mother. Lisa believed that her pregnancy at that time was the result of being involved in a casual relationship that resulted in pregnancy.

Wijnberg and Reding (1999) found that relationships where the same person is both supportive and critical presents a special complexity. The relationship is characterized by ambivalence and pain, yet the recipient of the criticism is dependent upon the relationship. Sarah, Ann, and Mary expressed similar feelings of ambivalence toward their mother. Ann's mother did not understand why it is taking Ann so long to complete school and expressed her concern to Ann. Nevertheless, at the same time she is always willing to assist Ann with childcare and transportation. Similarly, Sarah's two sisters provided basic support, but could not discuss school or school problems with her sisters or any other family.

Rosenberg and McCullough (1989) identified mattering as an important part of an individual's self-concept and that all individuals experience varying perceptions of mattering to society in general and to specific people. Mattering is essential to the individual's perception of 
who they are and their sense of self. Because these particular women felt no real connection to others, they believed they were not significant.

\section{Coping Strategies}

Coping strategies are a repertoire of behaviors utilized by an individual to alleviate stress. Individuals that believe that the outcome is dependent upon their own personal behaviors use more problem-focused strategies. Individuals that believe that the outcome is beyond their control use more emotion-focused strategies. The following coping themes emerged from the discussions with the study participants:

- Prayer/Spirituality

- Brainstorming/Writing

- Wishful thinking

- Avoidance

Prayer/Spirituality

Meisenhelder \& Marcum (2004) argued that religious coping is an effective method of stress reduction by recalling thoughts of comfort, control, and providing a decreased sense of isolation. All seven participants used prayer as a coping mechanism, and their spiritual beliefs provided meaning for their lives. Celeste, Ann, Sarah, and 
Mary all mentioned their active participation in church and church activities. For each of them their belief in prayer and the power of God was an important part of their daily lives. Ann described not getting high on Saturday so that she could attend church on Sunday. Additionally, when Ann decided to stop using drugs she found her strength in the church and in prayer. She also attended Narcotics Anonymous classes at her church.

Similarly, Mary described giving her life to God and all criminal activity stopped. She continues to "give everything to God". In contrast, Lisa and Desiree described as prayer being an important activity in their lives, but neither attended church on a regular basis.

Brainstorming/Writing

Pennebaker (1997) argued that writing increased insight and understanding of a problem or trauma. Similarly, brainstorming or seeking information and solutions allows the individual to search for or think about similar situations and use that information to cope with the current problem. Brainstorming and writing were grouped together because they were used together to cope and a way of identifying the problem and finding possible solutions. 
Desiree found writing as a way of sorting out problems, as well as the solution. Desiree recognized that her primary coping strategy had been to abuse drugs and alcohol for many years and used writing as a method of confronting the problem and to determine if there was more than one problem. Writing about the problem allowed Desiree to visualize the problem and not become overwhelmed. Once Desiree was able to see the problem, she then began to brainstorm to find a solution. Ann also used writing as a way to identify the problem and brainstorm regarding the solution.

Sarah used a combination of avoidance and brainstorming to resolve problems. Sarah described a threestep process that initially involved avoidance. Sarah described being overwhelmed by the problem and not attempting to resolve the problem until she had no choice but to respond. Sarah would then analyze the problem for possible solutions. Her final step was to use strategies that she had used in the past that had been successful and "prayed to God that one worked before it was too late." Celeste also used brainstorming as a strategy to resolve problems. Celeste would attempt to identify all the possible solutions and narrow it down to what she 
determined to be the best solution. Celeste also sought advice from others.

Wishful Thinking

Taylor and Armor (1996) argued that the wishful thinker focuses on how the individual wants the circumstances to change to reach the desired outcome. Lisa used wishful thinking regarding problems in her life, school, and childcare problems. Lisa changed her career goal from business administration to medical coding because she viewed medical coding as a quick fix to her financial situation. Lisa believed that she could complete the program in two semesters and work from home once she completed the program. She did not consider that the program also required an externship or that she needed a home computer to do her assignments and to work as a medical coder. When asked about the computer she responded:

There are places where you can buy a computer for $\$ 29$ a month or a free laptop. I've seen the ads on TV and stuff, you know. I'm not worried; I will have it when I need it. I have to take everything as I can get it. ( $L$ : L 290)

The same wishful thinking was used when she arranged childcare for the fall semester. The daycare provider had agreed to check Lisa's son's blood sugar, but not to give 
his insulin injections. Lisa's childcare plan required that her class schedule and work schedule would allow her time to give the insulin injections and not miss class or work. However, she did not know what her work hours would be when she made the childcare plan.

Similarly, both Celeste and Mary had bills that were several months past due, but neither of them had contacted the companies they owed to make payment arrangements and assumed that the bills would somehow get paid. For example, Celeste had not received a bill for her car payment for two months and assumed that her step-father had made a three-month payment when he helped her with the payment. Celeste had not confirmed the payment with her step-father, nor had she checked with the bank. Both women were hoping for a positive outcome without having to take any action to correct the problem.

Avoidance

Lazarus and Folkman (1984) defined stress as an encounter with the environment that is appraised by the individual as stressful and threatening his or her wellbeing. One strategy to escape the situation that is appraised as threatening is to avoid the situation. Avoidance may occur through inaction, delegating the 
responsibility or an individual psychologically avoiding the situation.

Lisa, Ann, and Trina used avoidance as a strategy to resolve problems. Ann and Lisa both avoided contact with the police when they were raped. Ann rationalized that no one would believe her and Lisa feared that her some would remain in foster care. Trina also used avoidance as a strategy when confronted with the need to discipline her sons or when she and her future husband disagreed. Sarah, when confronted with a problem, avoided what she perceived as a problem until she has no other choice but to attempt to resolve the problem. Table 7 represents the coping strategies used by each study participant. 
Table 7

Participant Coping Strategies

Coping Strategy Used Participant

$\begin{array}{ll}\text { Prayer/Spirituality } & \begin{array}{l}\text { Desiree, Mary, Ann, Sarah, } \\ \text { Celeste }\end{array} \\ & \begin{array}{l}\text { Trina and Lisa mention prayer } \\ \text { but had no strong religious } \\ \text { affiliation }\end{array} \\ \text { Brainstorming/Writing } & \begin{array}{l}\text { Ann, Desiree, Celeste, and } \\ \text { Sarah }\end{array} \\ \text { Wishful Thinking } & \text { Celeste, Mary, Lisa } \\ \text { Avoidance } & \text { Trina, Sarah, Lisa, and Ann }\end{array}$

Summary

To establish validity of the findings, the researcher used multiple sources of data, provided clarification of the researcher's bias, and interviewed each participant three times. Glasser and Srauss, 1967; Lincoln and Guba, 1985; and Seidman, 2003, argued that the size of the sample is sufficient when there is data saturation and the researcher is no longer hearing new information. Data saturation was achieved with a sample size of seven. To increase the reliability or trustworthiness of the data the researcher provided rich descriptions of the data so that 
the reader could see how closely the narrative matched the data analysis.

Schlossberg's transition theory identified four factors that determine how an individual copes with change and transition: situation, self, support, and strategies.

Using Horn's 1996 characteristics of nontraditional students, welfare recipients in this study exhibited four or more of the described characteristics of being lowincome, delayed enrollment in college, financially independent, and the single parent of at least one child. Other barriers to persistence included competing demands of family and school, TANF work requirements, the lack of family, and limited coping skills.

The participant's significant history of sexual assault, rape and domestic violence as children placed them at risk of becoming victims of violence as adults (Heyman and Slep-Smith (2002). The intersection of domestic violence and welfare receipt increased the likelihood for increased anxiety, hopelessness, low-self esteem and emotion-focused coping skills (Schewe, Riger, Howard, and Staggs and Mason, 2006).

The primary support systems identified by the study participants were friends and community. Only two participants identified family as a source of emotional and 
financial support. The coping strategies used by the study participants included prayer/spirituality, brainstorming/writing, wishful thinking, and avoidance. 


\section{CHAPTER V}

This chapter discusses the findings from Chapter IV. The discussion is presented using the research questions which are based on Schlossberg's transition theory and the four factors that influence the ability of an individual to cope. The foundation of the transition theory is that personal appraisal of the change determines the meaning of the transition. How recipients respond to the changes in the welfare rules regarding college attendance, and how they adapt to the change depend on their previous coping strategies. To understand the meaning of the transition, one must consider the type of transition, the context of the transition, and the impact. According to Goodman, et al. (2006), Schlossberg (1984), and Schlossberg, et al. (1995) there are four major factors that influence how an individual copes with the transition. The four factors are: situation, self support and strategies. Self describes the demographic and psychological make-up of the individual. Situation describes what is happening with the individual. Support describes the individual's support system, and 
strategies identify the coping strategies used by the individual. The final section makes recommendations for higher education, welfare policy, and for future research.

\section{DISCUSSION}

- Question 1: What are the personal and demographic characteristics of the study participants?

Six of the participants were African-American and one was of Iranian/Caucasian descent. The participants ranged in age from 23 years old to 42 years old.

Four participants, Trina, Lisa, Desiree, and Mary had two children each. Three participants, Celeste, Ann, and Sarah had one child each. Two participants were pregnant, Sarah and Lisa.

Six participants had a history of childhood sexual abuse or rape, physical abuse, and domestic violence. Lisa, Desiree, and Trina had been victims of domestic violence. Trina, Mary, Sarah, and Ann had been victims of childhood sexual abuse. Mary and Sarah had been physically abused as children, and Ann and Lisa had been raped as adults.

Desiree and Ann had histories of drug and alcohol abuse, as well as criminal histories related to their substance abuse. Mary's criminal history was initially in 
response to her childhood physical and sexual abuse and the failure of her mother to protect her from the abuse.

Personal characteristics include socioeconomic status, gender age, stage of life and ethnicity that in turn influence worldview. Pearlin and Schooler (1978) defined psychological resources as the "personality characteristics that people draw upon to help them withstand threats" (p.5). Psychological resources include locus of control, ego development, values, and self-efficacy.

Personal characteristics affect how a person views life. Two persons may experience the same transition, but approach it differently dependent upon their level of maturity and frame of reference. According to Parker (1994), psychosocial coping resources, including a sense of control, help to buffer the effects of stress and contribute to economic self-sufficiency.

Bandura (1997) argued that self-efficacy was dependent upon whether an individual perceived the ability to control their behavior and environmental demands. Closely related to self-efficacy is perceived control. Folkman (1984) argued that coping responses are linked to perceived control and responses are either problem-focused or emotion-focused. Each study participant's response to stress and transitions, will be determined by her perceived 
control of the event, and if the event is viewed as a threat.

- Question 2: How do study participants view their current situation?

All seven participants described the feeling of being pulled in every direction by the demands of school, work, and parenting. Finding time to get everything done was a great source of stress. Ann's response best described how she and the other participants viewed the demands on their lives.

I'm working, I'm going to school, I'm pregnant, I'm parenting, and I attend the group meetings where I live. I feel like I am being pulled in different directions and have little or no time for myself, and I have no control. Sometimes I get flustered because I have no time for me. (A: L 103)

Rattner (2004), working as a welfare rights advocate in New York documented the stories of women with whom she worked who were welfare recipients attending the City University of New York. One student described being on welfare as being "stuck." The student felt helpless and had a great deal of anxiety regarding time limits and the inability to handle the pressure of home, school, and work requirements. No longer able to handle the stress, one 
student was admitted to the mental health unit of the hospital. Other students expressed a sense of desperation and flattened expectations in response to the demands of welfare reform. Similarly, one participant in the study sought counseling when she could no longer handle the demands of school, parenting, and the TANF work requirements.

While the participants felt stretched to the limit with caring for their children, and juggling classes and work, they felt that is was important to be a positive role model for their children.

The participants in this study also discussed the lack of control in their lives. The welfare system was viewed as a threat due to the demands of the work requirement, problems with recertification and the threat of the lost of benefits. Lisa faced problems obtaining a childcare assistance referral, and felt she was at the mercy of the welfare system and had no control. The study participants did not view childcare itself as a problem, but viewed the recertification process as time consuming. The caseworkers frequently lost paperwork or did not forward the necessary paperwork to the childcare provider. There were similar problems with the reimbursement for transportation. The new reauthorization of TANF required that welfare recipients 
document class attendance and study time. As a result, participants had to obtain the instructors signature after each class. If a signature is missed, the transportation reimbursement was reduced or delayed until the participant can provide the appropriate documentation. The participants found the process cumbersome and embarrassing:

Sometimes they don't want to sign, or they ask why. I don't have the heart to tell them it's for welfare. I just kind of mumble something and they sign it most of the time. It is already october and I was told today that they will send the August check, but the September check will be four hours short because I forgot to get a signature. If I can come up with a signature for those four hours, I can get paid. It's a mess. (T: L 201)

Similarly, McPhee and Bronstein (2003) found that the welfare recipients worried about the impending loss of benefits. They also viewed the policies as limiting their independence and viewed education as a way of gaining access to economic independence and respect from society. Grabowski (2006) also found that the welfare recipients complained about the restraints of the TANF system.

The participants in this study also complained about the limitations placed on them by the TANF requirements. Trina believed that she had only half of her lifetime eligibility for TANF remaining. To extend her eligibility, the previous year Trina obtained a student loan. She 
stopped her TANF check for the year and reapplied for TANF just prior to the start of fall classes. Celeste, Sarah, Desiree, and Mary also obtained school loans to extend TANF eligibility and eliminate the 20-30 hour a week TANF work requirement. The loans were counted as income by TANF which made them ineligible for cash assistance. Although the loans are counted as income, they remained eligible for food stamps and a medical card.

I try to manage it because I don't know how long it will take me to finish school. I do it for 2-3 months and I cut it off, I do it for 2-3 months and I cut it off. I just keep going back and forth, I'm sick of that too. The months that I'm not on TANF I live off my student loan. I still have my work-study money. I use my student loan to pay my mortgage up and pay my bills up to the next semester. So my work-study money I pay the phone bill or LGE, bills like that. ( $T$ : $\mathrm{L}$ 182)

The participants did not view themselves as permanent welfare recipients. Their status of being on welfare was the result of unplanned pregnancy. Desiree sought welfare as a way to support herself and her son when she left an abusive relationship. Some of the participants saw welfare receipt as an option to support themselves and at the same time earn a college degree. Five of the participants were at least 20 years old before they had their first child and two were in their thirties. Their primary identity of themselves was that of an employee, not a welfare 
recipient. The participants had work histories that ranged from 3-10 years. Sarah stated, "I guess my identity has always been what I do..." Similarly, Celeste felt that she was in control of her life when she worked full-time.

The participants identified their relationships with men while attending college as too distracting. Three of the four have made the decision not to be involved romantically while attending school. Mary and Celeste stated, "it's too distracting, and I just don't have the time." Desiree had been married twice and both spouses and all other relationships with men had been abusive. Desiree stated, "Too many distractions, I've never had a healthy relationship so I need to figure it all out."

Sarah had recently dissolved a relationship because she viewed it as dysfunctional. Lisa and Ann were both pregnant, but did not discuss their male relationships, but implied that the relationship had been primarily sexual. Given the high incidences of sexual assault, rape, and domestic violence, the avoidance of male relationships may be a coping mechanism.

The participants in this study described being pulled in every direction and problems with balancing home, school, work, having time for themselves, or time to spend with their children. 
The participants discussed problems with the recertification process for childcare payments. They described the welfare caseworker as not returning calls or losing paperwork, and scheduling recertification appointments during class time. The reauthorization of TANF mandated that caseworkers document the time that participants spend in class or tutoring. As a result, the participants were required to obtain the signature of their instructor or tutor. Participant's transportation payments were delayed or denied if a signature is missed. The participants found the requirement demeaning.

- Question 3: What support systems do the study participants use?

The convoy of social support suggested by Kahn and Antonnucci (1980) proposed that each person moved through life surrounded by a group of significant others giving and receiving support. The foundation of the framework is that the convoy surrounding the individual is the smallest circle at the center and contains the individual and close family members. The middle circle that is larger contains close friends and family relatives, and the roles in this circle are stable. The outermost circle was made up of community agencies, co-workers, and distant relatives. The 
roles in the outermost circles constantly change. Kahn and Antonnucci also identified the three functions of support: affect, affirmation, and aid/assistance.

The findings of this study indicated that the majority of the participants sought support primarily in the middle and outer circles, which included friends and community agencies. The women in this study sought emotional support and affirmation primarily from friends. Similarly, in a study by Wijnberg and Weiger (1998), the participants acknowledged receiving practical support more frequently than emotional support. Practical support was in the form of childcare, transportation, or housing assistance. However, although they did need such practical assistance, the participants in this study expressed a stronger need for emotional support to assist in the coping process.

Trina's mother assisted Trina with childcare and transportation, but at the same time, thought Trina was taking too long to finish school. Trina did not understand how her mother could be both supportive and negative at the same time. Research indicated that this type of relationship is a source of stress because Trina remained dependent upon her mother to provide childcare and transportation. Yet, Trina did not understand the lack of 
support regarding her college attendance, particularly since college had been a parental expectation.

Mary, Ann, and Sarah, also felt ambivalent about their relationships with their mothers. As victims of childhood sexual abuse, each of them felt abandoned by their immediate family members. Sarah did not tell her mother about the sexual abuse until she was older and her mother's response was ambivalent. Sarah indicated that she did not want to "continue hating" her mother. In Ann's case, Ann told both her mother and her grandmother and was accused of lying and seeking attention. Similarly, both Sarah and Mary's mother were aware of their abuse but allowed the abuse to continue until their relationship with the abuser ended. Both Ann and Mary had positive and negative feelings toward their mothers. As victims of physical and sexual abuse, they both felt abandoned by their mother. Similarly, Lisa was physically attacked by her mother and described her relationship with her mother as unhealthy. As a result, these participants developed support systems with friends rather than family.

As the individual evaluates the transition, the response is determined by the available social supports. Kalil, Born, Kunz and Caudill (2001) argued that it is important to help welfare recipients to extend their social 
networks and social communities to assist them in making the transition from welfare to work. Six of the participants described small support systems that provided primarily emotional and financial support. The support systems may need to be expanded to include a larger system to assist in the coping process.

- Question 4: What are the coping strategies that the participants use to alleviate stress? Coping strategies include the individual's response to transition. They are the repertoire of behaviors that are utilized to solve problems and alleviate stress. The participants used a variety of coping strategies; however, prayer was the most frequently used coping mechanism. Prayer or religious beliefs demonstrate the participant's response to stress and problems in their lives. Spilika, Shaver, and Kirkpatrick (1985) identified three reasons why religion is used to cope with stress: (a) to provide meaning to life, and (b) to create a feeling of more selfcontrol over the individual's life and circumstances, and (c) to increase self-esteem. The following statements by Mary demonstrate feelings of control and providing meaning:

But I just believe that God is always in control and I'm allowing him to lead me. (M: L 433) 
Mary spoke proudly of the impact of her relationship with God and how her life and lifestyle has changed. Ann also found strength and support from the church when she decided to stop using drugs. Sarah found spiritual support, and community support through her affiliation with the church.

Each of the participants expressed their involvement in religious activities or the use of prayer as a coping mechanism to deal with problems. Valentine \& Feinaur (1993) in a study of 22 victims of childhood sexual abuse found that the participants identified spirituality as a source of support that aided in the process of making meaning and provided inner strength. In this study, Sarah, Ann and Mary, all victims of sexual abuse made similar statements regarding their relationship with God and God providing meaning and direction for their lives.

Lazarus (1984) found that individuals that cope effectively use both problem-focused and emotion-focused strategies. Individuals typically cope by seeking information, taking direct action or taking no action or using intra-psychic behavior (denial, dreaming, or distortion). The ability to cope is a dynamic process that constantly changes throughout the process of appraisal. The 
type of strategy used depends on whether or not the situation can be changed.

The findings of this study indicated that the study participants used both problem focused coping and emotion focused coping strategies to resolve problems. As an example of problem-focused, coping Sarah took direct action by writing down out her problems and all the possible solutions. Desiree also used writing as a way of identifying the problem and the possible solutions.

Lisa provided an example of emotion focused coping behavior. Lisa felt isolated and that she had no one, and in response, she got the attention she craved by becoming involved in casual sexual relationships with no thought of protecting herself. She consequently became pregnant.

Ann and Sarah used both emotion focused coping and problem focused coping for resolving problems. Both women used emotion focused behaviors initially by using isolation and avoidance, and moved to problem focused coping by brainstorming possible solutions.

Trina, Lisa, and Ann all used avoidance or wishful thinking as a strategy to act as if problems did not exist. Their thought pattern was, if I do not think about it, the problem does not exist or there is a magical solution and the problem will resolve itself. 
Thomas (2002) studied former welfare recipients and found that 86 percent of the women used prayer and talking to mentors and friends as a method of coping. The women frequently sought out friends or other single mothers who were also pursuing the same goal. Negative coping behaviors included drug and alcohol abuse, isolation from others, dysfunctional relationships, eating and sleeping disorders, and perfectionist behaviors. Similar to the literature, both Ann and Desiree have a history of using drugs and alcohol as a way of coping with problems. Mary's response to the events in her resulted in negative coping behaviors such as stealing and selling drugs.

Arthur and Heibert (1996) studied the coping strategies of students during their first year of college. In response to familiar demands, the students used coping strategies they had used in the past. At times, the strategies were not effective, but the students continued to use what was familiar and were unable to develop new coping strategies. Some of the participants in this study have developed new coping strategies; both Desiree and Ann are no longer abusing alcohol and drugs. However, it appears that Lisa continues to use the same strategies. While her son was in foster care, Lisa met all the CPS requirements. However, once she was no longer under 
pressure Lisa reverted to avoidance as a problem solving strategy .

Similarly, Sarah described avoidance when she is initially faced with a problem, and only used brainstorming when she has no other choice. As Sarah progresses to the upper division of the nursing program she will be confronted with complicated medical situations that need immediate attention. Sarah will need to develop a more problem-focused strategy by the time she reaches the clinical portion of the nursing program.

\section{SUMMARY}

This study supported Schlossberg's transition theory. Schlossberg's theory described four factors that determine how the individual copes with change or stress. The four factors are self, situation, supports and strategies.

Cross (1981) argued that adult students face situation, institutional and dispositional barriers to completing education programs. The participants of the study faced multiple barriers which impacted their coping skills. Consistent with the research literature, six of the study participants had significant histories of sexual assault, rape or domestic violence. Carlson (1997) identified several barriers to self-sufficiency for low- 
income women that leave violent relationships as housing childcare, economic loss of income, and low social networks to provide material assistance. The barriers faced by victims of domestic violence are many of the same barriers faced by welfare recipients and adult students.

Cognitive appraisal is the process by which the study participants evaluated their individual situations. Lazarus and Folkman (1984) argued that an individual's appraisal of an event as positive or negative influence how the individual copes with an event. The participants in this study felt as if they were stretched to the limit with the responsibility of parenting, attending school, and meeting the TANF work requirements. The participants felt that they had very little control over their lives and little time for themselves.

Other sources of stress included meeting the TANF regulations for reimbursement for transportation and recertification for childcare assistance. Intimate partners were viewed as a source of stress and six of the participants were not involved in a male relationship due to the time demands and added stress. One participant that was engaged to be married viewed the relationship as stressful. To relieve the stress the participant participated in pre-marital counseling. Support systems 
provide emotional or tangible assistance that the individual receives when confronted with a stressful event. Support can come from four sources, family, friends, intimate partners, or community agencies. For the participants in this study the primary source of support came from friends and community agencies rather than intimate partners or family.

The participants coping strategies remained primarily on managing the immediate stress of their multiple roles. The support systems at home and on campus were inadequate for at least four of the study participants. Even though four of the participants had work-study positions on campus, only one identified contacts or relationships on campus outside the work-study position. It is significant that the two participants that were ready to graduate had established relationship on campus (Mary and Desiree) which may indicate that over time, the relationships on campus may develop.

Prayer and emotional support provided by friends appear to be the most significant coping strategies used by the participants. Five of the participants indicated that their first response to stress or problems was generally prayer. For the participants prayer or the religious 
affiliation provided meaning for their life and created a sense of control.

Other coping strategies identified were brainstorming/writing, wishful thinking and avoidance. Brainstorming/writing were problem-focused coping strategies that sought to identify the problem and possible solutions. Wishful thinking and avoidance were emotionfocused strategies that employed magical thinking or total avoidance of the problem. The participants that employed avoidance as a coping strategy may be at risk of not persisting in college.

\section{RECOMMENDATIONS}

Anderson (2003) argued that as the number of adult students attending college increases, so does the diversity of the student population. These changes create a number of challenges for colleges and universities. Colleges must provide programs and services to students whose age, background, and socioeconomic status are varied. Each student comes with a variety of learning styles and attendance patterns. To address these complex issues, and to provide programs and services that meets the needs of all students, postsecondary institutions must be aware of and understand the coping strategies used, and the 
obstacles faced by various student groups. Schlossberg, Lynch, and Chickering (1989) proposed creating an integrated environment to support adult students.

\section{RECOMMENDATIONS FOR HIGHER EDUCATION}

Rosenberg and McCullough (1981) conceptualized mattering as an important part of an individual's selfconcept and knowing that the individual is important to those around him or her. Schlossberg (1989) expanded the mattering theory to include marginality.

Schlossberg argued that when students feel marginalized they are less responsive to learning and are pre-occupied with belonging. Students that feel like they matter and belong are more likely to persist. Pascarella and Terenzini (1991) indicated that students are retained when students develop on-campus relationships. To increase student contact outside of the classroom the following recommendations are made:

1. Four of the study participants had work-study positions on campus, but only two participants made contact on campus outside of the work-study job and the classroom. An expanded work-study program that links the work-study job with the student's field of study will increase student contact outside the 
classroom. It would provide an opportunity for the student to interact with other persons interested in the same field of study and may result in a mentoring relationship with a faculty member. As students increase their contact with faculty, staff and students their circle of support increases which provides new avenues to support the student as they transition through the university.

2. Six of the participants in the study were victims of sexual assault or domestic violence and only one participant sought counseling services on campus. Increased promotion of counseling services and support groups on campus might encourage participation in support groups and aid in the development of new coping skills and promote student contact outside the classroom. Rosenberg and McCullough (1981) related the sense of belonging and mattering to the feeling that others are interested in the individual. Involvement in a campus support group will provide the opportunity to create a sense of belonging and mattering to others.

3. The development of a campus based childcare center that provides extended hours, drop-in services, and 
accepts childcare subsidies provide an opportunity for participants to spend more time on campus and less travel time for the participants.

4. The participants in this study used prayer/spirituality as their primary coping strategy. Watts (2003) used focus groups to study the role of spirituality in the lives of African American women in college. The development of programs or workshops that are intentional and supportive of the understanding and importance of religion in the identity development of students will provide an opportunity for students to explore their spirituality and incorporate it in their daily lives. The development of such programs and workshops on spirituality provide the opportunity for staff administering the program to explore their own spirituality and to become more sensitive to the needs of students.

5. Ann began to use writing/journaling shortly after she was raped as a way of expressing her anger and pain. Over the years, Ann has continued to write and now uses writing to identify solutions to problems. Desiree also wrote to identify solutions to problems. Desiree identified her writing as a coping skill 
because her primary method of coping for many years had been using drugs. Pennebaker (1997) suggested that when individuals write about personal issues or traumatic issues there are also significant improvements in physical and mental health. The development of a support group or program that uses journaling may assist students expressing anger and pain, as well as assist in the development of new coping skills that will have a positive impact on physical and mental health.

6. Two participants in this study were former drug users and were faced with learning how to take care of themselves and their health care needs. The development of health education programs that specifically target former addicts to assist them in learning to take care of themselves physically.

\section{RECOMMENDATIONS FOR WELFARE POLICY}

This study focused on the coping strategies of welfare recipients attending postsecondary institutions, however, issues related to welfare policy surfaced during the interviews. The study participants voiced the recommendations for welfare policy reform:

1. Allow participants access to four-year institutions. 
Current policy only approves two-year vocational institutions .

2. Train caseworkers to be sensitive to the needs of the individual client.

3. Develop a method of documenting class attendance that does not involve faculty signatures. Participants were penalized if the faculty refused to provide their signature. Requiring faculty signatures to document student attendance is a clash of two cultures. The welfare culture requires faculty to be accountable for student behavior, while the collegiate culture expects the student to be accountable for their own behavior.

4. Collaborate between postsecondary institutions and TANF to have a TANF caseworker on campus one day a week for completion of paperwork or recertification appointments. This collaboration will eliminate the need for students to miss classes for appointments.

5. Dotolo (2007) described collaboration between social service agencies, workforce recruitment, and colleges and universities in the Tidewater area of Virginia that provided services to low income adults interested in attending the postsecondary institutions in the 
consortium. A similar collaboration or consortium could be developed to provide basic education services, testing services, and counselors to identify the possible barriers to participation in college. The consortium could include the public high schools to assist students that have children in transitioning into the community college or 4-year institution. This integrated model of providing services for students as they move into and transition through and out of the postsecondary setting has the potential of increasing persistence.

\section{FUTURE RESEARCH}

Because the sample size is small, the findings of this study may not be representative of the coping strategies used by all welfare recipients attending postsecondary institutions. The following recommendations are suggested for future research:

1. Replication of this study with a larger more racially and ethnically diverse population that includes the few males that are welfare recipients.

2. A comparative study of female and male welfare use and caseworker interactions. 
3. A longitudinal study that identifies the coping strategies welfare recipient use over the course of their college career.

\section{CONCLUSION}

Prior to welfare reform, welfare recipients were allowed to attend postsecondary institutions without the penalty of losing benefits. With the passage of welfare reform laws, welfare recipients are now restricted to twelve months of vocational education. Those who struggle to remain in school will face multiple barriers and will need multiple coping skills to persist.

Adult students are the fastest growing population of college student and will continue to increase according to Anderson (2003). Further exploration of the coping strategies used by welfare recipients and other low-income women attending postsecondary institutions is needed. Aslanian (2001) indicated that the majority of adults pursue higher education because of a life event that results in change. The stress may be the result of a life event, the fear of failure or of the unknown, or negotiating an unfamiliar environment. Bridges (1980) and Schlossberg, Lynch and Chickering (1989) identified three phases in an educational transition: moving into the 
college environment, moving through it, and moving out. Each phase of the transition demands change, and each student experiences the change in response both old and new responsibilities. Welfare recipients, similar to adult and nontraditional students exhibit similar characteristics of being low-income, single parents, delayed entry, and working part-time. Each transition is a process, requiring a repertoire of coping skills that ultimately determine whether a student persists or develops new coping skills. Increased knowledge of welfare recipients and adult lowincome students and how they cope with change is important in the development of programs and services that meet the needs of this population of students.

The findings identified multiple personal and psychological barriers to persistence. The participants had histories of childhood sexual abuse, rape, and domestic violence. Friends and community agencies, rather than family, provided the primary sources of emotional and financial support. To extend TANF benefits participants used school loans circumventing Temporary Assistant for Needy Families (TANF) work requirement. Sources of stress included time management, problems with caseworkers and the recertification process and male relationships. The study found that prayer/ spirituality was the primary coping 
strategy used by all the participants. Other coping strategies included brainstorming/writing, avoidance, and wishful thinking.

Schlossberg's transition theory places the emphasis on the individual student's view of his or her own situation. Because the emphasis is on the individual's situation, it allows for individual cultural differences. While programs and services cannot be individualized to meet the needs of the student as an individual, programs and services can be developed that take in consideration the needs of adult college students as they transition in, through and out of postsecondary institutions. 


\section{REFERENCES}

Abramovitz, M. (2000). Under attack, fighting back: Women and welfare in the United States (2nd ed.). New York: Monthly Review Press.

Adams, Gina \& Rohacek, M. (2002, February). Child care and welfare reform. Retrieved January 20, 2007 from WW. brookings . edu/wrb.

Allard, M. A. (1997). In harm's way? Domestic violence, AFDC receipt, and welfare reform in Massachusetts. Boston: University of Massachusetts at Boston.

Anderson, E. L. (2003, Spring). Changing U.S. demographics and American higher education. New Directions for Higher Education, No. 121, 3-12.

Anderson, R. J. (1993). Adapting to retention: A naturalistic study revealing the coping resources of non-promoted students and their parents. Proquest Dissertation and Thesis, 54/03. (UMI 9329824). Applied Research Center, (2001). Welfare reform as we know it. Oakland CA: Applied Research Center. 
Arthur, N. \& Heibert, B. (1996). Coping this transition to postsecondary education. Canadian Journal of Counseling, 30(2) 93-103.

Aslanian, C. B. (2001). Adult students today. New York: The College Board.

Aslanian, C. B., \& Brickell, H. M. (1980). Americans in transition: Life changes as reasons for adult learning. New York: College Entrance Examination. Austin, S. A., \& McDermott, K. A. (2003-2004). College persistence among single mothers after welfare reform: An exploratory study. Journal of College Student Retention, 5(2), 93-113.

Bandura, A. (1997). Self-efficacy: The exercise of control. New York: W. H. Freeman and Company. Bania, N., Coulton, C. \& Leete, L. (1999). Welfare reform and access to job opportunities in the Cleveland metropolitan area. Working Paper for the Center for Urban Poverty and Social Change, Cleveland $\mathrm{OH}$ : Case Western Reserve University.

Besharov, D. J., \& Germanis, P. (2000). Welfare reform: Four years later. Retrieved November 25, 2006, from http://welfareacademy.org/pubs/welfare/four_yea.html

Bok, M. (2004). Education and training for low-income women: An elusive goal. Affilia, 19(1), 39-52. 
Bowie, M. A. (2001). Women moving on from graduate school. Proquest Dissertation and Thesis, 39/03, (UMI 54606).

Brammer, L. M., \& Abrego, P. J. (1981). Intervention strategies for coping with transition. The Counseling Psychologist, 9(2), 19-34.

Bridges, W. (1991). Managing transition: Making the most of change ( $1^{\text {st }}$ ed.). Cambridge MA: Perseus.

----(2003). Managing transition: Making the most of change ( $2^{\text {nd }}$ ed.). Cambridge MA: Perseus.

----(1980). Transitions: Making sense of life's changes. Reading, MA: Perseus Books.

Brown, S. G., \& Barbosa, G. (2001). Nothing is going to stop me now: Obstacles perceived by low-income women as they become self-sufficient. Public Health Nursing, $18(5), 364-372$.

Brown V. L. \& Riley, M. A. (2005). Social support, drug use, and employment among low-income women. The Journal of Drug and Alcohol Abuse, 31, 203-223.

Browne, A., \& Bussuk, S. S. (1997). Intimate violence in the lives of homeless and poor houses women: Prevalence and patterns in an ethnically diverse sample. American Journal of Orthopsychiatry 67 (2), 262-278 . 
Browne, A., Salomon, A. \& Bassuk, S. S. (1999, April). The impact of recent partner violence on poor women's capacity to maintain work. Violence Against Women $5(4), \quad 393-426$.

Bundy, A. P. (2004). Rural women in career transition: A look at Schlossberg's 4Ss, situation, self, support, and strategies. Proquest Dissertation and Thesis, 65/03. (UMI 3126770).

Butler, S. S., \& Deprez, L. (2002). Something worth fighting for: Higher education for women on welfare. Affilia, 17(1), 30-54.

Caplan, G. (1976). The family as a support system. In G. Caplan, \& M. Killilea (Eds.), Support systems and mutual help: Multidisciplinary exploration (pp. 1936). New York: Green Stratton.

Carlson, B.E. (1997). A stress and coping approach to intervention with abused women. Family Relations, 46 (3), 291-299 .

Carnevale, A. P., Reich, K., Johnson, N. C., \& Sylvester, K. (2000). A piece of the puzzle: How states can use education to make work pay for welfare recipients. Retrieved October 15, 2001, from http://ets.org/publications 
Center for Women Policy Studies, (2004). A profile of lowincome women students in postsecondary educational institutions. Retrieved April 2, 2005 from http://WwW.centerwomenpolicy.org/report. cfm?ReportID=94 Center for Women Policy Studies, (1999). Analysis of TANF regulations. Retrieved 0ctober 15, 2003, from http:// WWW. centerwomenpolicy.org/pdf/pov3/pdf

Charner, I., \& Schlossberg, N. K. (1986). Variations by theme: The life transitions of clerical workers. Vocational Guidance Quarterly, 34, 212-224.

Christopher, K. (2005, September). Welfare recipients attending college: The interplay of oppression and resistance. Journal of Sociology and Social Welfare $32(3), \quad 165-185$.

Cohen, M. (1998). Postsecondary education under welfare reform. Welfare Information Network Issue Notes, 2 (8). Retrieved May 21, 2001, from WwW. financeprojects.org/publications/vocational\%20ed.h $\operatorname{tml}$

Colbry, S. (1995). Predicators of general well-being among female single parent college students. Journal of Divorce \& Remarriage, 23(3-4), 113-126. 
Communications Workers of America, (2006, March 02). TANF reauthorization: 109th Congress reauthorizes temporary assistance program contentious welfare legislative process concludes. Retrieved December 6, 2006, from Ww. cwa-legislative.org/fact sheets/page $\cdot$ jsp?itemID $=27482970$

Compas, B.E. \& Orosan, P. (1993). Cognitive appraisal and coping with stress. In B. C. Long \& S. E. Kahn (Eds.), Women, work and coping: A multidisciplinary approach to workplace stress. (pp. 219-237). Montreal Canada: McGill-Queens University Press.

Cox, K. L., \& Spriggs, W. E. (2002). The negative effects of TANF on college enrollment. Washington DC: National Urban League Institute for Opportunity and Equality.

Creswell, J. W. (1994). Research design: Qualitative \& quantitative approaches. Thousand Oak, CA: Sage Publications.

Creswell, J. W. (2003). Research design: Qualitative, quantitative, and mixed methods approaches ( $2^{\text {nd }}$ ed.). Thousand Oak, CA: Sage Publications. Cross, K. P. (1981). Adult as learners: Increasing participation and facilitating learning. San Francisco: Jossey-Bass . 
D'Ecrole, A. (1988, January). Single mothers: Stress, coping, and social support. Journal of Community Psychology, 16, 41-54.

Diehl, A. and Prout, M. (2002). Effects of posttraumatic stress disorder and childhood sexual abuse on selfsufficiency development. American Journal of Orthropsychiatry, 72 (2), 262-265.

Dotolo, L. G., (2007, Summer). Working with social service agencies: Providing access for the underserved. New Directions for Higher Education. No 138, 35-42.

Ebaugh, H. R. F. (1988). Becoming an ex: The process of role exit. Chicago: University Press of Chicago. Edin, K. \& Lein, L. (1997). Making ends meet: How single mothers survive welfare and low wages. New York: Russell Sage Foundation.

Evans, N. J., Forney, D.S. \& Guido-DiBrito, F. (1998). Student development in college: Theory research and practice ( $1^{\text {st }}$ ed.). San Francisco: Jossey-Bass.

Farel, A. M. \& Dobelstein, A. W. (1982, April). Support and deterrents for mothers working outside the home. Family Relations, 32(2), 281-286. 
Frank, A. (2006, December 12). Increasing opportunities: Creating and expanding transitional job programs for TANF recipients under the deficit reduction act. Retrieved January 13, 2006, from http://www.clasp.org/publications/increasing_opportunt ies.pdf

Friedman, P. (1999). Postsecondary options for low-income adults. Welfare Information Networks Issue Notes, 3 (12), Retrieved May 15, 2001, from http://welfareinfo.org/postseced2.htm.

General Accounting Office, (1998, May). Welfare reform transportations role in moving from welfare to work. Retrieved November 5, 2001 from: http://gao.gov/archive/1998/re98161.pdf .

Glaser, B. G. \& Stauss, A. S. (1967). The discovery of grounded theory: Strategies for qualitative research. New York: Aldine Transaction.

Glesne, C. (1999). Becoming a Qualitative Researcher: An introduction $\left(2^{\text {nd }}\right.$ ed. $)$. New York: Longman . Gilen, M. (1999). Why Americans have welfare: Race, media, and the politics of anti-poverty policy. Chicago: University of Chicago Press. 
Gill, W. J. (2001). Stress and coping experiences of women in transition: From welfare to work. Proquest Dissertation and Thesis,63/02. (UMI 3042687). Golonka, S., \& Matus-Grossman, L. (2001). Opening doors: Expanding educational opportunities for low-income workers. Retrieved 0ctober 9, 2001, from WWW.nga.org/center/divisions/1,1188,C_ISSUE_Brief^D_21 51.00.html.

Goodban, N. (1985). The psychological impact of being on welfare. Social Service Review, 59, 403-422. Goodman, J., \& Pappas, J. G. (2000). Applying the Schlossberg 4Ss transition model to retired university faculty: Does it fit? Adultspan Journal, 2, 15-28. Goodman, J., Schlossberg, N. K. \& Anderson, M. (2006). Counseling adults in transition: Linking theory to practice $\left(3^{\text {rd }}\right.$ ed). New York: Springer Publications. Goodwin, J. L. (1995, Winter). 'Employable mothers' and 'suitable work': A reevaluation of welfare and ageearning for women in the twentieth-century United States, Journal of Social History, 29(2), 253-274. Gordon, L. (1994). Pitied but not entitled: Single mothers and the history of welfare ( $1^{\text {st }}$ ed.). New York: Free Press 
Grabowski, L. J. (2006). It still don't make it feel like you're doin it: Welfare reform and perceived economic efficacy. Journal of Poverty, 10(3), 69-91.

Graham, P.K. (1994). From an adult viewpoint: The transition from non-student to student status. Proquest Dissertation and Thesis, 54/10. (UMI $9407149)$.

Greenburg, M., Strawn, J., \& Plimpton, L. (2000). State opportunities to provide access to postsecondary education under TANF. Center for Law and Social Policy.

Hagan, J. L. (1998, Nov/Dec). The new welfare law: Tough on work. Families in Society, 79(6), 596-605.

Haveman, R. (1997). Potentials and problems of a pre-post design for state-based evaluation of national welfare reform. Madison WI: Paper presented at the Evaluation Comprehensive State Welfare Reform: A Conference, Institute for Research on Poverty. Hayes, E. (1999). Policy issues that drive the transformation of adult literacy. In L. G. Martin, \& J. C. Fisher (Eds.), New directions for adult and continuing education: The welfare-to-work challenge for adult literacy educators (pp. 3-14). San Francisco: Jossey-Bass. 
Heyman, R. E. \& Slep-Smith, A. M. (2002). Do child abuse and interpersonal violence lead to adulthood family violence? Journal of Marriage and Family, 64 (4),864870.

Home, A. M. (1998, Winter). Predicting role conflict, overload and contagion in adult university students with families and jobs. Adult Education Quarterly, 48 (2), 85-98.

Hopson, B. (1981). Response to the papers by Schlossberg, Brammer \& Abrego. The Counseling Psychologist, 9 (2), 36-39 .

Horn, L. (1996). Nontraditional undergraduate: Trends in enrollment from 1986 to 1992 and persistence and attainment among 1989-90 beginning postsecondary students (NCES 97-578). Washington, DC: U.S. Department of Education, National Center for Education Statistics.

Horn, L., Cataldi, E. F., Sikora, A. (2005). Waiting to attend college: Undergraduates who delay their postsecondary enrollment (NCES 2005152). U. S. Department of Education. National Center for Education Statistics. Washington D. C.: U. S. Government Printing office. 
Illinois Welfare New (1999a, February). Postsecondary education opens up for TANF recipient. Retrieved October 22, 2001 from http://povertylaw.org/advocacy/iwn/iwnarticle. Illinois Welfare New, (1999b, August). IDHS's policies, practices undermine new program meant for TANF recipients to pursue postsecondary education. Retrieved October 22, 2001 from http://povertylaw.org/advocacy/iwn/iwnarticle Imel, S. (2000). Welfare to work considerations for adult and vocational education programs (Report No. 216). Clearinghouse on Adult, Career, and Vocational Education, ERIC Digest EDO-CEO९216. Jacobs, J. A., \& Winslow, S. (2003). Welfare reform and enrollment in postsecondary education. Annals of the American Academic of Political and Social Science, $586,194-217$.

Jarrett, R. L. (1996), Welfare stigma among low-income single parent African-American women. Social Problems, $45(1), 30-49$. 
Johnson, C. M. \& Kaggwa, E. (1998, August). Work-study programs for welfare recipients: A job creation strategy that combines work and education. Center on Budget and Policies \& Priorities. Retrieved october 22, 2001 from http://clobpp.org/8-19wtw.

Kahn, K. (1998, October). Workfare forces single mothers to abandon college education. Sojourner Feminist Institute, 24 (2), 31-32.

Kahn, P., \& Polakow, V. (2000, May). Getting smart about welfare: Policy research on the impact of welfare reform on low-income women enrolled in college. Retrieved October 6, 2001, from http://umich. edu cew/pubs/PolakowKahn2000.pdf -.--(2004). That's not how I want to live. In V. Polakow, S. S. Butler, L. S. Deprez, \& P. Kahn (Eds.), Shutout: Low income mothers and higher education in postwelfare America (1st ed., pp. 75-96). Albany, NY: State University of New York Press.

Kahn, R. L., \& Antonucci, T. C. (1980). Convoys over the life course: Attachments, roles and social support. In P. B. Battles, \& 0. G. Brim (Eds.), Lifespan development and behavior, (383-405). New York: Academic Press. 
Kalil, A., Born, C. E., Kunz, J., \& Caudill, P.J. (2001). Life stressors, social support and depressive symptoms in first time welfare recipients. American Journal of Community Psychology, 29 (2), 355-367.

Karier, T. (2000). Welfare college students: Measuring the impact of welfare reform. The Jerome Levy Economics Institute Retrieved May 15, 2001, from http://levy.org/docs/pn/๑९-3.html.

Kates, E. (1993). Access to higher education project (1st ed.). Northampton, MA: Smith College.

-.--(1998). Closing doors: Declining opportunities in education for low-income women. Waltham, MA: Welfare Education Training Access Coalition, Heller School, Brandies University.

-... (2004). Debunking the myth of the failure and training for welfare recipients: A critique of research. In V. Polakow, S.S. Butler, L.S. Deprez, \& P. Kahn (Eds.) Shut-out: Low income mothers and higher education in post-welfare America (1st ed., pp. 19-43). Albany, NY: State University of New York. 
Kaufmann, S.W., Sharp, S., Miller, J. E. \& Waltman, J. (2000, June). Michigan: A smart state for woman? Women and higher education. University of Michigan Center for Education of Women. Retrieved 0ctober 5, 2001 from http://umich . edu/ cew.

Kerbo, H. (1976). The stigma of welfare and a passive poor. Sociology and Social Research, 60(2), 173-187.

Kunz, J. \& Kalil, A. (1999). Self-esteem, self-efficacy, and welfare use. Social Work, 23(2), 119-126.

Lazarus, R. S., \& Folkman, S. (1984). Stress and appraisal of coping. New York: Springer Publishing.

LeCompte, M. D. \& Preissle, J. (1993) Ethnography and qualitative design in educational research $\left(2^{\text {nd }} \mathrm{ed.}\right)$ San Diego, CA: Academic Press.

Lincoln, Y. S. \& Guba, E. G. (1985). Naturalistic inquiry. Beverly Hills CA: Sage Publications.

Littleton, H. \& Breitkopf, C. R. (2006). Coping with the experience of rape. Psychology of Women Quarterly, 30, $106-116$. 
London, R. (2004). Welfare recipients' college attendance and consequences of time-limited aid. Center for Justice, Tolerance and Community Working Paper. University of California Santa Cruz. Retrieved December 20, 2004, from http:/respositories.cdlib.org/cjtc/pis/cjtc_RL_2004_01 Macari, D. P., Maples, M. F., \& De'Andrea, L. (2005-2006). A comparative study of psychosocial development in nontraditional and traditional college students. Journal of College Student Retention, 7 (3-4), 283-302 Marshall, C. \& Rossman, G. B. (1999). Designing qualitative research. Newbury Park, CA: Sage. Maxwell, J. A. (1996). Qualitative research design: An interactive approach. Thousand Oaks: Sage. Mazzeo, C., Rab, S., \& Eachus, S. (2003). Work-first or work-only: Welfare reform, state policy and access to postsecondary education. Annuals of the American Academy of Political and Social Science, 586, 144-171. Mcclary, S. A. (1990). Stress, coping and adult education. In M. H. Rossman \& M. E. Rossman (Eds.) New Directions for Adult and Continuing Education, No. 45 (pp. 65-75). San Francisco: Jossey Bass. 
McPhee, D. M. \& Bronstein L. R. (2003, Spring). The journey from welfare to work: Learning from women living in poverty. Affilia 8(1), 34-48.

Meisenhelder, J.B. \& Marcum, J.P. (2004). Responses to

9/11: Posttraumatic stress, coping and religious outcomes. Journal for the Scientific Study of Religion $43(4), \quad 547-554$

Mercer, R. T., Nichols, E. G., \& Doyle, G. C. (1989). Transitions in a woman's life: Major life events in developmental context. New York: Springer Publishing. Merriam, S. B. (1998).Qualitative research and case study applications in education. San Francisco: Jossey-Bass. Merriam, S. B., \& Clark, M. C. (1991). Lifelines: Patterns of work, love and learning in adulthood. San Francisco: Jossey-Bass.

Miles, M.B. \& Huberman, A. M (1994). Qualitative data analysis: An expanded sourcebook. Thousand Oaks: Sage Mingle, J. R. \& Birkes, A. Y., (2004). Targeting the adult learning challenge in SREB states. Challenge to Lead Southern Regional Education Board. 
Mitchell, T. (2003). If I survive it will be despite welfare reform: Reflections of a former welfare recipient. In V. C. Adair, \& S. L. Dahlberg (Eds.), Reclaiming class: Women poverty and the promise of higher education in America (1 ${ }^{\text {st }}$ ed., pp. 113-118). Philadelphia: Temple University Press.

Moos, R. H., \& Tsu, V. (1976). Human competence and coping: An overview. In R. H. Moos (Ed.), Human adaptation: Coping with life crises (1st ed., pp. 13). Lexington MA: Heath.

Ntiri, D. W. (2000). The transition of female family heads of household from welfare to work: Implications for adult education. The Western Journal of Black Studies, $24(1), 34-42$.

Neubeck, K. J., \& Cazenave, N. A. (2001). Welfare racism: Playing the race card against America's poor (1st ed.). New York: Rutledge.

Padgett, D. K. (1998). Qualitative methods in social work research: challenge and rewards. Thousand Oaks, CA: Sage Publications.

Pandy, S. ,Zahn, M., Neeley-Barnes, S. \& Menon, N. (2000, December). The higher education option for poor women with children. Journal of Sociology and Social Welfare, 27, 109-170. 
Parker, L. (1994, April). The role of workplace support in facilitating self-sufficiency among single mothers. Family Relations, 43(1), 168-173.

Parkes, C. M. (1971). Psycho-social transitions: A field for study. Social Science and Medicine, 5, 105-115. Pascarella,E. \& Terenzini, P.T (1991). How college affects students: Findings and insights from twenty years of research. San Francisco: Jossey-Bass.

Patterson, J. T. (1996). America's struggle against poverty (1 $1^{\text {st }}$ ed.). Cambridge, Massachusetts: Harvard University Press.

Patton, M. (1990). Qualitative evaluation and research Methods ( $2^{\text {nd }}$ ed.). Newbury Park, CA: Sage Publications .

-.-(2001). Qualitative evaluation and research methods ( $3^{\text {rd }}$ ed.). Newbury Park, CA: Sage Publications Pearlin, L. I., \& Schooler, C. (1978). The structure of coping. Journal of Health and Social Behavior, 19(1), 2-21.

Pearson, R. E. \& Petitpas, A. J. (1990). The transition of athletes: Developmental and preventative perspectives. Journal of Counseling, 69, 7-10. 
Pennebaker, J.W. (1997). Opening up: The healing power of confiding in others. New York: William Morrow.

-.--(1997). Writing about emotional experiences as a therapeutic process. Psychological Science, 8, 162166.

Piven, F. F., \& Cloward, R. A. (1993). Regulating the poor: the function of public welfare $\left(2^{\text {nd }}\right.$ ed.). New York: Vintage Books.

Quadagno, J. (1994). The color of welfare: How racism undermined the war on poverty ( $1^{\text {st }}$ ed.). New York: Oxford University Press.

Rattner, L. (2004). Failing low income students: Education and training in the age of welfare reform. In $\mathrm{V}$. Polakow, S.S. Butler, L.S. Deprez, \& P. Kahn (Eds.) Shut-out: Low income mothers and higher education in post-welfare America (1 $1^{\text {st }}$ ed., pp. 45-74). Albany, NY: State University of New York.

Rice, J. K. (1993). Back to school: Women, welfare, and access to higher education. Adult Learning, 4(5), $10-13$ 
Rock, T. P. (2002). Thresholds to success: An analysis of the college admission process as an elite private secondary school and an aspiring public school in an urban setting. Proquest Dissertation and Thesis, 63/05 (UMI 3052909).

Rodgers, H. R. (1990). Poor women, poor families: The economic plight of America's female-headed households (2nd ed.). New York: M. E. Sharpe, Inc.

Rodin, J. (1990). Control by any other name: Definitions concept and processes. In J. Rodin, C. Schooler, \& K.W. Schaie (Eds.), Self-directedness: Cause and effects throughout life course (p. 1-17). Hillsdale, $\mathrm{NJ}$ : Lawrence Erlbaum Associates.

Rosenberg, M., \& McCullough, B. (1981). Mattering: Inferred significance and mental health among adolescents. Research in Community and Mental Health, 2, 163-182. Ross, G. J. M. (1992) AFDC mothers at college: A study of low income mothers as returning students. Unpublished doctoral dissertation, Indiana University.

Sargent, A. G. \& Schlossberg, N. K. (1988). Managing adults in transitions. Training and Development Journal, 41, $58-60$. 
Sargent Shriver National Center on Poverty Law, (2006, July). New TANF rules: Less flexibility, more red tape. Retrieved December 5, 2006, from http://www. povertylaw.org/news-and-events/povertyaction-report/2006-july/new-tanf-rules .

Schewe, P., Riger, S., Howard, A., Staggs, S. L. and Mason, G.E. (2006). Factors associated with Domestic violence and sexual assault victims. Journal of Family Violence, 21, 469-475.

Schlossberg, N. K. (1981). A model for analyzing human adaptation to transition. The Counseling Psychologist, $9(2), 2-18$.

-.--(1984). Counseling adults in transition: Linking theory to practice (1st ed.). New York: Springer Publishing.

-.--(1989). Marginality and mattering: Key issues in building community. New Directions for student Services, 48, 5-15.

Schlossberg, N. K., Lynch, A. Q., \& Chickering, A. W. (1989). Improving on higher education environments for adults. New York: Jossey-Bass.

Schlossberg, N. K., Waters, E. B., \& Goodman, J. (1995). Counseling adults in transition: Linking theory to practice $\left(2^{\text {nd }}\right.$ ed.). New York: Springer Publishing. 
Schram, S. F. (1995). Words of welfare: The poverty of social science and the social science of poverty $\left(1^{\text {st }}\right.$ ed.). Minneapolis: University of Minnesota Press.

Seccombe, K. (1999). So you think I drive a Cadillac:

Welfare recipients' perspectives on the system and its reform. Boston: Allyn \& Bacon.

Seidman, I. E. (2003). Interviewing as qualitative research: A guide for researchers in education and the social sciences ( $3^{r d}$ ed.). New York: Teachers College Press.

Shaw, K. M., Goldrick-Rab, S., Mazzeo, C., \& Jacobs, J. (2006). Putting poor people to work (1 $\left.1^{\text {st }} \mathrm{ed}.\right)$. New York: Russell Sage Foundation.

Skocpol, T.,Abend-Wein, M., Howard, C., Lehmann, S. G. (1993, Sept.). Women's associations and the enactment of Mothers' Pensions in the United States. The American Political Science Review, 87(3), 686-701. Spilka, B., Shaver, P. \& Kilpatrick, L. (1985). A general attribution theory for the psychology of religion. Journal of the Scientific Study of Religion, 24, 1-20. State Policy Documentation Project (2000). Work requirements: Postsecondary education. Center for Law and Social Policy, Retrieved May 15, 2006 from http:// WwW.spdp.org/tanf/postsecondary.PDF. 
Stenson, J. A. (1989). The effects of social support on the well-being of single-mothers enrolled in a rural community college. Proquest Dissertation and Thesis, 50/05. (UMI 8918709).

Strawn, J., (2000, February). Workforce development for the unemployed and low-wage workers: The role of postsecondary education. Center for Law and Social Policy, Retrieved May 15, 2001 from http:// clasp.org.pubs/jobseducation/lowwagesandpostsecond arydraft.html.

Stone, V. N., Nelson, J. R., \& Nieman, J. (1994). Poor single-mothers college students' views on the effects of some primary sociological belief factors of their academic success. Journal of Higher Education, 65(5), $571-583$.

Sugarman, L. (1986). Life-span development: Concepts, theories and interventions (1st ed.). New York: Methuen.

Taylor, S.E. \& Armor, D.A. (1996). Positive illusions and coping with adversity. Journal of Personality 64 (4) 873-898. 
The Education Resources Institute [TERI] (1997). Missed opportunities: A new look at disadvantaged college aspirants. Boston: Higher Education Information Center .

Thoits, P. A. (1986). Social support as coping assistance. Journal of Consulting and Clinical Psychology, 54, $426-423$.

Thomas, R. A. (2002). African-American women: From welfare to professional careers. Proquest Dissertation and Thesis, 63/05. (UMI 3053019).

U.S. Department of Health and Human Services, Administration for Children, (2006). Temporary assistance for needy families active caseload. Retrieved November 1, 2007 from http:// WWW.acf, hhs.gov/programs/ofa/charcter/FY2006/tab41.htm U.S. Department of Health and Human Services (1998). HHS fact sheet: The Personal Responsibility and Work Reconciliation Act of 1996. Retrieved June 10, 2006, from http://www.acf.dhhs.gov/programs/csenew/prwora Valentine, L. \& Feinaur, L.L. (1993) Resilience factors associated with female survivors of childhood sexual abuse. American Journal of Family Therapy, 21(3), 216224. 
Waechler, E. (1974). The developmental model. In M. E. Kalkman, \& A. J. Davis (Eds.), New dimensions in mental health nursing (pp. 31-57). New York: McGrawHill.

Wider Opportunities for Women, (2006, October). TANF implementation: What are states doing? Retrieved January 3, 2006, from http:// WWW.clasp.org/publications/tanf_participation_rate_str ucture.pdf

Wiesenberg, F. (2001, Fall). The roller coaster life of online learners: How distance educators can help students cope. Canadian Journal of University Continuing Education, 27 (2), 33-59.

Wijnberg, M.H. \& Reding, K. M., (1999, Sep/Oct). Reclaiming a stress focus: The hassles of rural, poor single mothers. Families in Society: The Journal of Contemporary Human Services, 80(5), 506-515. Wijnberg, M. H. \& Weinger, S., (1998, March/April). When dreams with and resources fail: The social support of poor single mothers. Families in Society: The Journal of Contemporary Human Services, 79(2), 212-219. 
Wolf, L. R., \& Tucker, J. (2001a). Clipping our wings: The impact of welfare reform on the aspirations of lowincome women. Washington DC: Center for Women Policy Studies.

----(2001b). Getting smart about welfare: Policy research on the impact of welfare reform on low-income women enrolled in college. Center for Women Policy Studies. Retrieved 0ctober 7, 2001 from http://centerwomenpolicy.org Yin, R. K. (1994). Designing case studies. In R. K. Yin Case study research: Design and methods (Eds.) ( $2^{\text {nd }}$ ed). Thousand Oaks: Sage Publications. ---(2003). Applications of case study research ( $2^{\text {nd }}$ ed.) Thousand Oaks: Sage Publications. 


\section{APPENDICES}


Appendix A

INFORMED CONSENT

\section{Introduction and Background Information}

You are invited to participate in a research study. The study is being conducted by Michael J. Cuyjet, Ed.D and Kathy J. Pendleton, doctoral candidate. The study is sponsored by the University of Louisville, Department of Educational and Counseling Psychology and is part of a dissertation to be submitted as partial fulfillment of the requirements for the degree of Doctor of Philosophy. The study will take place home of the study participant or where the participant feels the most comfortable. Approximately 5-7 subjects will be invited to participate.

\section{Purpose}

The purpose of this study is to identify the coping strategies used by welfare recipients attending college.

\section{Procedures}

In this study, you will be asked to complete a demographic questionnaire that will take approximately five minutes to complete. You will also be asked to participate in at least three (3) interviews sessions. Each interview will last 6090 minutes. The interview sessions will be audiotape recorded and transcribed. The researcher will also take brief notes during each session. You will have the opportunity to review the information gathered and to provide feedback to the researcher during the last interview session.

\section{Potential Risks}

There are no foreseeable risks other than possible discomfort in answering personal questions.

\section{Benefits}

The possible benefits of this study will aid in the understanding of how welfare recipients cope with the transitional nature of the welfare laws as well as attend college. The information collected may not benefit you 
directly. The information learned in this study may be helpful to others.

\section{Compensation}

You will be compensated for your time, inconvenience, or expenses for your participation in this study. You will receive $\$ 10.00$ at the completion of each interview.

\section{Confidentiality}

Total privacy cannot be guaranteed. Your privacy will be protected to the extent permitted by law. If the results from this study are published, your name will not be made public. While unlikely, the following may look at the study records by the University of Louisville Institutional Review Board, Human Subjects Protection Program Office, or $\mathrm{Dr}$. Michael Cuyjet, principle investigator. The data will remain in a locked file cabinet or on a password-protected computer.

\section{Conflict of Interest}

This study involves no conflict of interest

\section{Voluntary Participation}

Taking part in this study is voluntary. You may choose not to take part at all. If you decide to be in this study you may stop taking part at any time. If you decide not to be in this study or if you stop taking part at any time, you will not lose any benefits for which you may qualify.

\section{Research Subject's Rights, Questions, Concerns, and Complaints}

If you have any concerns or complaints about the study or the study staff, you have three options.

1. You may contact the principal investigator at 502-8526495.

2. If you have any questions about your rights as a study subject, questions, concerns, or complaints, you may call the Human Subjects Protection Program Office (HSPPO) (502) 852-5188. You may discuss any questions 
about your rights as a subject, in secret, with a member of the Institutional Review Board (IRB) or the HSPPO staff. The IRB is an independent committee composed of members of the University community, staff of the institutions, as well as lay members of the community not connected with these institutions. The IRB has reviewed this study.

3. If you want to speak to a person outside the University, you may call 1-877-852-1167. You will be given the chance to talk about any questions, concerns or complaints in secret. This is a 24-hour hot-line answered by people who do not work at the University of Louisville.

This paper tells you what will happen during the study if you choose to take part. Your signature means that this study has been discussed with you, that your questions have been answered, and that you will take part in the study. This informed consent document is not a contract. You are not giving up any legal rights by signing this informed consent document. You will be given a signed copy of this paper to keep for your records.

Signature of Subject/Legal Representative

Date Signed

Signature of Person Explaining the Consent Form Date Signed (if other than the Investigator)

LIST OF INVESTIGATORS

Kathy J. Pendleton
PHONE NUMBERS

$502-852-0285$ 


\author{
APPENDIX B \\ Letter of Introduction
}

Date

Dear

You are being invited to participate in a research study about the coping strategies used by welfare recipients attending college. There are no known risks for your participation in this research study. The information collected may not benefit you directly. The information learned in this study may be helpful to others. The information you provide will used to complete research for a doctoral dissertation. Your completed interviews will be stored at locked file at the University of Louisville. The three interviews will take approximately one hour to one and a half hours time to complete.

Individuals from the Department of Education and Counseling Psychology, the Institutional Review Board (IRB), the Human Subjects Protection Program Office (HSPPO), and other regulatory agencies may inspect these records. In all other respects, however, the data will be held in confidence to the extent permitted by law Should the data be published, your identity will not be disclosed.

Taking part in this study is voluntary. By signing the consent form, you are agreeing to take part in this research study. You do not have to answer any questions that make you uncomfortable. You may choose not to take part at all. If you decide to be in this study, you may stop taking part at any time. If you decide not to be in this study or if you stop taking part at any time, you will not lose any benefits for which you may qualify.

If you have any questions, concerns, or complaints about the research study, please contact: Kathy J. Pendleton at 502-852-0285 You may also contact the faculty advisor Dr. Michael Cuyjet at 502-852-6495.

If you have any questions about your rights as a research subject, you may call the Human Subjects Protection Program 
Office at (502) 852-5188. You can discuss any questions about your rights as a research subject, in private, with a member of the Institutional Review Board (IRB). You may also call this number if you have other questions about the research, and you cannot reach the research staff, or want to talk to someone else. The IRB is an independent committee made up of people from the University community, staff of the institutions, as well as people from the community not connected with these institutions. The IRB has reviewed this research study.

If you have concerns or complaints about the research or research staff and you do not wish to give your name, you may call 1-877-852-1167. This is a hot-line answered by people who do not work at the University of Louisville.

Sincerely,

Dr. Michael J. Cuyjet

Kathy J. Pendleton 


\section{Appendix C}

\section{Interview Guide}

The following questions are designed to create a conversation between you and me. I may ask more questions for clarification Remember, there is no right or wrong answers. You may decline to answer any question or to stop the interview at any time.

I am going to ask you questions about your view of welfare reform and how it impacts school and you personally. I will also ask questions about how you see yourself, your support system, and your coping strategies. I will be audio taping the interviews with your consent. I will also take some written notes during the interview These notes will help me to generate new questions and to remember something that I need to clarify I will provide you a copy of the transcribed interviews to review during the third interview. The demographic sheet will ask you to provide a name by which you will be identified for the purpose of this study I am the only person who will know who you are.

I am going to ask you complete the demographic information sheet. Are you ready?

\section{Complete the demographic information sheet.}

\section{Situation: An overall picture}

- Give me a brief overview of your life and any important changes or experiences.

- Are there any other important experiences for me to know about?

- How old were you when you became a welfare recipient?

- Tell about your experiences with welfare/TANF

- What event or experiences motivated you to enroll in college?

- Where did you find information about college?

- What is a regular day like for you?

- Are there other sources of stress that you have not discussed? 


\section{Self: Inner strengths or weaknesses}

- What is your greatest strength? Why?

- What is your greatest weakness? Why?

- When do you feel you have the most control over your life?

- When do you feel you have no control?

- Complete this statement: When things go wrong I......

\section{Support: Available resources}

- Who is your primary source of support?

- What kinds of support are provided? (money, childcare, transportation)

- How do you get to school, work, and childcare?

- What resources have you used on campus?

- What resources have you used in the community?

- In an emergency, what resources are available?

\section{Strategies: Coping}

- What do you do when there is a problem?

- If the problem is not resolved, what do you do?

- What strategies are the most effective?

- When there is a time conflict, how do you resolve the conflict?

- What is it like being a parent and going to school?

- How do you manage your time with all your responsibilities?

- How do you find time for your child? (self)

- What do you for fun?

- Are there problems related to child care or $4 c^{\prime} s$ ? 


\section{APPENDIX D}

DEMOGRAPHIC INFORMATION

Name to be used in the study

Number of Children Ages of Children

Marital Status:

Married

Separated/Divorced

Never Married

Living with significant other

\section{Race/Ethnicity:}

African-American

White

\section{Employed :}

Full-time

Part-time

Work-study
Hispanic

other: Please

Specify

Attending College: Full-time Part-time \# of Credit hours this semester

Academic level today:

Completed an Associate's Degree

Completed a Bachelor's Degree Master's level or higher

Freshman Sophomore Junior Senior

Best way to contact you: 


\author{
APPENDIX E \\ MEMBER CHECKING MEMO
}

MEMO

TO: Dissertation Research Participants

FROM: $\quad$ Kathy J. Pendleton

Re: $\quad$ Member Checking

Thank you for participating in this research study. Please read the attached case study report. Check to see if the information is correct and if you would like to add or change something that I have written. I will work with you to make changes directly to the report.

Please document your participation in this process (reviewing and checking) on the attached form. Please put your initials by the name you used for the interviews. 


\author{
APPENDIX F \\ MEMBER CHECK FORM
}

NAME USED

DATE

I have reviewed the case study report and (check one) I have made the attached changes or suggestions. There were no changes or suggestions. 


\section{Appendix G}

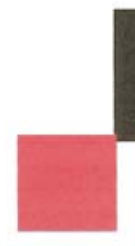

UNIVERSITY of IOUISVILLE

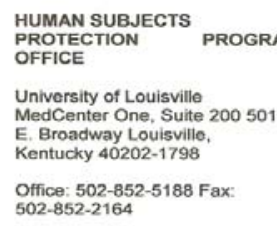

July 18, 2007

Michael Cuyjet, Ed.D. Education \& Counseling Psychology College of Education and Human Development University of Louisville Louisville, Kentucky 40292

RE: $\quad 330.07$ - Using Schlossberg's Transition Theory to Identify Coping Strategies of Welfare Recipients Attending Postsecondary Institutions

Dear Doctor Cuyjet:

This study has been reviewed by the chair of the Institutional Review Board (IRB) and approved through the Expedited Review Procedure, according to 45 CFR 46.110(b), since (7) Research on individual or group characteristics or behavior (including, but not limited to, research on perception, cognition, motivation, identity, language, communication, cultural beliefs or practices, and social behavior) or research employing survey. interview, oral history, focus group, program evaluation, human factors evaluation, or quality assurance methodologies.

The following items have been approved:

- Research Application, dated 6/28/2007

- Informed Consent, not dated

- Letter of Introduction, not dated

- Study Advertisement

- Demographic Information Sheet

- Interview Guide

This study now has final IRB approval through 7/16/2008. You should complete and return the Progress Report/Continuation Request Form EIGHT weeks prior to this date in order to ensure that no lapse in approval occurs. The committee will be advised of this action at their next full board meeting.

Please note that the IRB follows the principles of the Belmont Report, is in compliance with Good Clinical Practice Guidelines as defined by the U.S. Food and Drug Administration and the Department of Health and Human Services under the Code of Federal Regulations (21 CFR Parts 50 and 56; 45 CFR 46) and International Conference on Harmonization $(\mathrm{ICH})$ Guidelines (Section E6).

Best wishes for a successful study. Please send all inquires and electronic revised/requested items to our office email address at hsppofc@louisville.edu.

Sincerely,

Patival K feitol

Patricia K. Leitsch, Ph.D., Chair,

Social/Behavioral/Educational Institutional Review Boarc 
CURRICULUM VITAE

NAME :

Kathy Jamelle Pendleton

ADDRESS :

Disability Resource Center

Robbins Hall, Room 203

University of Louisville

Louisville KY 40292

DOB :

Chicago, Illinois - July 2, 1949

EDUCATION

\& TRAINING

B.S., Home Economics-Family Services

Eastern Illinois University

$1976-1979$

M.S., Home Economics-Family Services

Eastern Illinois University

$1979-1980$

M.Ed., College Student Personnel

University of Louisville

$1997-2000$

Ph.D., College Student Personnel

University of Louisville

2001- 2007

AWARDS

Graduate Deans Citation, University of Louisville, 2000

Alice Eaves Barnes Award, University of Louisville, 2000

Outstanding Service, University of

Louisville, Disability Resource Center, 2002

PROFESSIONAL SOCIETIES:

National Association of Student Personnel Administrators

Association of Higher Education and Disabilities Affiliate Representative 2003-2007 
Kentucky Association of Higher Education and Disabilities

Immediate Past President 2007-present

President 2006-2007

Secretary 2003-2006

Learning Disabilities Association 